\title{
BAMBOO: AN ALTERNATIVE BUILDING MATERIAL FOR URBAN ETHIOPIA
}

\author{
A Project Report \\ Presented to the Faculty of \\ California Polytechnic State University, \\ San Luis Obispo
}

In Partial fulfillment

of the requirements for the Degree

Master of Science in Architecture

by

Bewketu Z. Kassa

April 2009 
(C) 2009

Bewketu Z. Kassa

ALL RIGHTS RESERVED 


\section{COMMITTEE MEMBERSHIP}

TITLE:

AUTHER:

DATE SUBMITTED:

COMMITTEE CHAIR:

COMMITTEE MEMBER:

COMMITTEE MEMBER:

COMMITTEE MEMBER:
Bamboo: An Alternative Building Material for Urban Ethiopia

Bewketu Z. Kassa

April 2009
Arthur J. Chapman, Professor Architecture Department

Jens G. Pohl, PhD, Professor

Graduate Coordinator

Architecture Department

Howard Weisenthal, Professor Architecture Department

Jacob Feldman, Professor Architectural Engineering Department 


\section{ABSTRACT \\ Bamboo: An Alternative Building Material \\ For Urban Ethiopia}

Bewketu Z. Kassa

This project explores the potential of bamboo as an alternative building material for low cost housing units suitable for urban Ethiopia. The rational for the application of bamboo comes from its abundance throughout the country, and its proven physical properties that equate it to other building material like timber, steel and concrete. The proposed bamboo based design solution concentrates on simplification of construction methods, prefabrication of structural components and vertical densification of housing units, addressing the lack of skilled labor, cost of construction time and urban land respectively. An understanding of the design solution was established by constructing a full-scale section prototype and performing laboratory tests on key structural components. 


\section{ACKNOWLEDGEMENT}

I would like to extend a special thank you to my Committee Chair Professor Art Chapman and Committee Members Dr. Jens Pohl, Professor Howard Weisenthal, Professor Jake Feldman for providing their valuable guidance throughout my project and graduate studies.

My fellow classmates Mary-Alice Avila, Eileen Joseph, and Jenny Ferguson from whom I have learnt a great deal, thank you for the two exciting and memorable years we spent together. Special thanks to Mary-Alice for reviewing my report and encouraging me to finalize it.

Last but not least, to my wonderful parents and three sisters I want to say thank you for your moral support and encouragement, which helped me pursue my higher education. 


\section{TABLE OF CONTENTS}

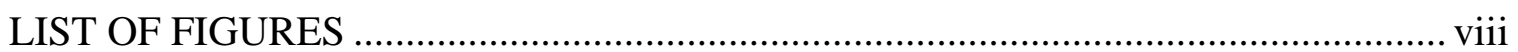

\section{CHAPTERS}

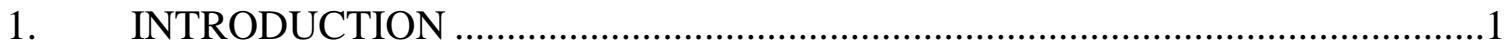

2. HOUSING CONDITIONS IN URBAN ETHIOPIA ......................................

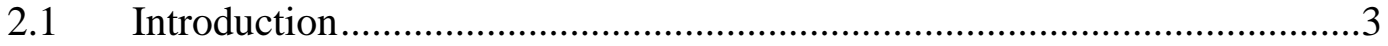

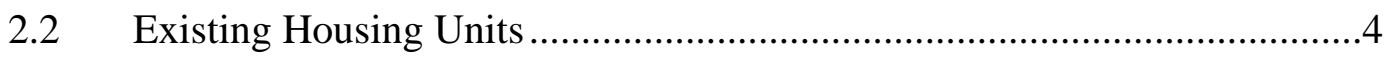

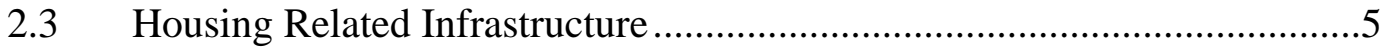

2.4 Recent Developments in Housing........................................................

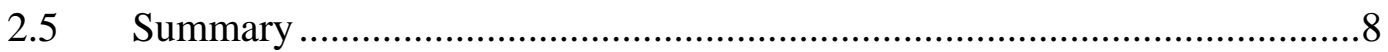

3. THE POTENTIAL FOR BAMBOO IN ETHIOPIA ........................................11

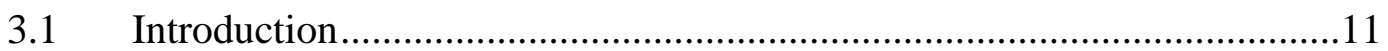

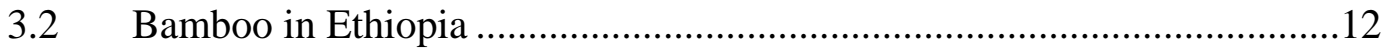

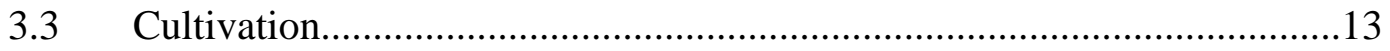

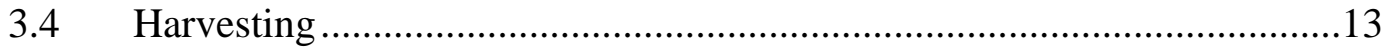

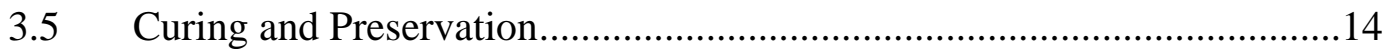

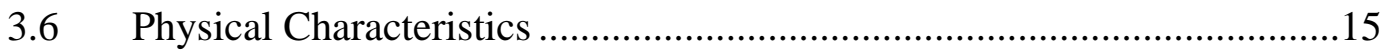

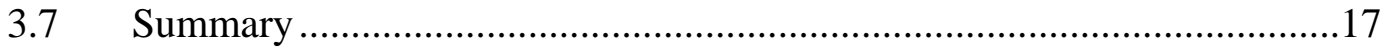

4. BAMBOO FRAMED LOW COST HOUSING SOLUTION .............................19

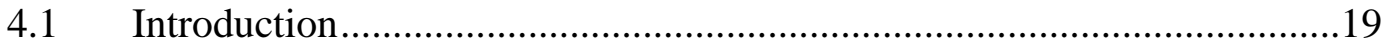

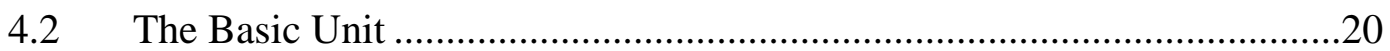

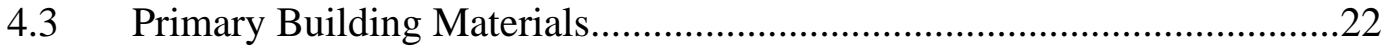




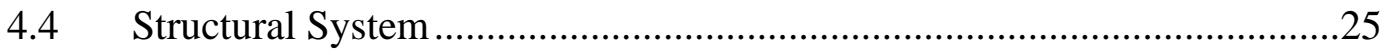

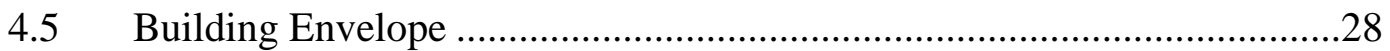

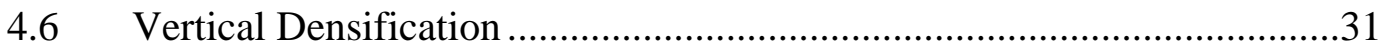

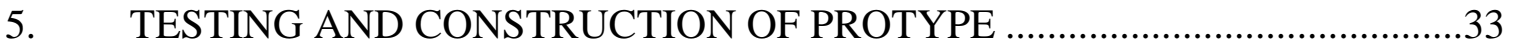

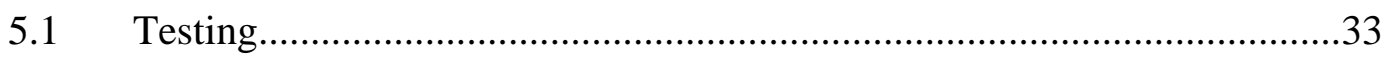

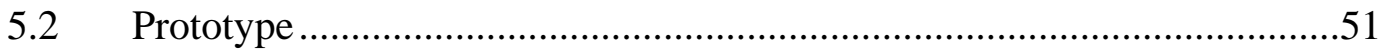

6. RECOMMENDATIONS AND CONCLUSION …........................................61

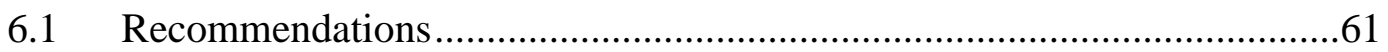

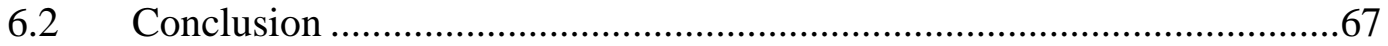

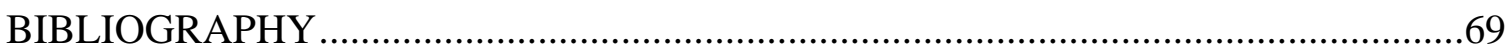




\section{LIST OF FIGURES}

Figure

Page

2.1 Typical housing units, built from mud and wood, found throughout central parts of Addis Ababa

2.2 The Condominium Housing Project: project co-developed and built by Ethiopia’s Housing Development Office (HDO) and the German Technical Co-operation (GTZ) 7

3.1 Distributions of Oxytenanthera abyssinica (A) and Yushane alpine (B) in the lowland and highlands of Ethiopia

3.2 Pressure injection system used to preserve bamboo prior to application in construction

4.1 The Basic Unit: Low cost housing solution for urban Ethiopia

4.2 Low Cost Housing Community System: Basic units supported by communal kitchens, bathrooms, gathering space, and other essential infrastructure

4.3 Section view showing bamboo structural framing, interior woven bamboo and exterior corrugated iron envelopes ............................... 22

4.4 Prototype: a full-scale section of the proposed low cost housing unit ................ 24

4.5 Basic Structural System: Bamboo post and beam framing built on precast concrete footings.

4.6 Prefabricated Column: An assembly of four bamboo poles and 1 foot long bamboo spacers of similar diameter bolted using threaded rods. ...

4.7 Prefabricated Beams: Beam A supports roof load and creates rigid connection; Beam B supports the floor system

4.8 Basic wall system composed of corrugated iron exterior and woven bamboo mat interior envelope

4.9 A floor system composed of woven bamboo mat covering over a one inch diameter bamboo decking supported by a series of bamboo joists

4.10 A flat roof system with three sided flashing and drainage system directed towards the rear of the unit 
4.11 A concept for low cost housing communities composed of multistory structures assembled from adjoined basic units stacked perpendicularly up to four stories

5.1 Trussed beam with concrete filled top chord, single vertical support and 22 gauge steel strap used as the tension member 34

5.2 A comparison of results gathered from three separate load tests ......................... 35

5.3 Trussed beam with concrete filled top chord, two vertical supports and 16 gauge steel strap used as the tension member 37

5.4 Graph showing two separate results from tests performed on trussed beams constructed from bamboo beam and steel strap 38

5.5 Eight foot bamboo truss with steel wire bracing 40

5.6 Graph showing a result from a single test performed on a standard bamboo truss with steel wire bracing

$5.7 \quad$ Double bolted column test................................................................................ 43

5.8 Graph showing two separate results from tests performed on double bolted column constructed from 2 foot bamboo poles

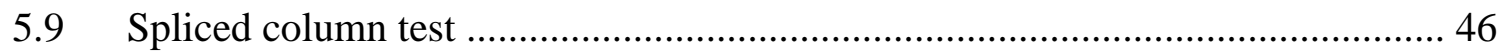

5.10 Graph showing two separate results from tests performed on spliced column constructed from 2 foot bamboo poles

5.11 Top left: the initial test sample. Top right: modified test sample Bottom Rigid connection

5.12 A full-scale section prototype constructed to test the feasibility of the proposed low cost housing solution 50

5.13 Upper portion of the prototype showing parts of the structural system, a partial roof system and the internal wall covering 51

5.14 Lower portion of the prototype showing a floor system and decking constructed from 1 inch poles and woven mat covering 52

5.15 Lower external portion of the prototype showing three precast concrete footings and uncovered parts of the column system 
5.16 Regular wood and drywall screw in comparison to self tapping screw ideal for attaching corrugated sheet to bamboo poles

6.1 A) General purpose twist bit ideal for drilling holes on bamboo poles. B) Spur point bit or commonly known as wood or dowel bit that causes bamboo to split easily

6.2 Left: crushed hollow pole. Right: Concrete reinforced pole ................................ 64

6.3 Left: Steel strap reinforcement crushing the end of bamboo pole Right: Steel washer used to prevent steel strap crushing the end of bamboo pole 65

6.4 Trussed beam: Bamboo top chord, two vertical supports, 16 gauge steel strap bolted with $3 / 8$ " threaded rods 65

6.5 Top: Column and beam connection bolted at 6 inch intervals. Bottom: Column and footing connection and spacers 66 


\section{CHAPTER 1}

Introduction

Among the many challenges facing urban dwellers in Ethiopia, the shortage of low cost housing stands as the most critical. The increasing cost of concrete and steel, the most prevalent construction material for urban housing, has exacerbated the growing demand for housing. Based on United Nations population projections for the next few decades, the demand for housing in urban Ethiopia is expected to grow exponentially. ${ }^{1}$

The reliance on masonry and reinforced concrete building systems has made even the most modest housing units too expensive for the majority of urban dwellers. ${ }^{2}$ In contrast; rural housing is more affordable due to the common application of indigenous construction material like bamboo. This is especially true in tropical parts of Ethiopia where bamboo can be harvested from the wild in large quantities. The potential adaptation of indigenes and abundant building material like bamboo as an alternative construction material for modern structures could alleviate the cost of housing units in urban Ethiopia.

This project deals with the design of a bamboo framed low cost housing unit, testing of its key structural components, and construction of a full-scale section prototype. Through this work the designer hopes to show the potential of bamboo as a viable building material for urban housing in Ethiopia and other bamboo growing developing nations.

Chapter 2 will look into current housing conditions in the capital Addis Ababa, which reflects the most common housing problems in Ethiopia's nine urban regions. The designer will identify key issues surrounding the housing shortage, and the main group of 
the urban population especially affected by these issues. Chapter 3 will focus on Ethiopia's bamboo resource, and its potential as a construction material for urban housing.

Information gathered in chapter 2 and 3 will be used to establish a design concept for the appropriate type of housing unit and structural design solution, which will be discussed in chapter 4 . Chapter 5 will discuss test results of key structural components, and the construction process of a prototype.

The project will conclude by offering recommendations based on the designer's first hand experience in working with bamboo, lessons learnt from testing of structural components, and construction of the prototype.

\footnotetext{
${ }^{1}$ United Nations Department of Economic and Social Affairs (ESA), "World Population Prospects: The 2006 Revision Population Database,” http://esa.un.org/unpp/ (accessed 15 January 2008).

${ }^{2}$ United Nations Human Settlement Program, "Situation Analysis of Informal Settlements in Addis Ababa," (Nairobi: UN-HABITAT, 2007), 54.
} 


\section{CHAPTER 2}

The Housing Condition in Urban Ethiopia

\subsection{Introduction}

In a typical growth pattern of a developing nation, Ethiopia's population is increasing at a very high rate. The latest population and housing census conducted in 2007 by the Central Statistics Agency (CSA) shows the country’s population at 74 million; $50.5 \%$ male and $49.5 \%$ female. ${ }^{1}$ United Nations population projections show this number passing the 100 million mark by 2015 and reaching close to 190 million by $2050 .^{2}$

Although the least urbanized nation in Africa, in the past ten years Ethiopia's urban population has been growing rapidly. This growth is mainly attributed to the influx of rural dwellers in search of a better life and employment opportunities in urban center. Currently $17 \%$ of the country's total population lives in urban centers, and in a typical growth pattern of least urbanized nations, its urban population is growing at $5 \%$ per year making Ethiopian cities some of the fastest growing in the world. ${ }^{3}$

Among many complex problems, the population explosion has exacerbated the existing shortage of housing throughout the country's nine major urban centers. Affordable housing units offered by the government are too expensive, even for moderate income families. The urban poor and migrants from rural areas have no options other than finding accommodations in inner-city slums or to create new squatter settlements. 


\subsection{Existing housing units}

In the past ten years, Addis Ababa has seen an increase in new upper middle class residential areas, but the housing need for the average urban dweller has worsened. The majority of existing housing units in Addis Ababa, similar to the ones illustrated in Figure 2.1, are made of corrugated iron, mud and wood. These type of buildings generally age rapidly and always require major repair. The lack of proper foundation and poor quality structure makes the majority of these housing units only fit for demolition. In Addis Ababa, 97\% of the total housing stock is single story and nearly $60 \%$ row housing. ${ }^{4}$ The majority of these units have no private bathrooms or kitchens. Only $17 \%$ of the total housing stock is considered to be in good condition. ${ }^{5}$

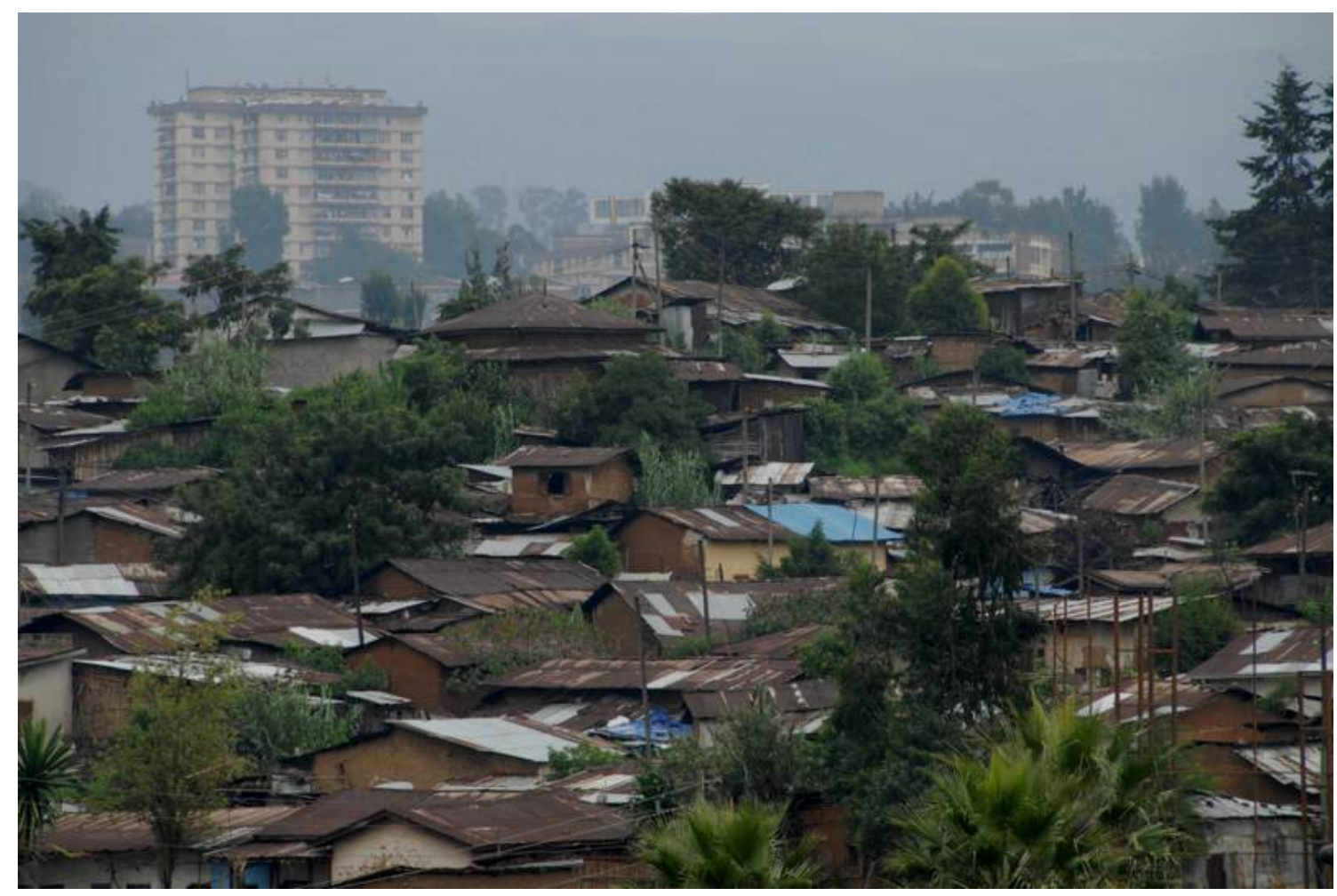

Figure 2.1 Typical housing units, built from mud and wood, found throughout central Addis Ababa. Source: http://abandoned-orphaned.typepad.com/photos/uncategorized/2007/09/16/ethiopiaslum2.jpg 


\subsection{Housing related infrastructure}

A small percentage of urban Ethiopia has adequate shelter related infrastructure. The inner parts of urban areas have the least developed infrastructure and high concentration of slums. In general a significant amount of housing units do not have direct access to sanitary infrastructure or paved roads, and are accessible by foot only. Access to clean water and electricity is also a major problem for most unplanned parts of cities and slum areas. The lack of paved roods, sanitary infrastructure and congestion are a major fire and health risk to the residents of these areas.

\subsubsection{Roads}

In general, much of the country is not served by paved roads, and existing paved roads suffer from poor maintenance or total neglect. In the rainy parts of the country, the lack of proper drainage systems causes the majority of the damage to roads and other infrastructures. According to a recent study by Planning and Development Collaborative International (PADCO), only 29\% of Addis Ababa's roads have proper drainage, and non-asphalted roads connecting much of the city suffer the most damage from erosion. ${ }^{6}$

\subsubsection{Electricity}

Access to electricity in urban areas is better relative to other infrastructure. Even though the power that reaches some residential areas is so weak it is hardly used for anything other than lighting. Often low-income households can only use a single light bulb situated in a way to serve separate rooms. The condition is even worse in the slum

areas where most electricity is obtained illegally. Sharing of a single electric meter by 
several households is quite common. The absence of streetlights only adds to existing problems. Even some well planed parts of Addis Ababa lack adequate streetlights.

\subsubsection{Water}

Limited access to potable water is a problem shared by both rural and urban dwellers in Ethiopia. Unlike rural areas where relatively clean water can be obtained from rivers or lakes, urban areas are totally dependent on water provided by the city. Rivers and other natural water sources in urban centers are usually too polluted to be used even for washing clothing or bathing. Public water fountains serve a large percentage of households in slum areas. Leakage due to aging plumbing systems, and decades old water treatment facilities designed to support a fraction of the current population contribute a great deal to the shortage and occasional absence of potable water. ${ }^{7}$

\subsubsection{Sanitation and Drainage}

Only $10 \%$ of Addis Ababa's built up area is connected to a modern sewerage system; even though the city has a system designed to serve 40,000 houses, only 1600 units are currently connected to the system. ${ }^{8}$ Liquid waste generated by most of the city will end up in open drainage systems that lead directly to streams and rivers.

The city's limited drainage systems are in most cases blocked by refuse, which in turn causes major overflow during the rainy season. In addition to the obvious health risk to residents, overflowing runoff is the primary cause for damage to paved and unpaved roads throughout the city. The frequency of flooding and the amount of damage is overwhelming to the city and leads to neglected roadways. 


\subsection{Recent developments in housing}

The Condominium Housing Project shown in (Figure 1.2), a massive bilateral low cost housing project conducted by Ethiopia's newly established Housing Development Office (HDO) and the German Technical Co-operation (GTZ), ${ }^{9}$ is the only large-scale housing project addressing the housing shortage in urban Ethiopia. In addition to creating new settlements on the peripheries of cities, the project aims at upgrading congested inner city areas.

In Addis Ababa, the goal is to build 200,000 residential units over a five year period, and since the project was launched in 2005, over 40,000 units have been completed. ${ }^{10}$ The housing units range from small villas to studio and multiroom apartments in buildings up to five stories high. Eligible applicants are expected to take over the units through a rent-and-own process extending over 15 to 20 years, and are expected to pay at least $10 \%$ of the project cost upfront. ${ }^{11}$
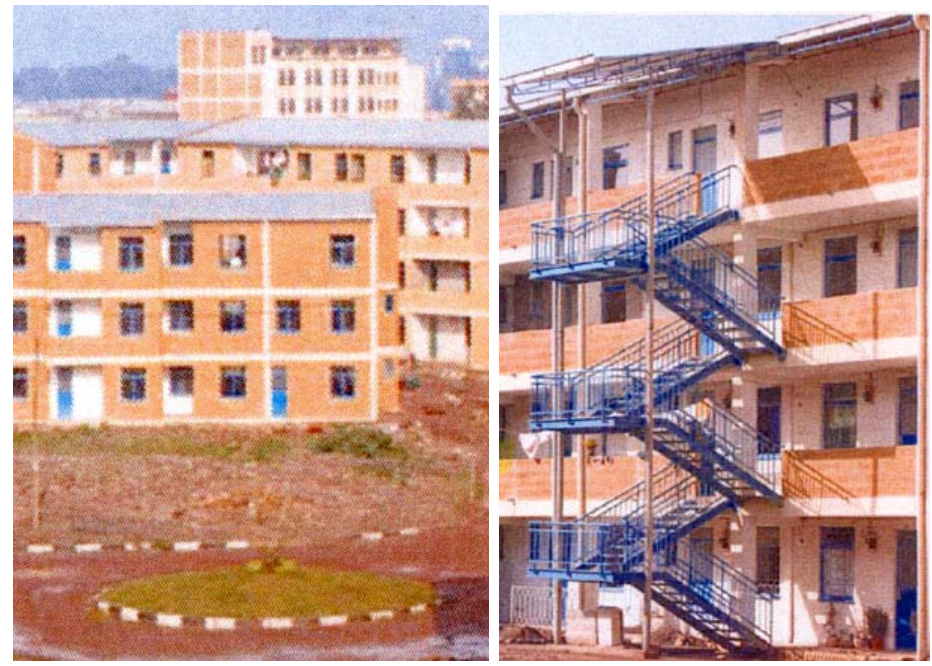

Figure 2.2 The Condominium Housing Project: project co-developed and built by Ethiopia's Housing Development Office (HDO) and the German Technical Co-operation (GTZ). Source: Low Cost Housng: Technical Manual by German Technical Co-operation. 
In spite of this effort the majority of the target population cannot afford even the most modest housing units. ${ }^{12}$ Mortgage loans are simply unthinkable for most lowincome households who make just enough to pay for food. Major financial assistance from government and private sector is required to enable more people own a home of their own.

\subsection{Summary}

Ethiopia's rapidly growing urban population is exacerbating the existing shortage of housing in urban centers. Migrant workers from rural Ethiopia, the group mostly responsible for the growth and also affected by the shortage, are forced to seek shelter in inner-city slums or create new squatter settlements.

As the urban population continues to grow the need for a type of housing that costs significantly less than what is available in the market is becoming more apparent. This can be achieved by creating a design solution that takes advantage of local resources like cheap labor and abundant building material like bamboo, corrugated iron, etc...

\footnotetext{
${ }^{1}$ Federal Republic of Ethiopia Population Census Commission, Summery and Statistical Report of the 2007 Population and Housing Census, (Addis Ababa: CSA 2008), 1-2.

2 United Nations Department of Economic and Social Affairs (ESA), "World Population Prospects: The 2006 Revision Population Database,” http://esa.un.org/unpp/ (accessed 15 January 2008).

${ }^{3}$ United Nations Human Settlement Program, Situation Analysis of Informal Settlements in Addis Ababa, (Nairobi: UN-HABITAT, 2007), 1.

${ }^{4}$ United Nations Human Settlement Program, 29.

${ }^{5}$ United Nations Human Settlement Program, 29.

${ }^{6}$ Solomon Mulugeta and Ruth McLeod, Application of Community-Led Infrastructure, (Addis Ababa: Homeless International, 2004), 6.
} 
${ }^{7}$ Mulugeta and McLeod, 16.

${ }^{8}$ Mulugeta and McLeod, 17-18.

${ }^{9}$ Carsten Stammeier, Ruth Eribeck and Ralph Trosse, Low Cost Housng: Technical Manual, (Addis Ababa: German Technical Co-operation 2003), 4.

${ }^{10}$ United Nations Human Settlement Program, 54.

${ }^{11}$ United Nations Human Settlement Program, 54.

${ }^{12}$ United Nations Human Settlement Program, 55. 


\section{CHAPTER 3}

The Potential for Bamboo in Ethiopia

\subsection{Introduction}

Over a 1000 species of bamboo classified in roughly 90 genera grow in diverse climates throughout the world. Although most bamboo is harvested from the wild, about 50 to 100 useful species are domesticated and cultivated for commercial use. ${ }^{1}$ Some species grow up to 150 feet, and this makes bamboo the largest member of the grass family. Compared to trees like Douglas fir, a premium framing timber that take decades to fully mature, individual bamboo culms could mature and be ready for cultivation in just a few years. ${ }^{2}$

Bamboo is a multipurpose plant used for everything from food to fuel and irrigation systems to construction. An estimated $\$ 4.5$ billion is generated from the global and domestic use of bamboo by roughly 2.5 billion people; in addition export of bamboo

products is estimated to generate $\$ 2.7$ billion. ${ }^{3}$ Bamboo supports the livelihood of millions of rural dweller in developing nation, and in particular women and children who do most of the harvesting.

Several species of bamboo grow in Sub-Saharan Africa, but their uses have been limited to constructing traditional houses, irrigation systems, handcrafts, fuel and food. Unlike Asia and the Americas where pulp and paper production and other large scale industrial uses of bamboo are prevalent, Africa's large bamboo resource is virtually unexploited in any significant way. In the past few years several organizations have been promoting the potential for this vast resource, but their success is yet to be seen. 


\subsection{Bamboo in Ethiopia}

Two indigenous species of bamboo, Oxytenanthera abyssinica (lowland bamboo) and Yushane alpine (highland bamboo), grow in the south-west, south and central parts of Ethiopia (Figure 3.1) in an area close to 4,000 square miles.$^{4}$ Due to the lack of sufficient rainfall the eastern part of the country does not support bamboo habitation. Overall Ethiopia has the largest bamboo growing area in Africa.

Oxytenanthera abyssinica grows up to 20 feet in length and 2 inches in diameter, while Yushane alpine can reach up to 60 feet high and 4 inches in diameter. Of the total consumption of bamboo in Ethiopia, only 15\% Oxytenanthera abyssinica and $20 \%$ of Yushane alpine is used for construction. ${ }^{5}$ Although its use may be limited in a national scale, people in bamboo growing parts of the country greatly depend on this resource.
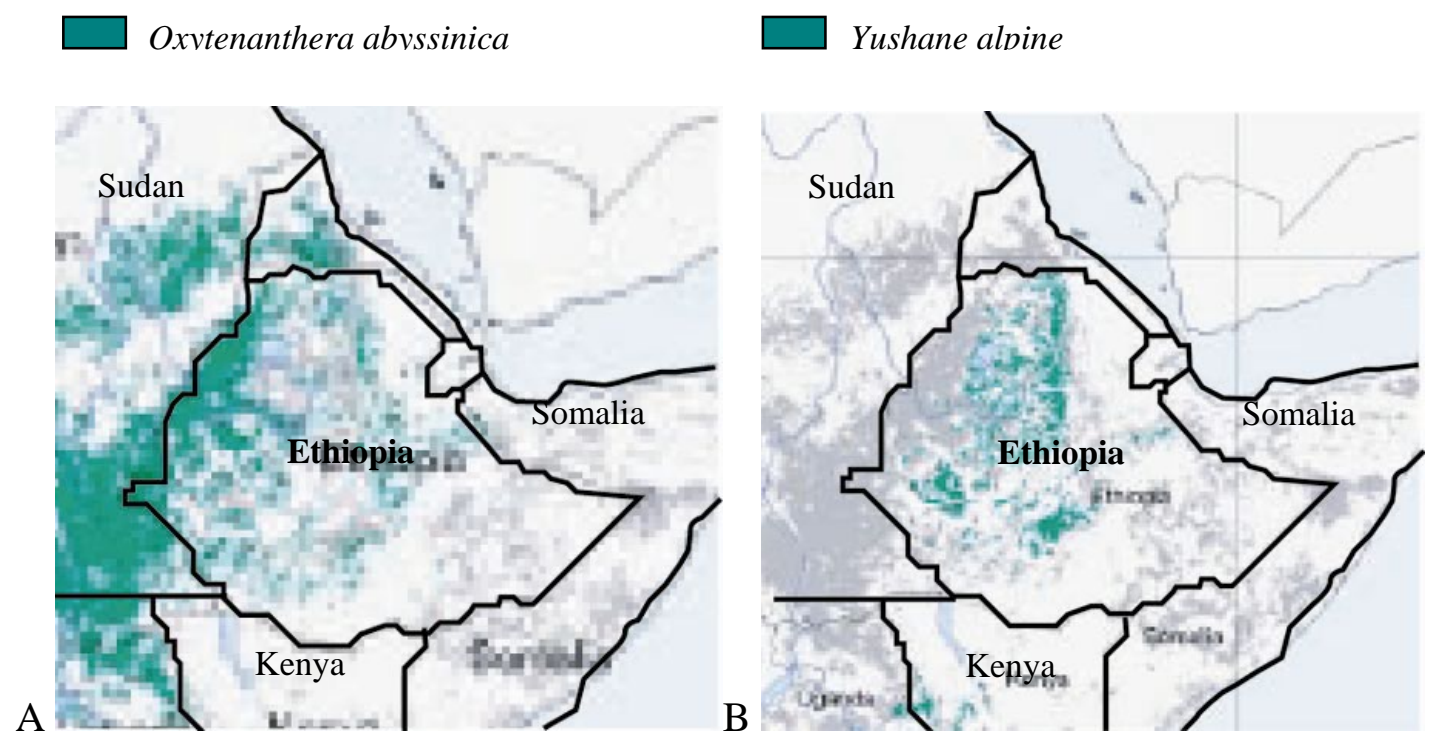

Figure 3.1 Distributions of Oxytenanthera abyssinica (A) and Yushane alpine (B) in the lowland and highlands of Ethiopia. Source: http://www.unep-wcmc.org/resources/UNEP_WCMC_bio_series/19.htm 


\subsection{Cultivation}

Bamboo grows in two general patterns “clumping” and "running”. Clumping bamboo species simply grow by expanding their root mass whereas the more aggressive running bamboo species spread their rhizome (horizontal stem) underground, and allow new culms break out of the surface. Bamboo culms are produced annually and the diameter and height of culms increases year after year until the plant fully matures. ${ }^{6}$

The increasing demand for bamboo has created an opportunity for largescale commercial bamboo cultivation in some parts of the world. Useful species are introduced to new locations to further satisfy the demand. Researchers are also working on creating hybrid species to improve the physical properties and insure successful

cultivation. $^{7}$ Asian nations like India and Japan have well established farms while in South America and Africa most bamboo is harvested from the wild.

\subsection{Harvests}

Bamboo is harvested in a 3 to 5 year cycle. Individual culms are cut 1 to 2 feet above ground using traditional tools like axes, machetes or in more mechanized farms small tractors and other advanced farming equipment. ${ }^{8}$ Traditional cutting tools allow selective cutting of matured or dead culms and allow younger culms reach maturity. Some matured culms are left to preserve the structural integrity of the plant and provide support to new shoots. In areas where there is a guaranteed market for all the cut culms, the forest or farm is clear cut using more mechanized equipment. Depending on the species it is possible to harvest up to 20 to 30 tons of bamboo per hectare annually. ${ }^{9}$ 


\subsection{Curing and Preservation}

\subsubsection{Clump curing}

One of the most economical ways of curing bamboo is clump curing. Freshly cut culms are clumped together and leaned against uncut culms and left to dry for 4 to 8 days. ${ }^{10}$ The leaves on the freshly cut culms are left on during the drying process to decrease the starch level which insects feed on. The clumped culms need to be raised and the ground below treated with pesticides to prevent insect and fungus attack. ${ }^{11}$

\subsubsection{Air drying}

Air drying in well ventilated warehouses or covered yards is another common curing practice. Bamboo culms are stored horizontally for 3 to 4 weeks in an environment free of organic matters. It is critical to prevent exposure to direct sunlight and rapid change in humidity which could result in cracking. Air dried culms could further be treated with smock from open charcoal pits which coats the surface with creosote like film, or boiled in caustic ash solutions. ${ }^{12}$

\subsubsection{Pressure injection system}

A pressure injection system is the most effective way used to displace sap from freshly harvested bamboo culms and replace it with antiseptic solutions. Boric acid, a naturally occurring salt used as fertilizer, is commonly used to replace the starchy sap which prevents insect and microbe attacks by making the cellulose indigestible. ${ }^{13}$ Borates are also used as a fire retardant in various applications. Although there are no known test 
on their resistance to fire, boric acid treated culms are ideal for constructing long lasting structures. $^{14}$

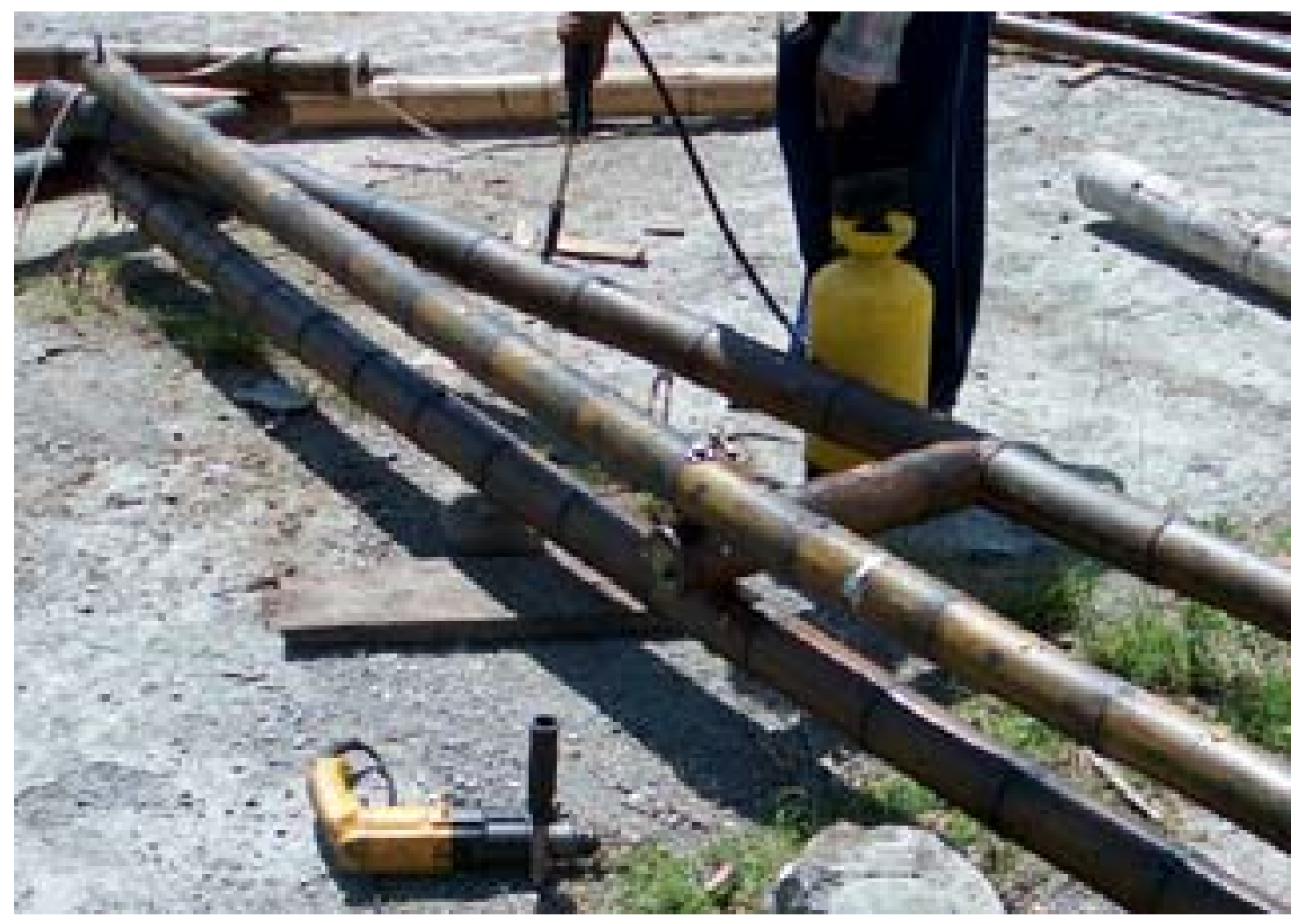

Figure $3.2 \quad$ Pressure injection system used to preserve bamboo prior to application in construction. Source: http://www.mangroveactionproject.org/images/map-programs/toolkit/bamboo-treatment.jpg

\subsection{Physical characteristics}

During his travel in Shanghai, British scientist William Portland described the surface of bamboo cane as "finely polished and almost unnatural” he further explained the reason for its soft yet simultaneously hard finish, "the reason for this is the wax and silicon secreted by the epidermis. The waxed surface is the basis of the finish, whilst the silicon hardens.” ${ }^{15}$ Table 3.1 shows various characteristics of bamboo compared with other building material. 
Table 3.1 Comparison of bamboo with other construction material

\begin{tabular}{|c|c|c|c|c|}
\hline & Bamboo & Spruce & Concrete & Steel \\
\hline Tensile strength & $35-300 \mathrm{~N} / \mathrm{mm}^{2}$ & $9 \mathrm{~N} / \mathrm{mm}^{2}$ & $\begin{array}{l}\text { 1/10 of } \\
\text { compressive } \\
\text { strength }\end{array}$ & $250-350 \mathrm{~N} / \mathrm{mm}^{2}$ \\
\hline Compressive strength & $64-110 \mathrm{~N} / \mathrm{mm}^{2}$ & $4.3 \mathrm{~N} / \mathrm{mm}^{2}$ & $12.6-126 \mathrm{~N} / \mathrm{mm}^{2}$ & $250-350 \mathrm{~N} / \mathrm{mm}^{2}$ \\
\hline Shape characteristics & $\begin{array}{l}1.9 \text { times stronger } \\
\text { than solid because } \\
\text { of hollow } \\
\text { cylindrical shape. } \\
\text { Efficient in } \\
\text { compression and } \\
\text { bending }\end{array}$ & & $\begin{array}{l}\text { Because it's solid, } \\
\text { more weight to get } \\
\text { same load-carrying } \\
\text { capacity with } \\
\text { reinforcing in } \\
\text { tension zone }\end{array}$ & $\begin{array}{l}\text { Most efficient in } \\
\text { tension. Capable } \\
\text { of most work in } \\
\text { smallest cross } \\
\text { section }\end{array}$ \\
\hline $\begin{array}{l}\text { Fire resistance (seconds } \\
\text { until ignition) }\end{array}$ & $\begin{array}{l}\text { Acts as firebreak } \\
\text { when growing } \\
\text { (61.2 untreated). }\end{array}$ & (19.1) & $\begin{array}{l}\text { Will not burn, but } \\
\text { prone to spalling as } \\
\text { steel expands }\end{array}$ & $\begin{array}{l}\text { Loses elasticity, } \\
\text { risk of quick } \\
\text { failure }\end{array}$ \\
\hline Embodied energy Btu/ft ${ }^{3}$ & $\begin{array}{l}\text { Minimal, unless } \\
\text { imported }\end{array}$ & $\begin{array}{l}\text { Transportation can be } \\
\text { high. * }\end{array}$ & $42-96,000$ & 91,618 \\
\hline $\begin{array}{l}\text { **Regenerative capacity/ } \\
\text { year }\end{array}$ & $\begin{array}{l}80-300 \%(28,000- \\
50,000 \text { lb/acre) }\end{array}$ & $\begin{array}{l}3-6 \%(16,000 \text { lb/acre- } \\
\text { pine) }\end{array}$ & None & None \\
\hline Time to maturity & 7-9 year & $60-80$ year & & \\
\hline $\begin{array}{l}\text { Subsequent maturity } \\
\text { after initial harvest }\end{array}$ & 1 year & $60-80$ year & & \\
\hline $\begin{array}{l}* * * \text { Conforms to Natural } \\
\text { Step's four system } \\
\text { conditions }\end{array}$ & Yes & Yes & No, fails first three & No, fails all four \\
\hline
\end{tabular}

* From forest to mill to lumber yard to construction site.

**Although this is the only U.S. study that compared the yields of bamboo and pine, W.H. Hodge of the U.S. Department of Agriculture (USDA) estimated that bamboo annually produces six times as much cellulosic material per acre as southern pine.

***1. Substances from the earth's crust must not systematically increase in the biosphere.

2. Substance produced by society must not systematically increase in the biosphere.

3. The physical basis for the productivity and diversity of nature must not be systematically deteriorated.

4. There must be fair and efficient use of resources with respect to meeting human needs.

Source: Adapted from “Alternative construction: Contemporary Natural Building Methods,” by Lynne Elizabeth and Cassandra Adams 2005, 242. 


\subsection{Summary}

Ethiopia has the largest natural bamboo forests and bamboo growing area in Africa. Although currently under utilized, there is great potential for this vast resource in large-scale commercial applications that could benefit millions of rural as well as urban dwellers.

Its potential application in the construction industry as an alternative to timber and other scarce building material could have a chain effect in promoting large-scale bamboo farming and processing. Rural dwellers living in bamboo growing areas of the country would benefit from revenues generated from farming and processing, whereas the urban poor would benefit from having access to less expensive bamboo based dwellings.

1 Kassahun Embaye, Ecological Aspects and Resource Management of Bamboo Forests in Ethiopia (Uppsala: SLU Service repro 2003), 8.

2 Lynne Elizabeth and Cassandra Adams, Alternative Construction: Contemporary Natural Building Methods (New York: John Wiley \& sons, Inc. 2005), 235.

${ }^{3}$ Wikipedia, “General information on bamboo” http://en.wikipedia.org/wiki/Bamboo (accessed 27 January 2008).

${ }^{4}$ Embay, 8.

${ }^{5}$ Nadia Bystriakova, Valerie Kapos and Igor Lysenko, "Bamboo Biodiversity - Africa, Madagascar and the Americas.” http://www.unepwcmc.org/resources/publications/UNEP_WCMC_bio_series/19.htm (accessed 15 December 2008).

${ }^{6}$ Dinesh Mohan and D. Narayanamurti, The use of Bamboo and Reeds in Building Construction (United Nations, New York 1972), 17.

${ }^{7}$ Mohan and Narayanamurti, 17.

${ }^{8}$ Klaus Dunkelberg, Bamboo: Building with Vegetal Rods (Stuttgart: Karl Krämer, 2001), 92.

${ }^{9}$ Dunkelberg, 92. 
${ }^{10}$ Mohan and Narayanamurti, 21.

${ }^{11}$ Mohan and Narayanamurti, 23.

${ }^{12}$ Mohan and Narayanamurti, 23.

${ }^{13}$ Lynne Elizabeth and Cassandra Adams, Alternative Construction: Contemporary Natural Building Methods (New York: John Wiley \& sons, Inc. 2005), 251.

${ }^{14}$ Elizabeth and Adams, 251.

${ }^{15}$ Simon Velez, Jean Dethier and Klaus Steffen, Grow your own house: Simon Velez and Bamboo Architecture (Vitra Design Museum 2000), 237. 


\section{CHAPTER 4}

\section{Bamboo Framed Low Cost Housing Solution}

\subsection{Introduction}

The proposed bamboo framed low cost housing unit addresses key issues regarding the shortage of housing discussed in chapter 2 . The application of bamboo as the primary building material takes into account the vast amount of this resource available throughout Ethiopia, and its potential application as a sustainable and economical building material. The main focus is to provide a housing solution that costs significantly less than currently available affordable housing units.

The design solution utilizes prefabrication of building components, vertical densification of individual units and simplification of the construction process as key cost reduction components addressing the high cost of construction, scarcity of urban land, and lack of skilled workers respectively.

Active community and owner involvement in the planning and construction processes is another important component that will instill a sense of pride in and ownership by all parties involved and ensure the successful implementation of projects. Additionally, creating a sense of ownership will encourage proper usage and maintenance, which in turn would ensure a longer life cycle for the housing units.

The primary target populations for these housing units would be lower income individuals living throughout Ethiopia's major urban centers. The units could be used to replace individuals existing homes or upgrade entire communities. The units could also 
be used by organizations in need of mass housing for construction projects, disaster relief efforts and similar urgent need applications.

\subsection{The Basic Unit}

The proposed low cost housing unit illustrated in Figure 4.1 would serve an individual's basic shelter needs as a sleeping quarter and storage space for personal items. The unit could be expanded horizontally and stacked up vertically as the need for more space arises. In order to eliminate the requirement to outfit each unit with plumbing and drainage systems, a group of units would be supported by communal kitchens, bathrooms and gathering areas as illustrated in Figure 4.2. The housing units could be used to upgrade inner-city slums or start new communities. The essential infrastructure for new communities would need to be provided by local government.

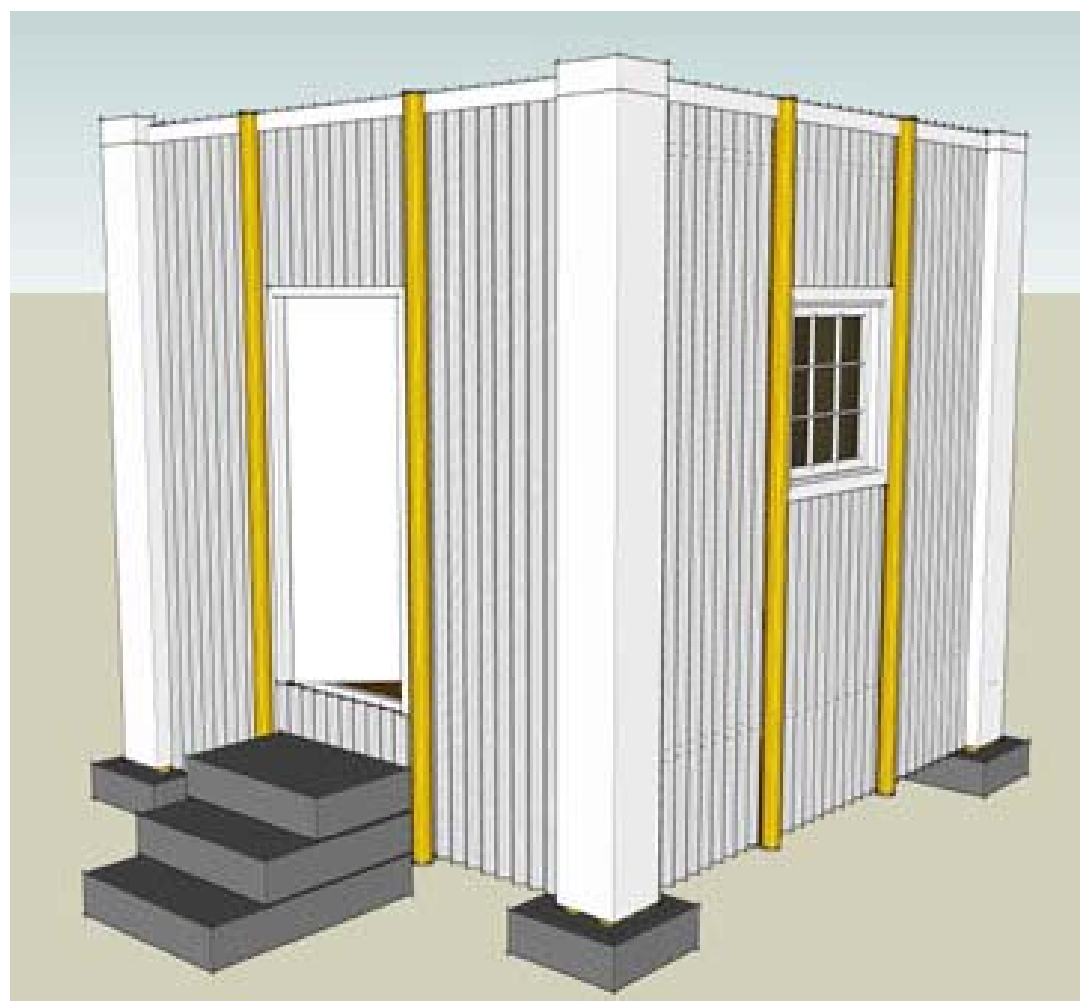

Figure 4.1 The Basic Unit: Low cost housing solution for urban Ethiopia. Source: Concept by Author, and created in Google SketchUp. 


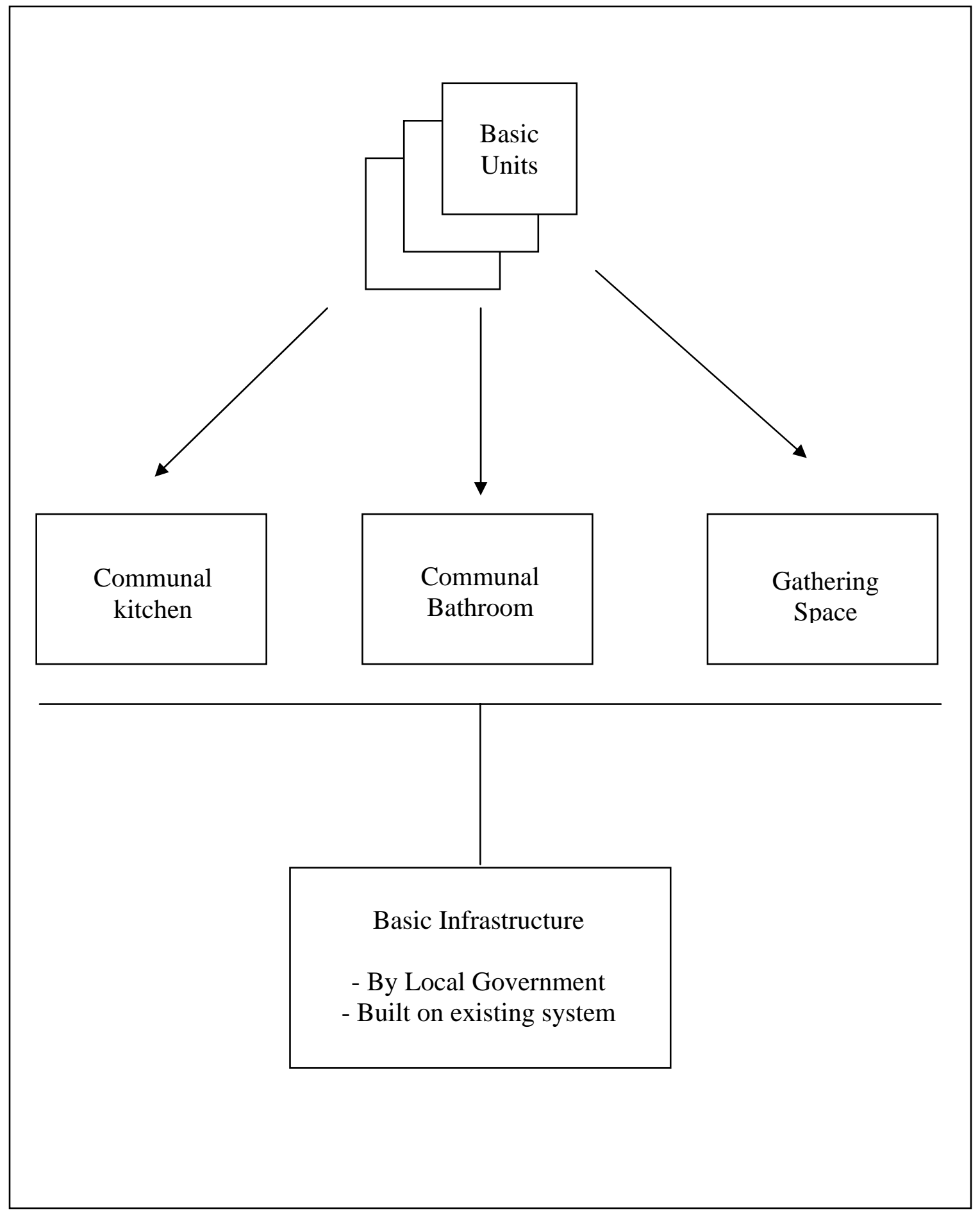

Figure 4.2 Low Cost Housing Community System: Basic units supported by communal kitchens, bathrooms, gathering space, and other essential infrastructure. Source: Concept by Author. 


\subsection{Primary Building Materials}

The basic unit is primarily constructed from prefabricated bamboo structural components, locally manufactured corrugated iron sheet and woven bamboo mat. As illustrated in Figure 4.3, the exterior corrugated iron covering protects the structural components from direct exposure to sunlight and rain, which could easily crack and rot bamboo poles. The interior bamboo mat covering is the most durable and cheapest building material commonly used in traditional homes, and has multiple functions as a wall, floor and ceiling covering.

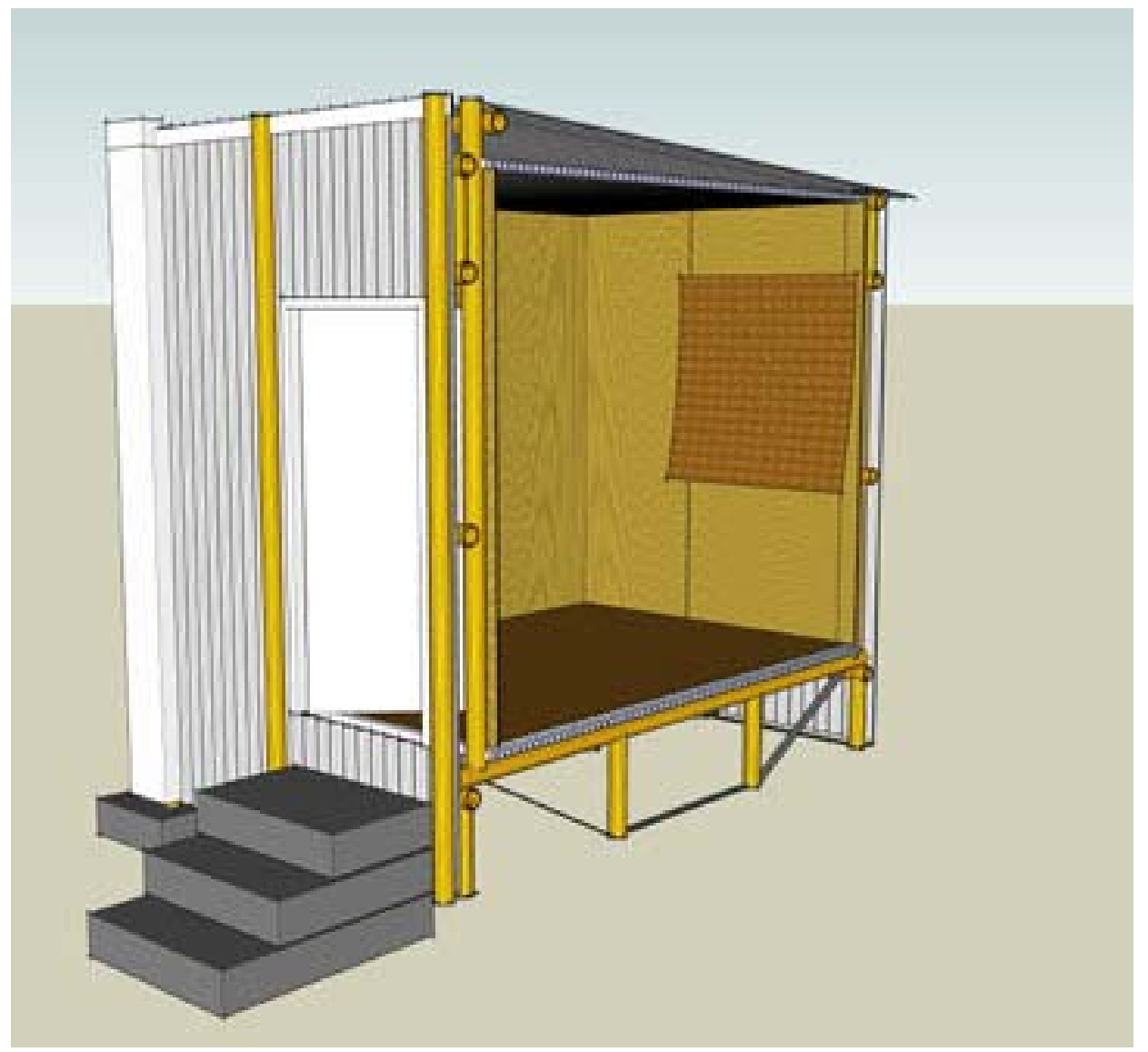

Figure 4.3 Section view showing bamboo structural framing, interior woven bamboo and exterior corrugated iron envelopes. Source: Concept by Author, and created in Google SketchUp. 


\subsubsection{Bamboo Poles}

The type of bamboo poles used range from 2 to 4 inches in diameter with up to 1/4 inch wall thickness. The 2 inch diameter poles are ideal for building single story structures and non structural components. The 4 inch diameter poles could be used to build long columns and beams ideal for multistory structures. Widely available 3/4 and 1 inch diameter poles are used for floor and ceiling coverings. Depending on the original length of bamboo culms, 10 to 20 feet long poles with even diameter can be produced. Results from laboratory tests performed on 2 inch single poles and prefabricated structural components will be illustrated in subsection 5.1.4 of chapter five discussing testing and construction.

Cracked and damaged poles can be used to build non structural components and coverings. Poles can also be split and woven to produce different sizes of bamboo mats used for covering floors, walls and ceilings.

\subsubsection{Woven Bamboo}

Woven bamboo mats are commonly used to build fences, sheds, and floors throughout Ethiopia. If protected from direct exposure to sunlight and rain, woven bamboo mats can last up to fifty years. This can be seen on traditional huts throughout the country built over half a century ago. Although used as an interior covering in the proposed low cost housing design, woven bamboo mat can also be used as an exterior

covering in warmer regions of Ethiopia with low annual moisture. In this situation it would be necessary to incorporate a roof design with a larger overhang or a patio to minimize direct exposure to sunlight. 


\subsubsection{Corrugated Iron}

Locally manufactured in large quantities, corrugated iron is the cheapest and most prevalent roofing material for urban housing in Ethiopia. Its application as an exterior envelope for the proposed low cost housing unit helps protect bamboo structural components from being exposed to direct sunlight and rain. The sheet could easily be attached to bamboo poles using self-taping* screws illustrated in chapter five Figure 5.16, which prevents poles from cracking while being drilled in. As images of the prototype in Figure 4.4 show the unit is designed to take advantage of commonly available 4 foot by 8 foot sheets of corrugated iron.
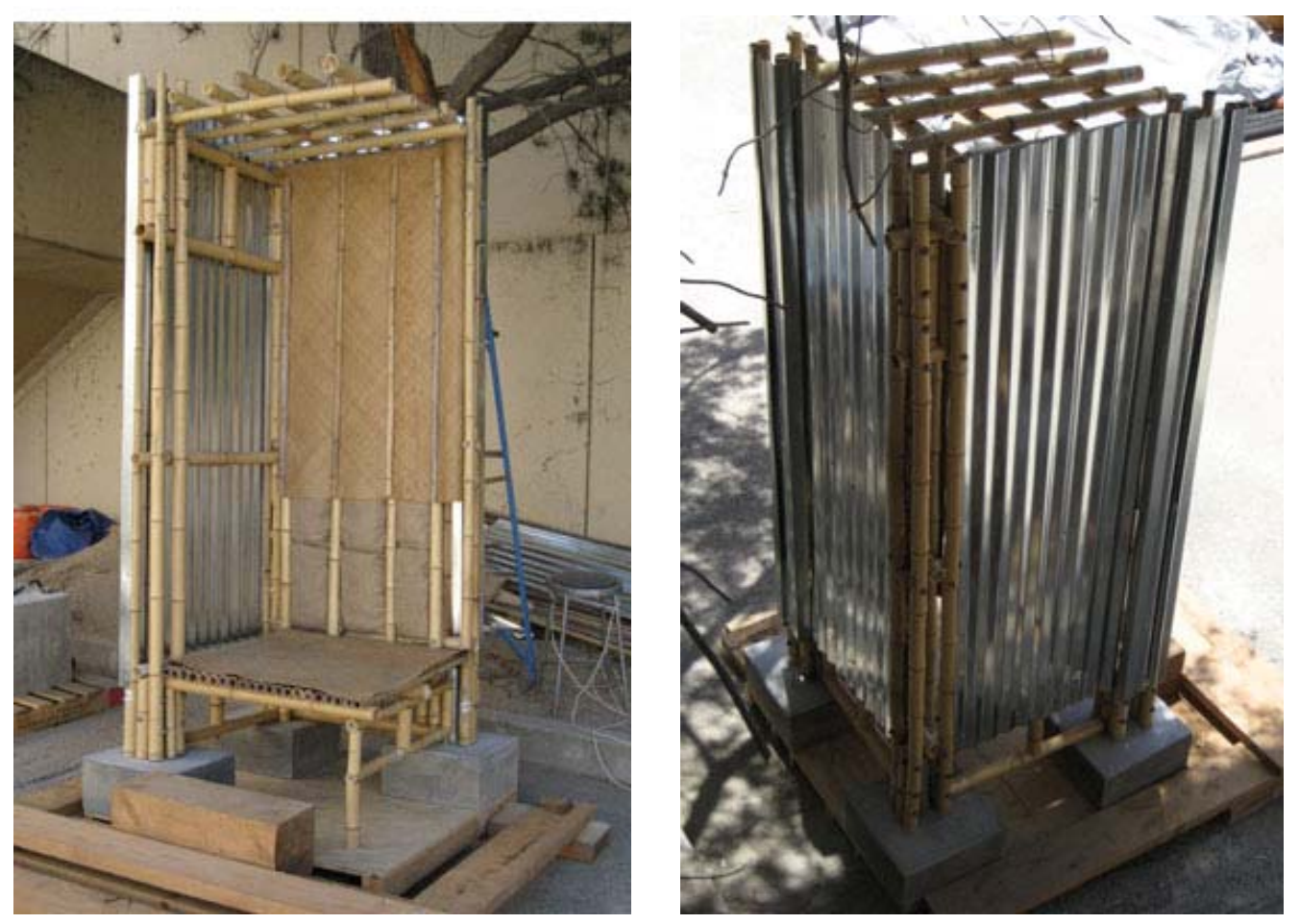

Figure 4.4

Prototype: a full-scale section of the proposed low cost housing unit. Source: Photograph by Author.

* Self-tapping is the ability of a screw to advance when turned, while creating its own thread. (Self-tapping screws are commonly used with sheet metal and plastic components.) This ability is created sometimes by having a gap in the continuity of the thread on the screw. These edges can cut their own threads as the screw is driven in to the material, usually metal or plastic. They function by having a cutting edge which drills away the material, making a hole for the screw to go into. Source: http://en.wikipedia.org/wiki/Selftapping (accessed February 2009) 


\subsection{Structural System}

The proposed bamboo post and beam structural system, illustrated in Figure 4.5 consists of prefabricated bamboo columns and beams. The structural components are assembled from 2 inch or 4 inch diameter poles suitable for single units or multistory structures respectively. In order to minimize damages from insects and ground moisture, the structure is designed to sit on precast concrete piers above ground. The prefabrication of components as well as assembly of the structure can be accomplished using simple hand tools and workers with minimal training.

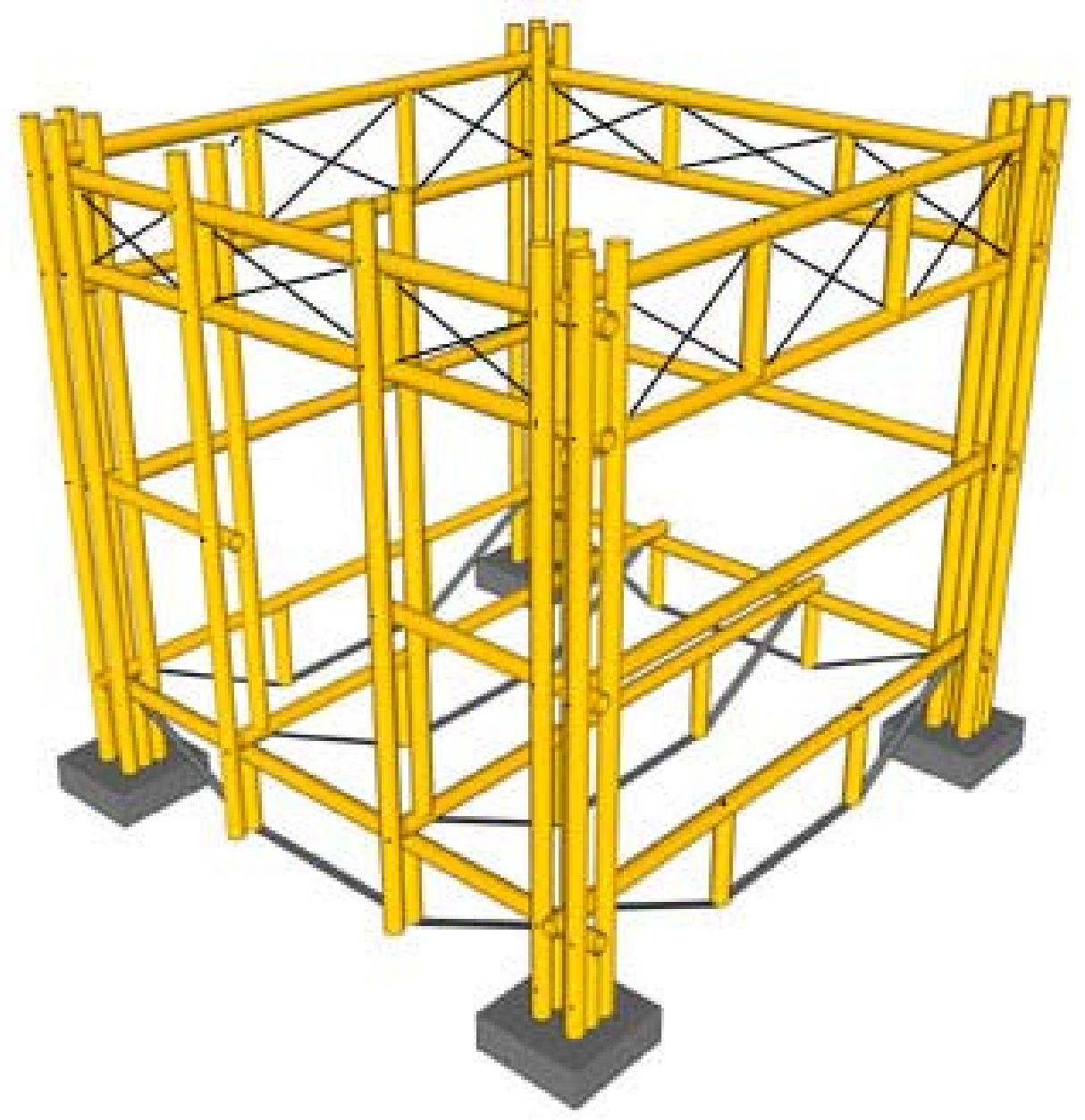

Figure 4.5 Basic Structural System: Bamboo post and beam framing built on precast concrete footings. Source: Concept by Author, and created in Google SketchUp. 


\subsubsection{Column}

A column illustrated in Figure 4.6 is an assembly of four bamboo poles and bamboo spacers of similar diameter. Locally manufactured threaded rods are used to bolt the assembly. Columns for the basic unit use 10 foot poles, but longer columns up to 20 feet long can be constructed from quality bamboo culms with consistent diameter. The 10 foot columns are designed to be stacked up in order to create multistory units. Detailed specifications and test results are discussed in chapter five, subsection 5.1.4.

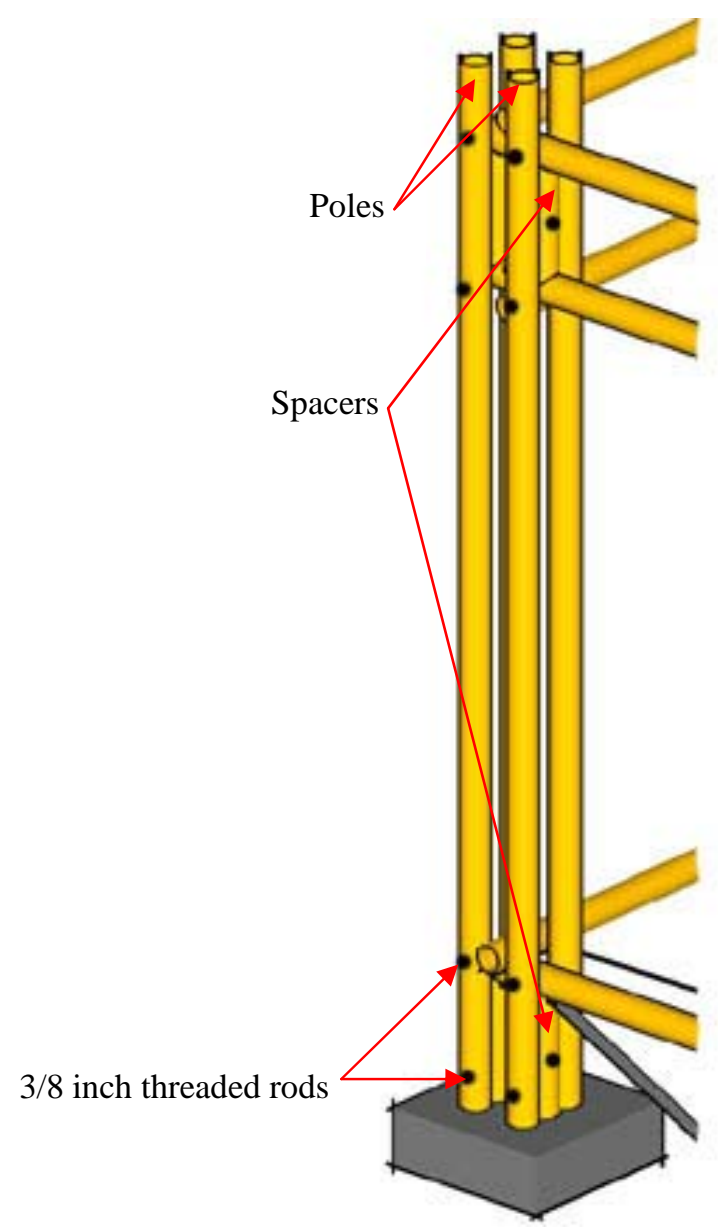

Figure 4.6 Prefabricated Column: An assembly of four bamboo poles and 1 foot long bamboo spacers of similar diameter bolted using threaded rods. Source: Concept by Author, and created in Google SketchUp. 


\subsubsection{Beams}

The structural system utilizes two types of beams. Beam A, shown in Figure 4.7 supports the roof load and creates a rigid post and beam framing. The component is prefabricated in 10 or 20 foot long pieces for a single 10 foot by 10 foot unit or a wider 10 foot by 20 foot unit suitable for staking up to four stories. Beam B is designed to support the floor system and to span 10 feet. Detailed specifications and test results for each beam are discussed in chapter five, subsection 5.1.1.

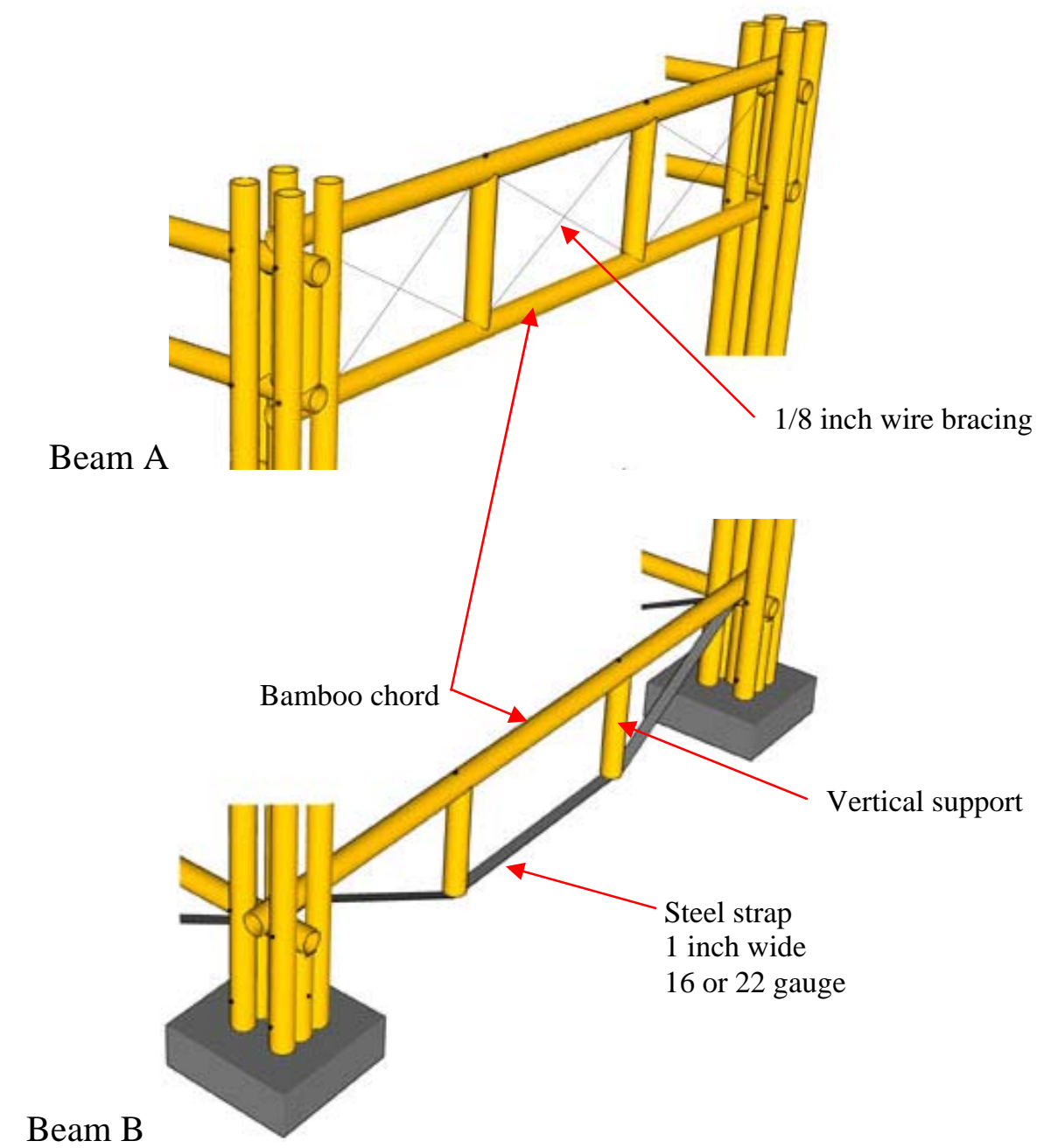

Figure 4.7 Prefabricated Beams: Beam A supports roof load and creates rigid connection; Beam B supports the floor system. Source: Concept by Author, and created in Google SketchUp. 


\subsection{Building Envelope}

The basic unit utilizes locally manufactured and inexpensive coverings suitable for most of Ethiopia's environment. Standardized 4 foot by 8 foot sheets of bamboo mat and corrugated iron are used to increase efficiency of construction and eliminate waist. The cover require simple hand tools to install, and the installation process can be accomplished by workers with minimal training.

\subsubsection{Wall System}

A typical unit would have a wall type constructed from corrugated iron exterior and woven bamboo mat interior (Figure 4.8). Depending on the diameter of bamboo poles used in the structural framing there will be a 2 or 4 inch gap between the envelopes. In cooler environments the gap could be used to install wall insulation, and in warmer environments the opening could be used for air circulation.

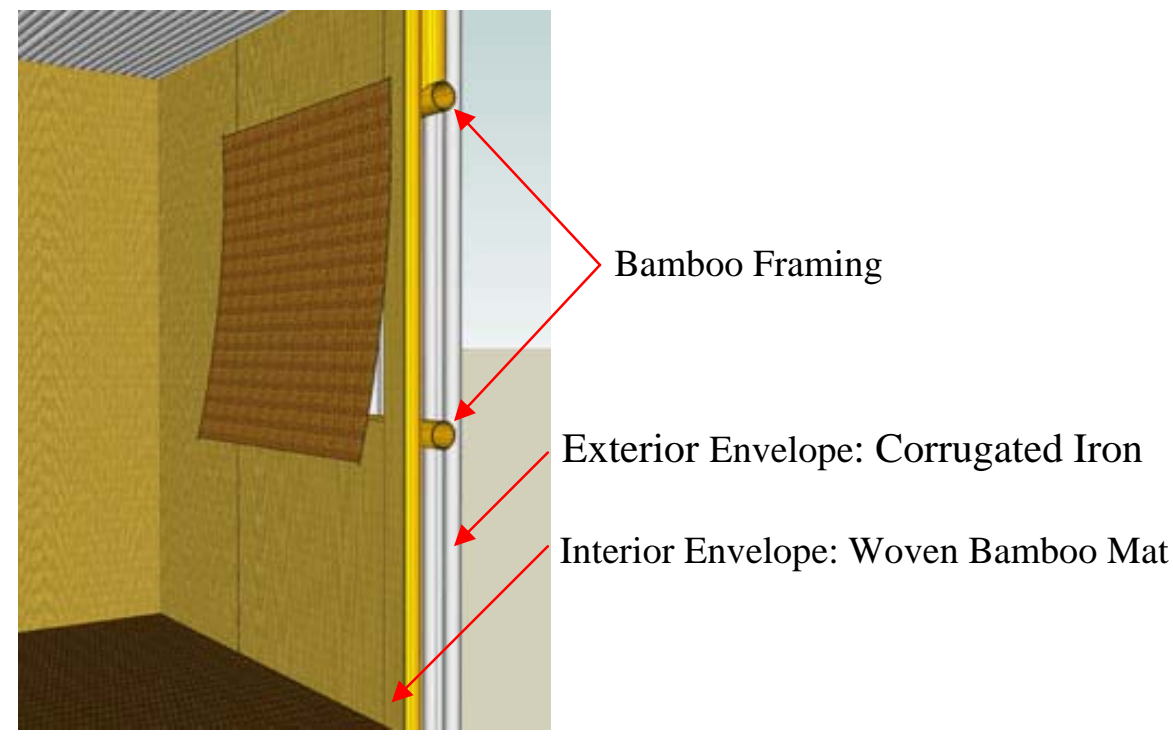

Figure 4.8 Basic wall system composed of corrugated iron exterior and woven bamboo mat interior envelope. Source: Concept by Author, and created in Google SketchUp 


\subsubsection{Floor system}

The basic floor system is composed of one inch diameter bamboo decking supported by a series of bamboo joists referred to as beam B in section 4.4.2. Woven bamboo mat over the decking provides a comfortable and even surface for walking and installing furniture. Depending on the environment additional coverings and insulation may be incorporated in the system. The floor load is directly transferred to the ground through precast concrete piers supporting the structure. The floor system sits above ground to minimize damage from insects and ground moisture. Details regarding feasibility of the system and construction will be discussed in sections 5.1 and 5.2 of chapter five.

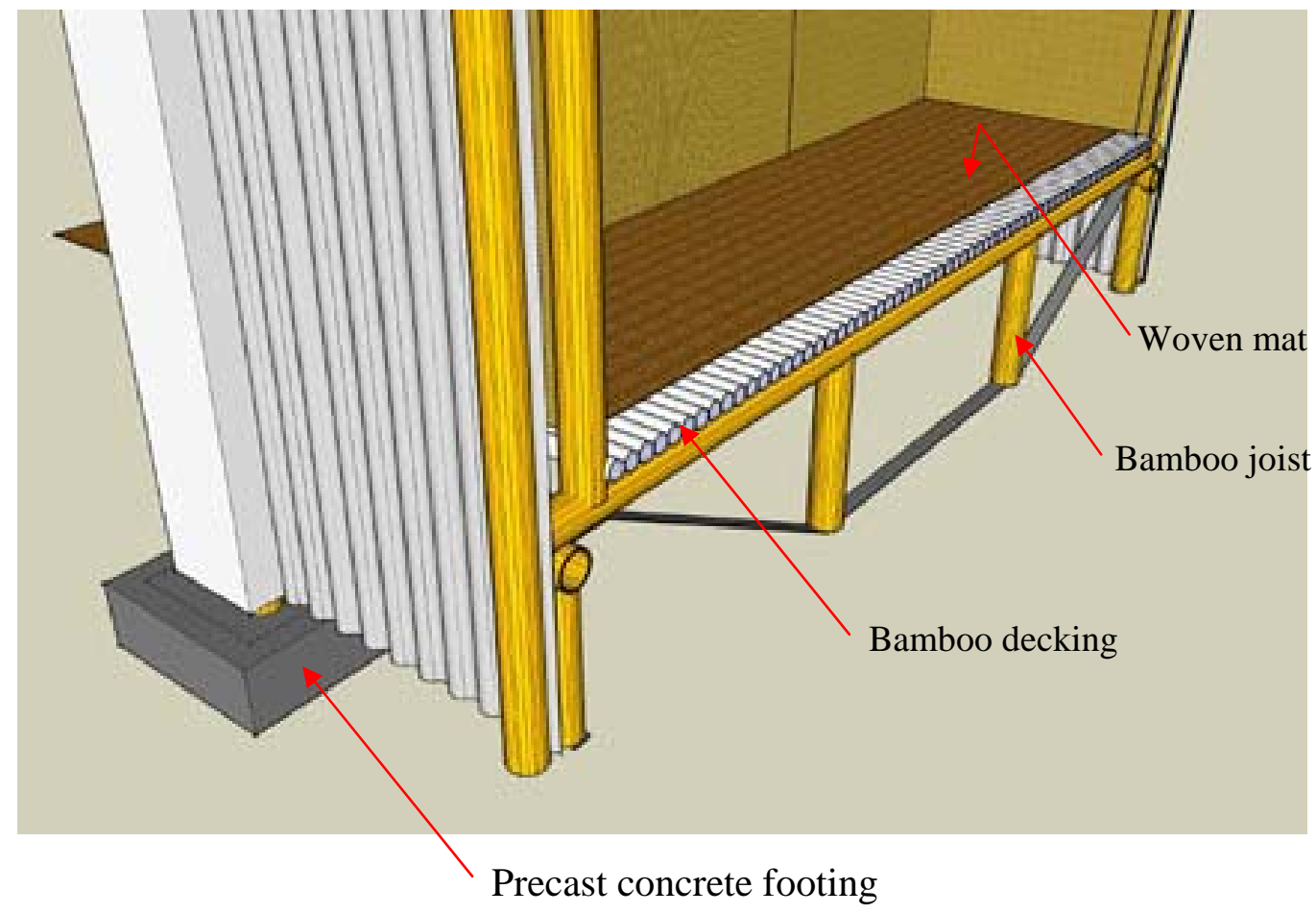

Figure 4.9 A floor system composed of woven bamboo mat covering over a one inch diameter bamboo decking supported by a series of bamboo joists. Source: Concept by Author, and created in Google SketchUp 


\subsubsection{Roof System}

The basic unit has a flat roof system that utilizes corrugated iron sheet covering and sheet metal flashing (Figure 4.10). The roof is inclined to drain water to the rear side of the unit. The flashing surrounding three sides of the unit prevent the passage of water in to the structural system.

A ceiling system similar to the floor decking (one inch bamboo layer covered with woven bamboo mat) can be incorporated in the roof system. Details of the roof system and construction will be discussed in subsection 5.2 of chapter five.

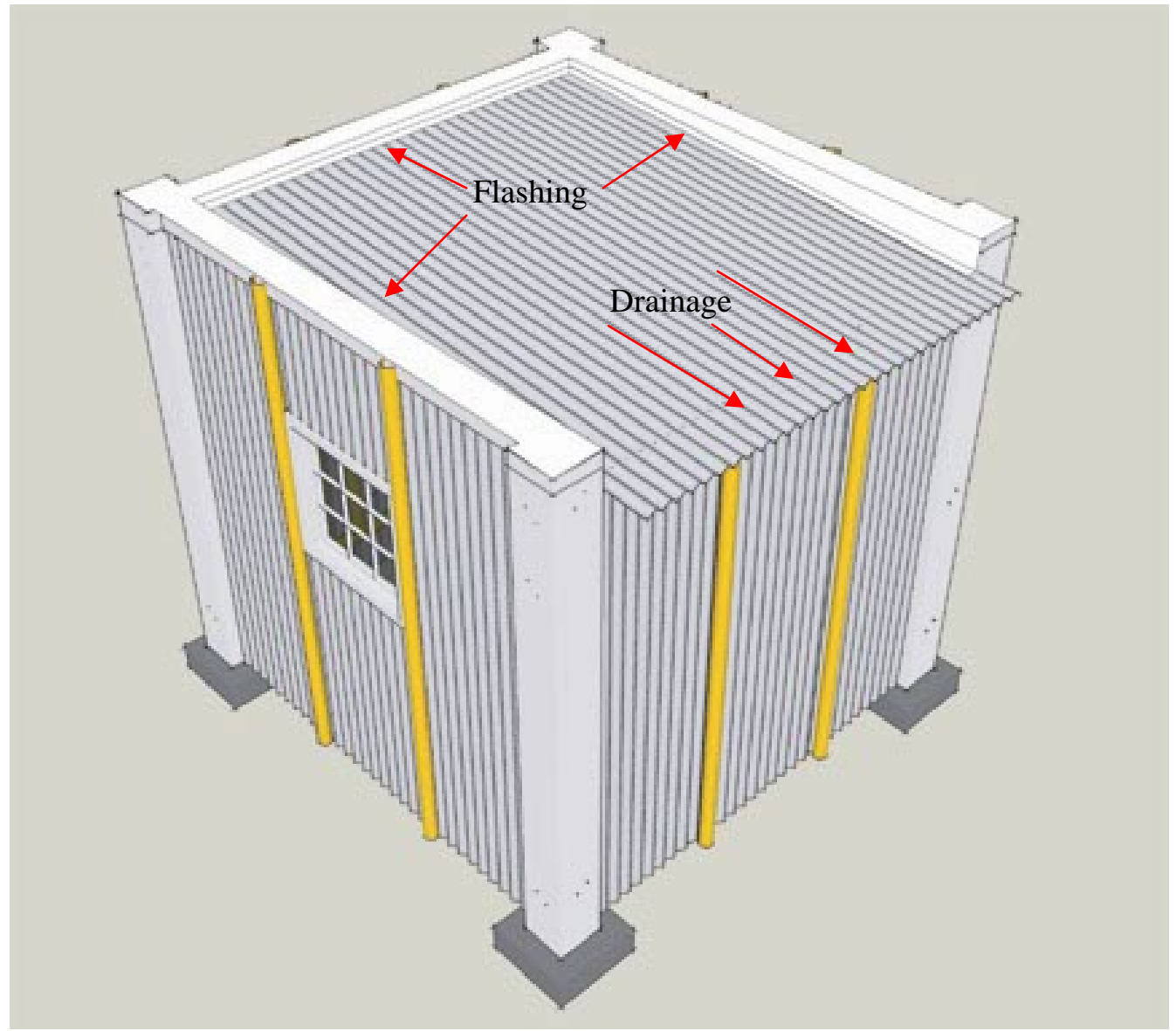

Figure 4.10 A flat roof system with three sided flashing and drainage system directed towards the rear of the unit. Source: Concept by Author, and created in Google SketchUp. 


\subsection{Vertical Densification}

Considering the high cost of land in urban Ethiopia, the low cost housing unit is designed to be stacked up to four stories as illustrated in Figure 4.11. Local building codes allow for the construction of multistory structures up to four stories without the need for an elevator system. In order to create a stable multistory structure, the basic 10foot by 10 -foot unit is expanded to two adjoined units of 10 -foot by 20 -foot and staked perpendicularly. The vertical growth could be executed at the initial construction stage, or over time as the need for more space arises.

In large scale projects units could be assembled in a factory setting or a temporary assembly area to insure quality construction and save time. Technical details regarding construction and overall feasibility of stacking individual units are discussed in chapter five, subsection 5.2 .

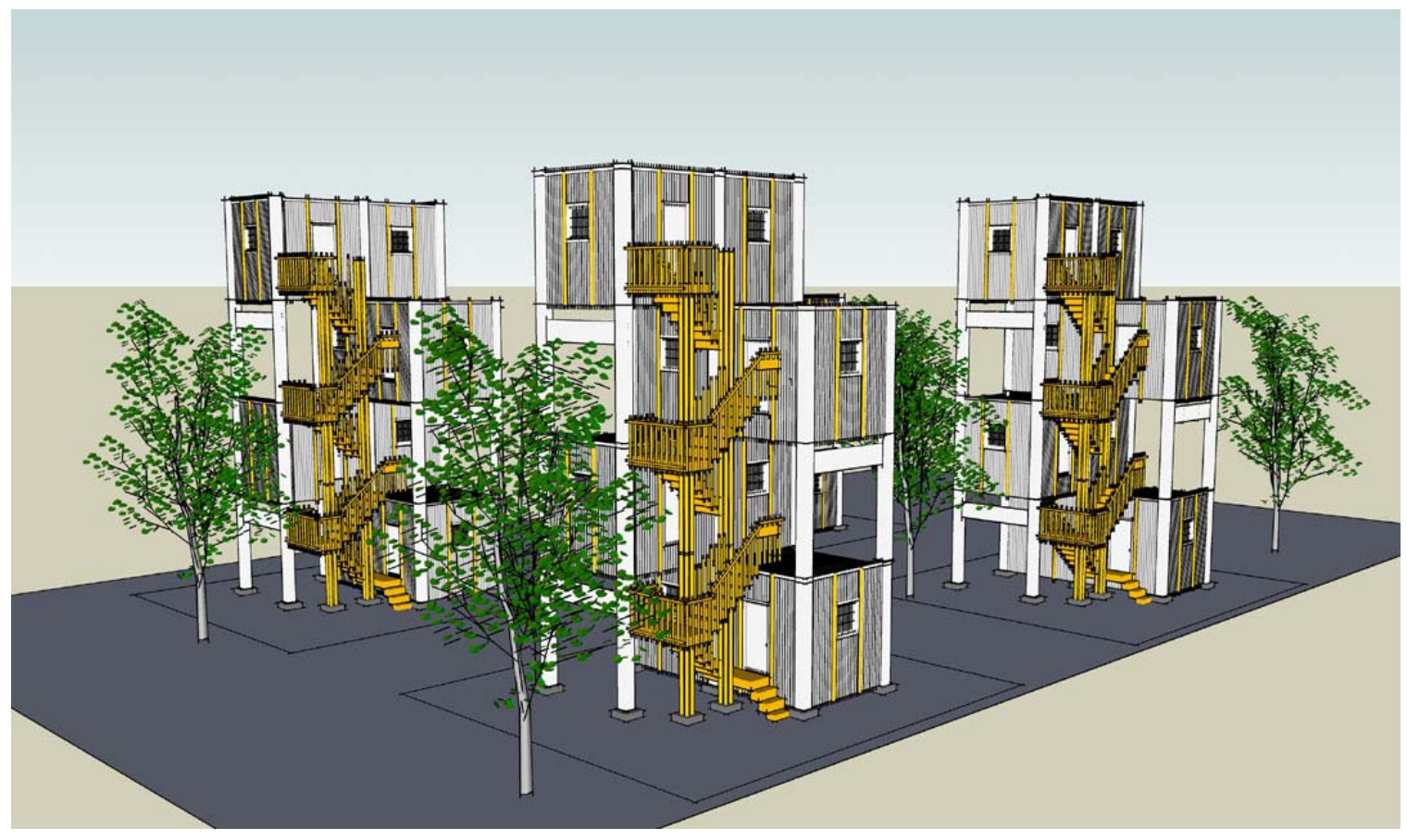

Figure 4.11 A concept for low cost housing communities composed of multistory structures assembled from adjoined basic units stacked perpendicularly up to four stories. Source: Concept by Author, and created in Google SketchUp 


\section{CHAPTER 5 \\ Testing and Construction of Prototype}

\section{$5.1 \quad$ Testing}

The main objective of the load tests was to study and gauge the feasibility of bamboo based structural components intended for the construction of modern structures suitable for urban environments. The tests performed on full-scale structural components of the proposed low cost housing unit were conducted at Cal Poly State University's high bay laboratory.

Multiple tests were performed on columns, beams and joints critical for the stability of the proposed bamboo post and beam framing. Some components were reinforced using concrete, steel wires and straps. Although concrete and steel are expensive building material, their minimal application in reinforcing key components compensates for the shortcomings of bamboo poles.

Results from the various tests are illustrated in the following sections using graphs and photographs taken during and after the tests were performed. Test results for similar components are plotted in the same graph for easier comparison. For example the graph in Figure 5.2 shows results from three separate tests performed on three trussed beams assembled from components with different physical properties. Of the hundreds of photographs taken during and after the testing processes, a selected few that show critical points of the process are included and described briefly. 


\subsubsection{Trussed beam test (single vertical support)}

Three similar load tests, illustrated in Figure 5.1, were performed on trussed beams constructed from hollow or concrete filled bamboo chord (8 feet long, 2 inch diameter), 1 foot vertical support and 22 or 16 gauge steel strap.

One point load test:

Test \# 1) Hollow bamboo chord, vertical support and 22 gauge steel strap.

Test \# 2) Concrete filled bamboo chord, vertical support and 22 gauge steel strap.

Test \# 3) Concrete filled bamboo chord, vertical support and 16 gauge steel strap.

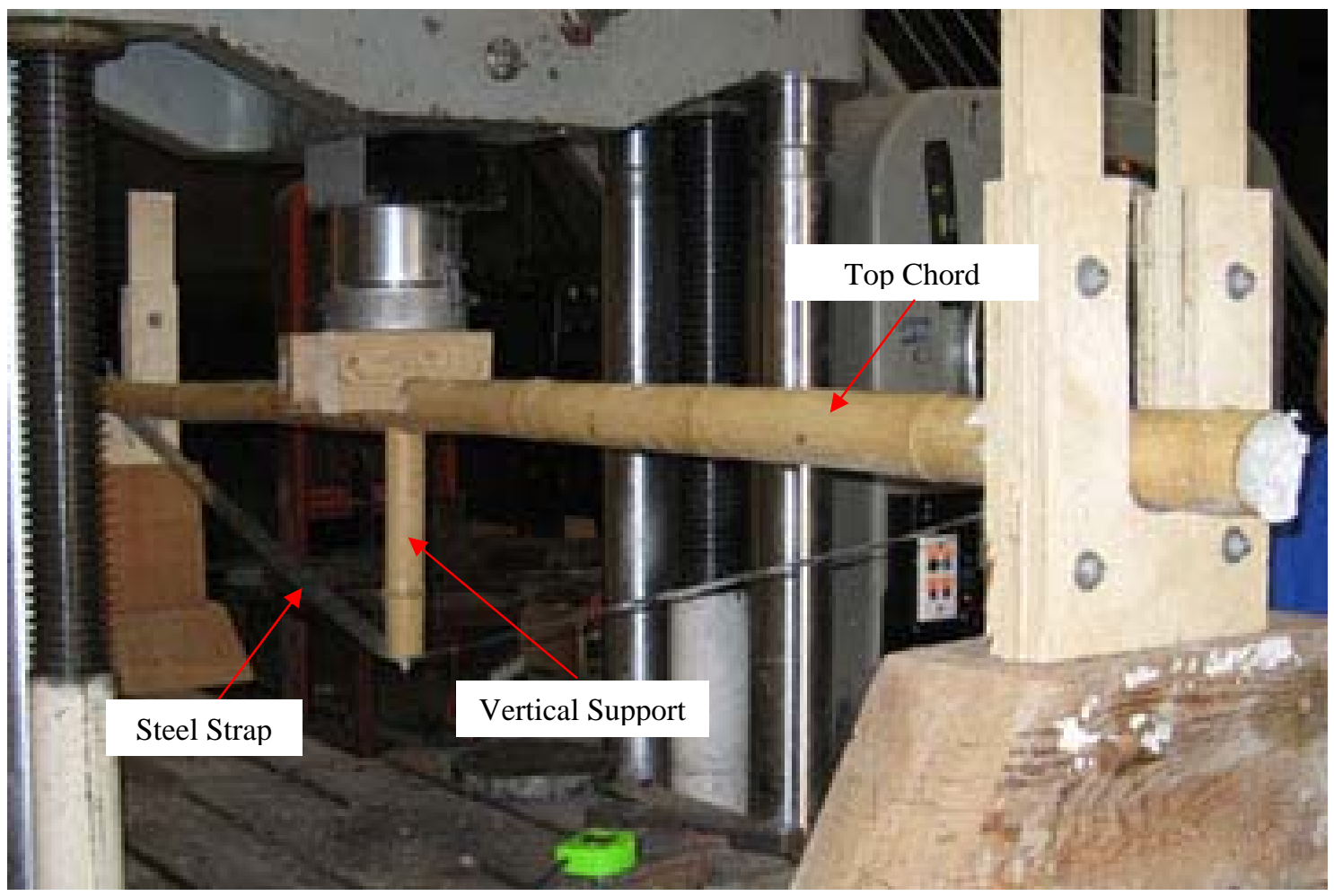

Figure 5.1 Trussed beam with concrete filled top chord, single vertical support and 22 gauge steel strap used as the tension member. Source: Photograph by Author. 
The test results illustrated in Figure 5.2 compare performances of the three trussed beams described above. Test number one produced the least desirable performance due to the failure of the bamboo chord at the end joints. Test number two was performed on a beam with concrete reinforced joints. In this test the 22 gauge steel strap failed before any significant damage was done to the bamboo cord. In test number three the 22 gauge steel strap was replaced with a thicker 16 gauge steel strap. Although the strap eventually failed, it did improve the overall performance of the beam.

The combination of concrete reinforced joints and 16 gauge steel strap did reduce the deflection of the trussed beam while increasing its load carrying capacity.

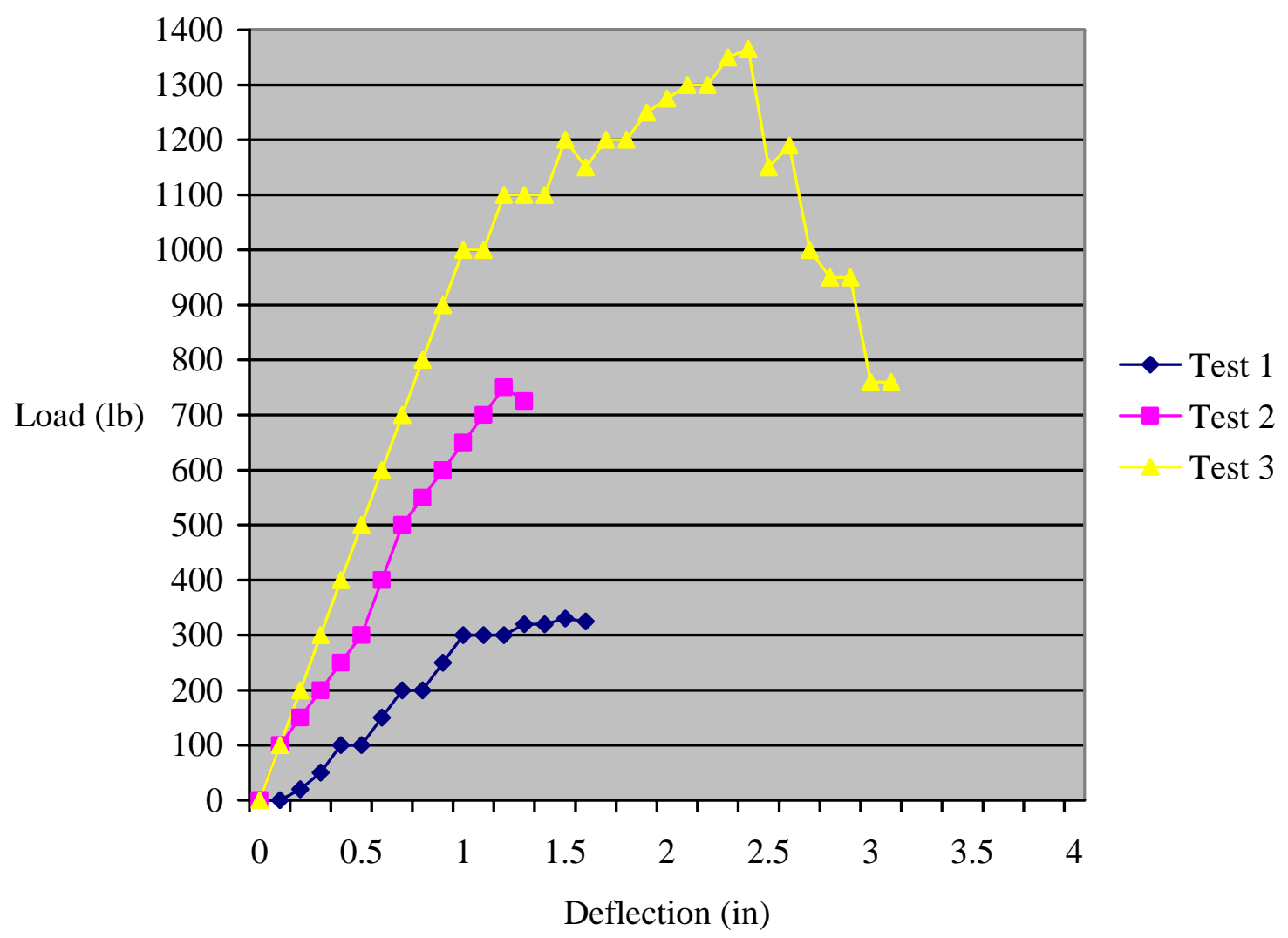

Figure $5.2 \quad$ A comparison of results gathered from three separate load tests. Source: Data collected by Author. 
Image taken at the end of test number one shows hollow bamboo chord crushed at the joint.

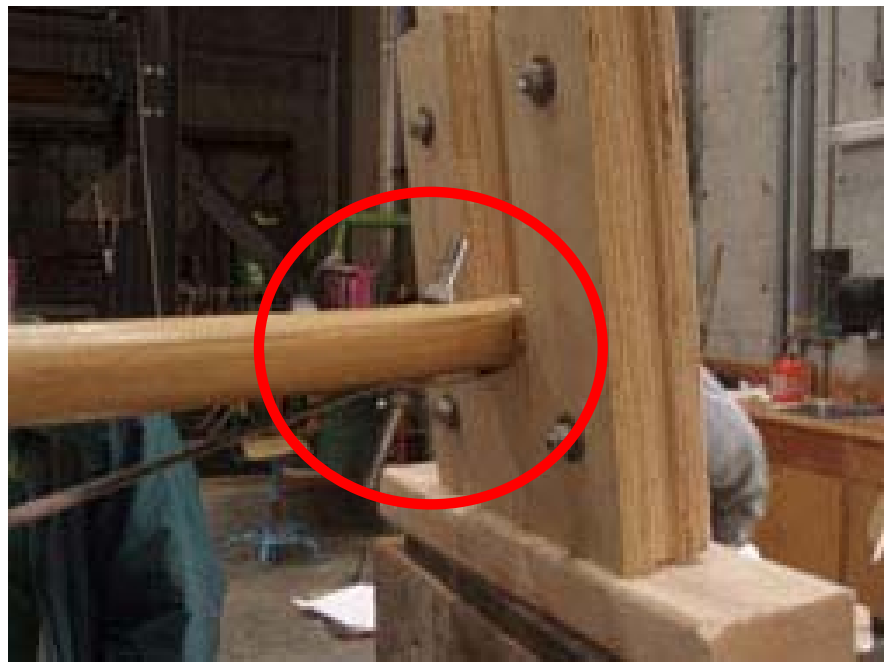

In test number two, concrete filled joints significantly increased the strength of bamboo chord. The image shows the 22 gauge steel strap failing before any significant damage is done to the bamboo chord.

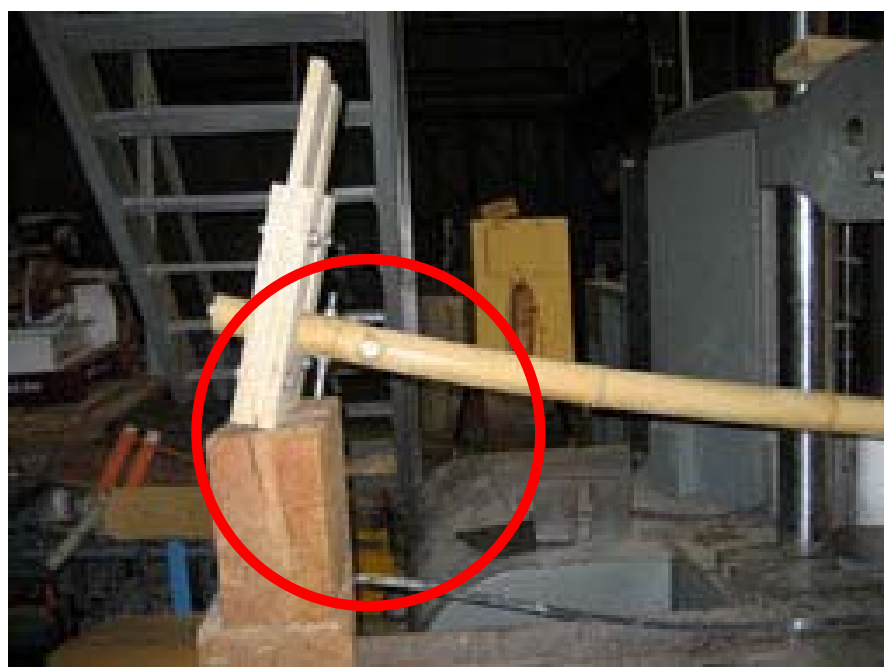

In test number three the 22 gauge strap was replaced with a thicker 16 gauge strap to prevent premature breakage, and the result was a significantly stronger beam. The image shows all members still intact at loads over $1000 \mathrm{lb}$.

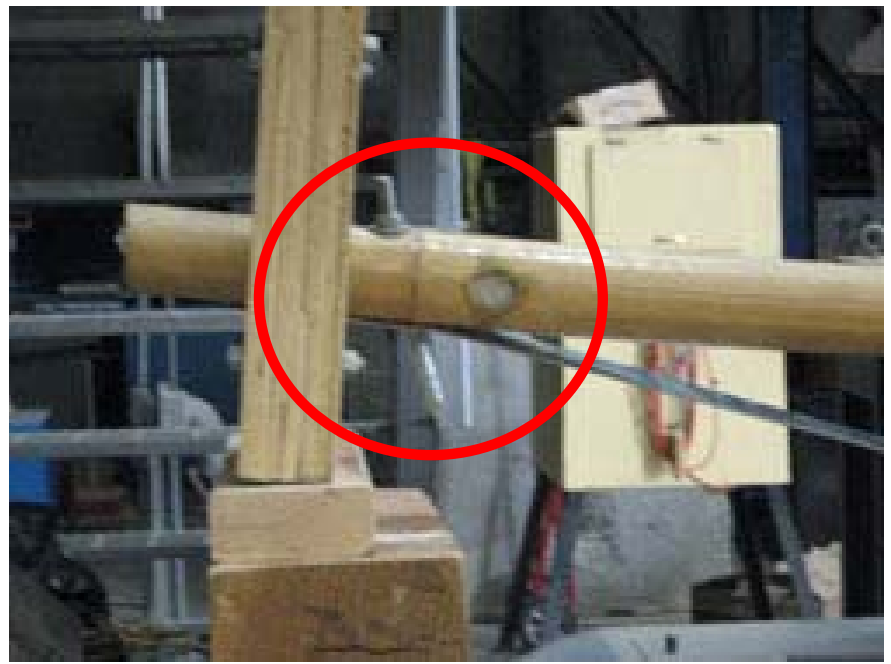




\subsubsection{Trussed beam test (double vertical support)}

Two separate load tests were performed on trussed beams constructed from hollow or concrete filled bamboo chord (8 feet long, 2 inch diameter), two foot long vertical supports and 22 or 16 gage steel strap similar to the one illustrated in Figure 5.3.

Two point load test:

Test \# 4) Concrete filled bamboo chord, vertical supports and 22 gage steel strap.

Test \# 5) Concrete filled bamboo chord, vertical supports and 16 gage steel strap.

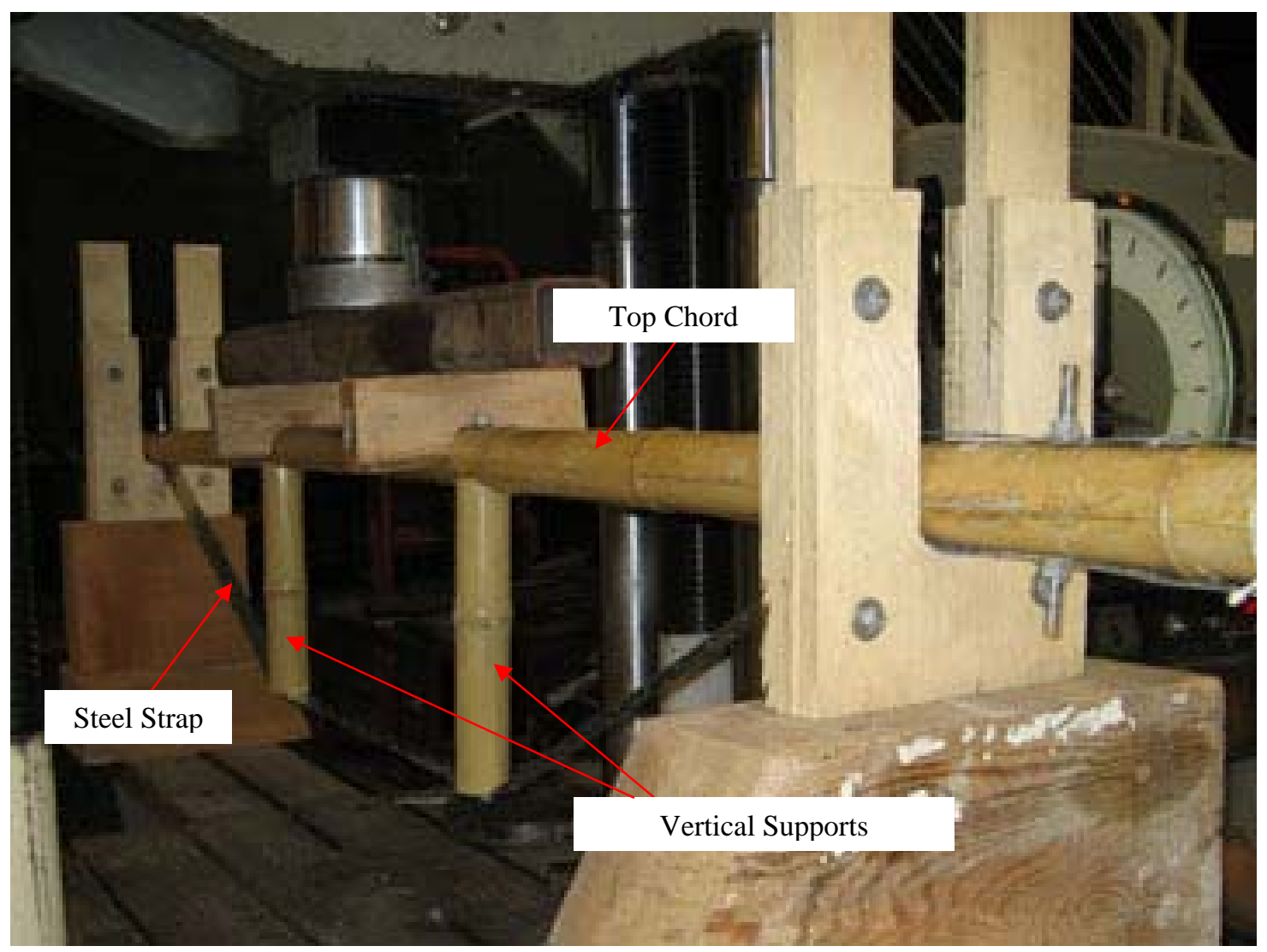

Figure 5.3 Trussed beam with concrete filled top chord, two vertical supports and 16 gauge steel strap used as the tension member. Source: Photograph by Author. 
As the graph in Figure 5.4 illustrates, test number four and five performed significantly better than the previous three tests. The addition of a second vertical support reduced the deflection of the trussed beams while increasing their load carrying capacity. In a similar fashion to test number two, the 22 gauge steel strap used in test number four failed at a relatively lower load point, while 16 gauge strap used in test number five was able to take on more than twice the amount of load.

Overall, the addition of a second vertical support in combination with concrete reinforced joints and 16 gauge steel strap improved the performance of the trussed beam.

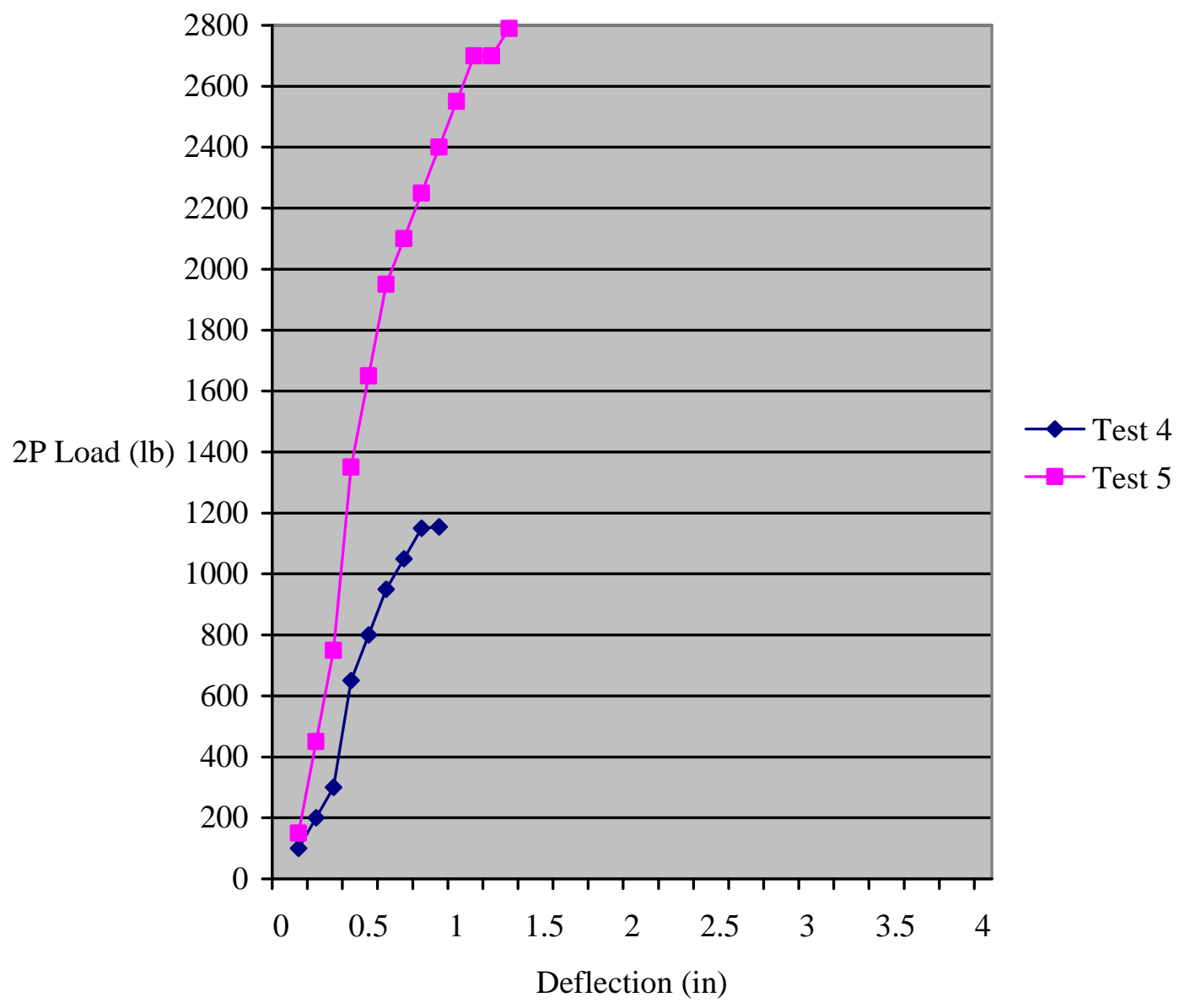

Figure 5.4 Graph showing two separate results from tests performed on trussed beams constructed from bamboo beam and steel strap. Source: Data collected by Author. 
Test number four was terminated after the steel strap broke around 1200 lbs. Since there was no major damage done to the bamboo parts, the same component was re-tested after the strap was replaced with 16 gauge one.

The following two images were taken before and after the 16 gauge strap broke during test number five. - The reinforced joint and strap were strong enough to bend the steel washer.

- After taking on close to 3000 lbs, the bamboo parts were still usable for further experiments.
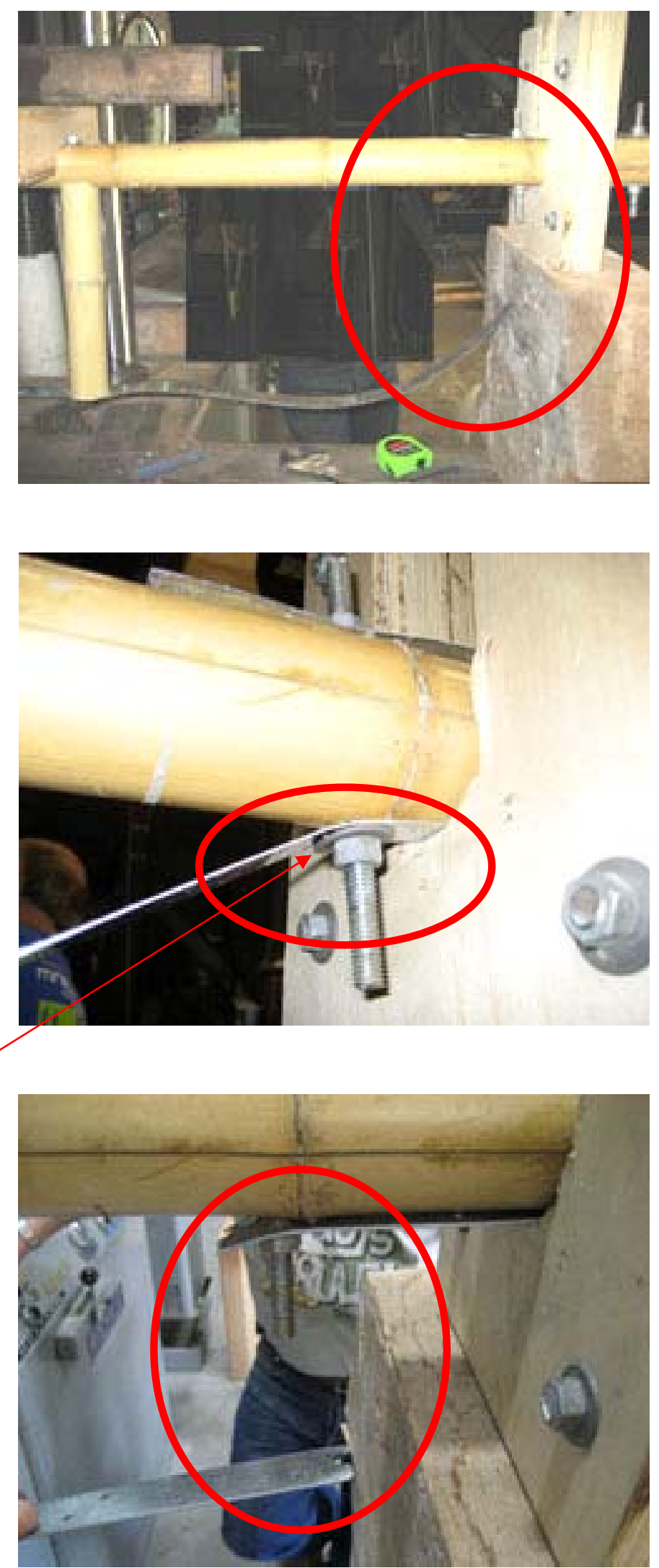


\subsubsection{Bamboo truss}

A single test was performed on a standard truss shown in Figure 5.5 built from bamboo chords (8 feet long and 2 inches in diameter) and evenly spaced vertical supports. Quarteer inch steel wire was used as diagonal bracing.

One point load test:

Test \#6) Hollow bamboo chords, six vertical supports and 1/4” steel wire bracing.

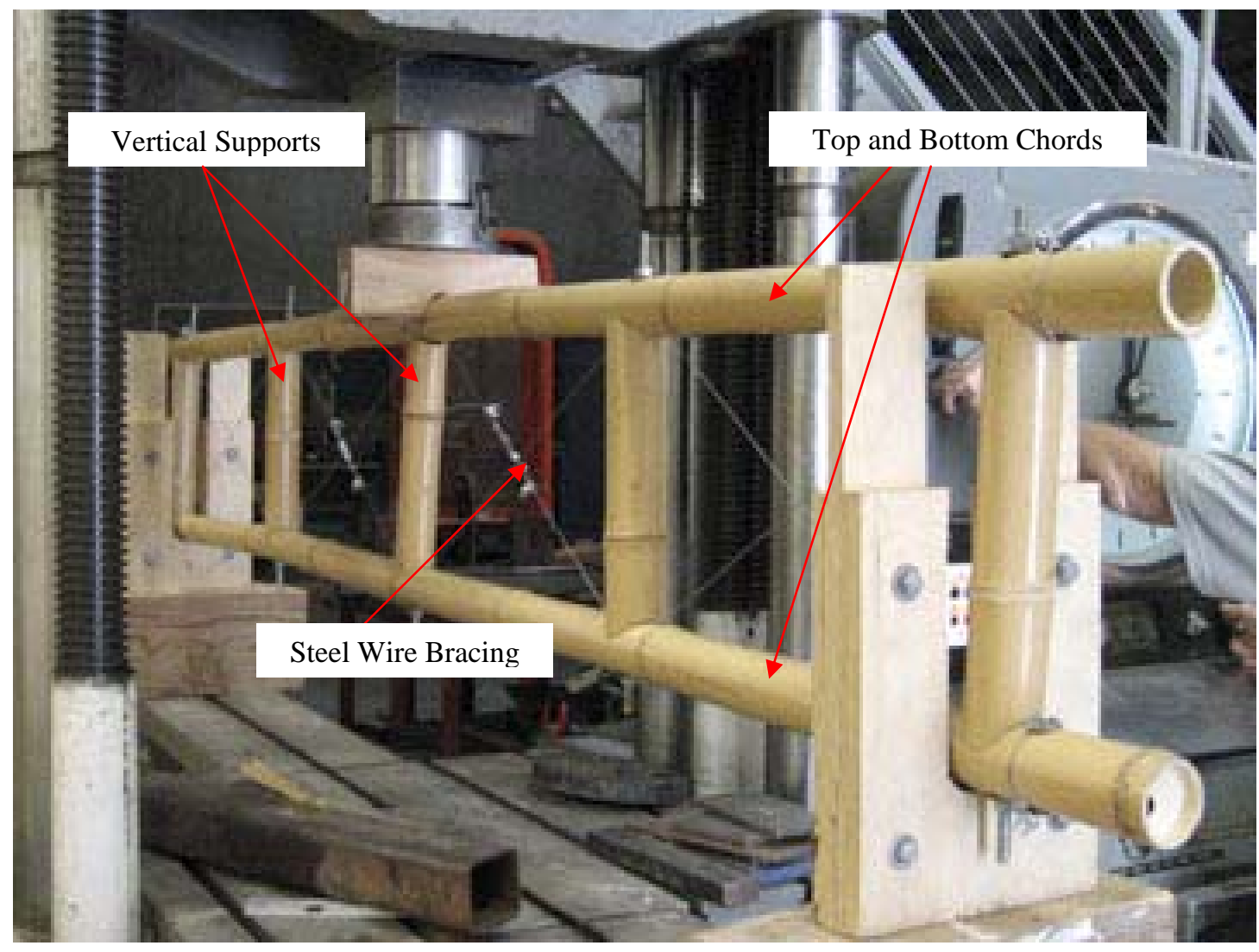

Figure $5.5 \quad$ Eight foot bamboo truss with steel wire bracing. Source: Photograph by Author. 
The overall performance of the bamboo truss was poor. As the graph in Figure 5.6 illustrates, the truss deflected about one inch close to the $100 \mathrm{lb}$ mark, and at the point of complete failure the truss had deflected close to three inches. The wire bracing was ineffective and did cause major structural damage by slicing through the skin of bamboo chords.

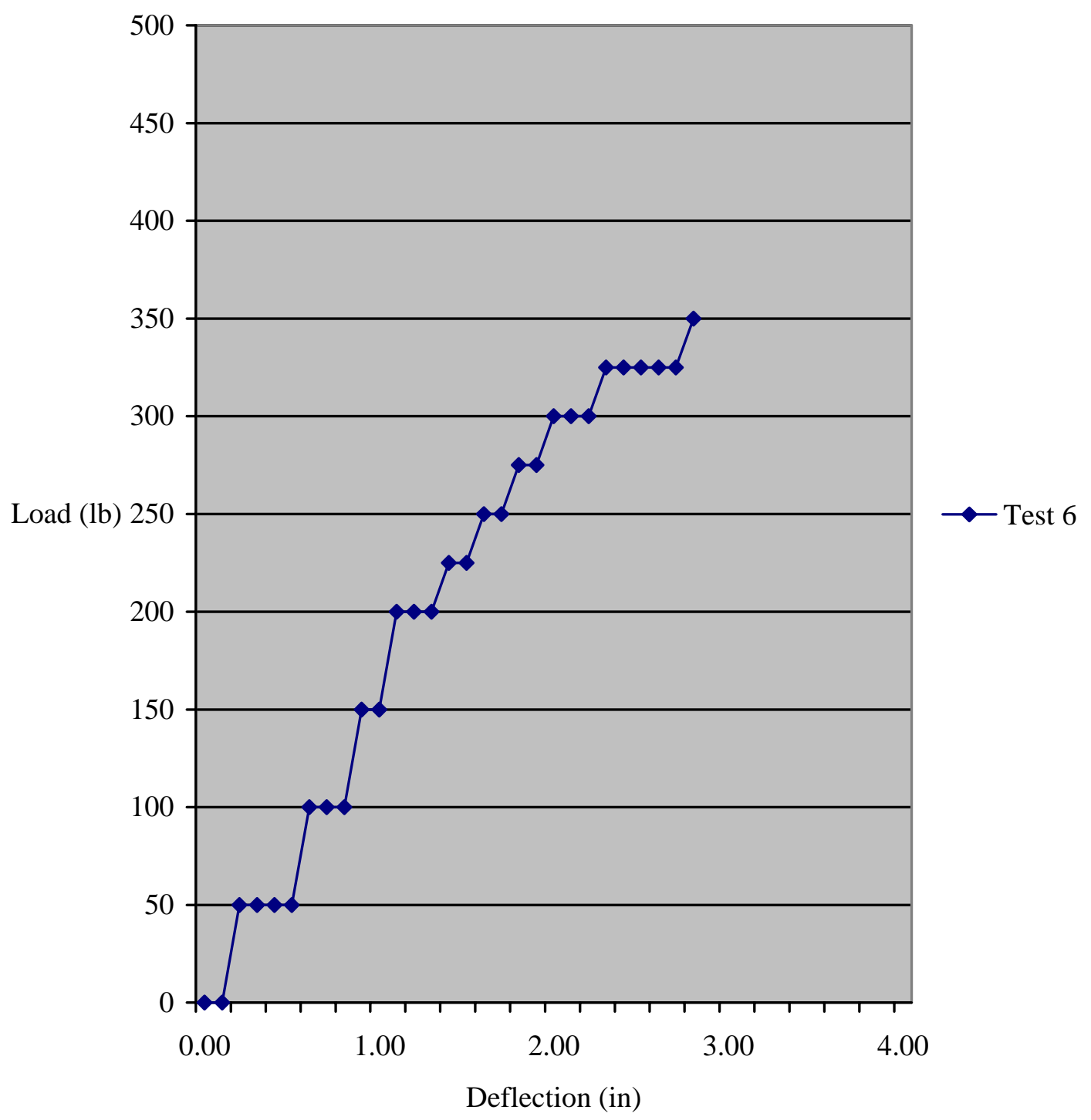

Figure 5.6 Graph showing a result from a single test performed on a standard bamboo truss with steel wire bracing. Source: Data collected by Author. 
The photo shows the level of deflection before any significant damage was done to bamboo members.

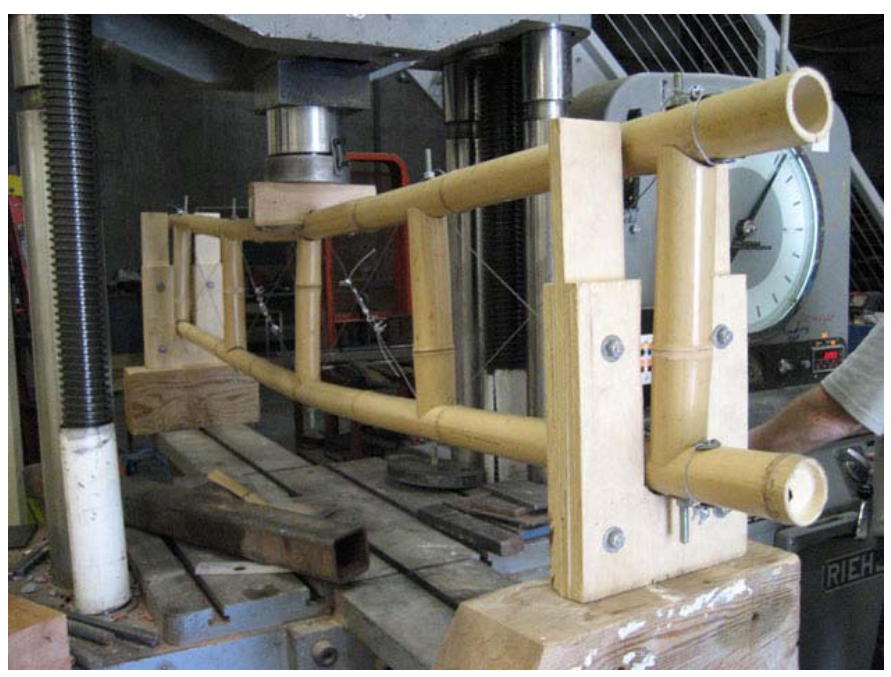

Steel wire bracing was ineffective.

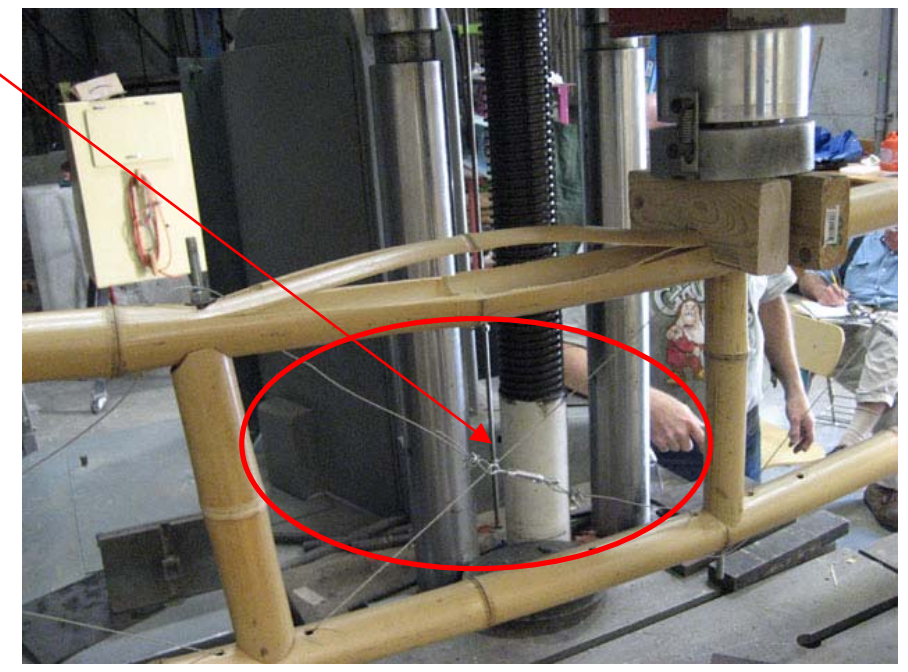

Top bamboo chord failure

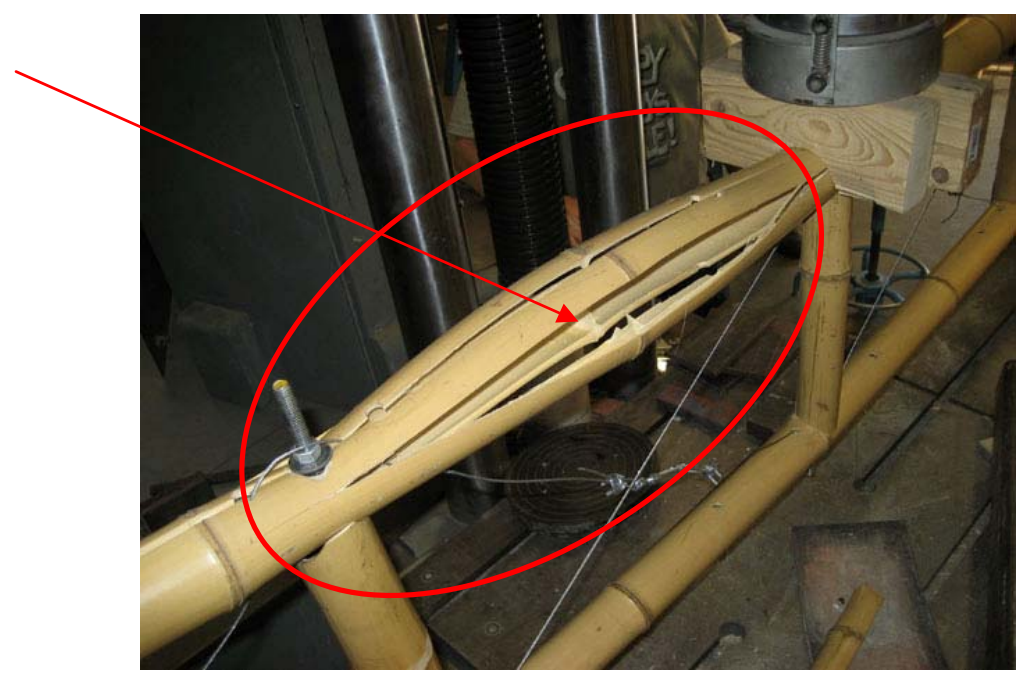




\subsubsection{Column test (double shear)}

The column test was conducted on two similar samples built from 2 foot bamboo poles bolted six inches apart using 3/8” diameter threded rods. Figure 5.7 illustrates test sample number 7 just before testing was conducted.

Test \# 7 and \#8) Double bolted bamboo column

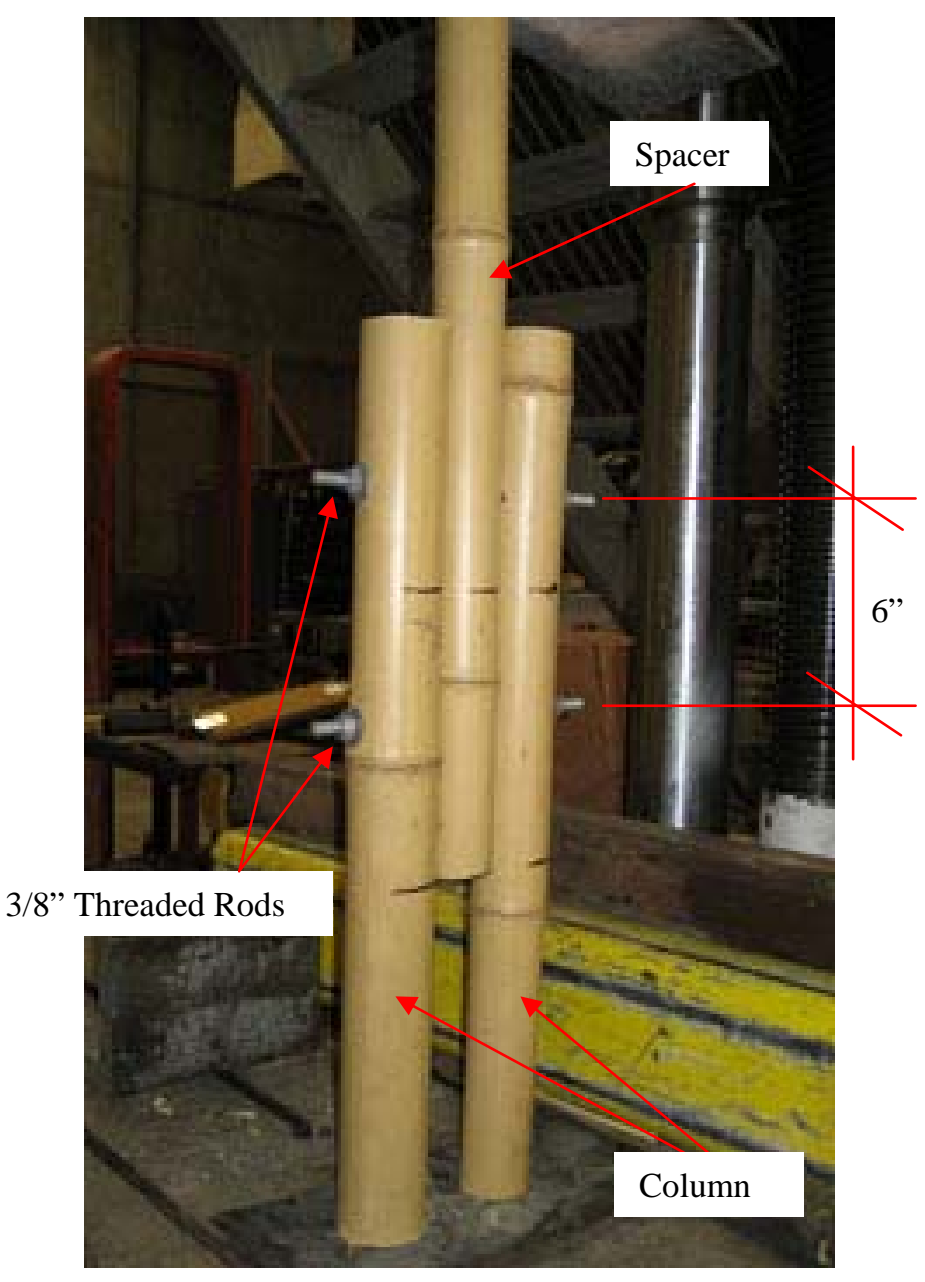

Figure 5.7 Double bolted column test. Source: Photograph by Author. 
Test results illustrated in Figure 5.8 show a consistent result between tests 7 and 8 . Both samples were able to carry close to 1000 lbs before visible fractures started to develop. In both cases the spacers were split in half. In test number 7 all three pieces eventually showed major damage.

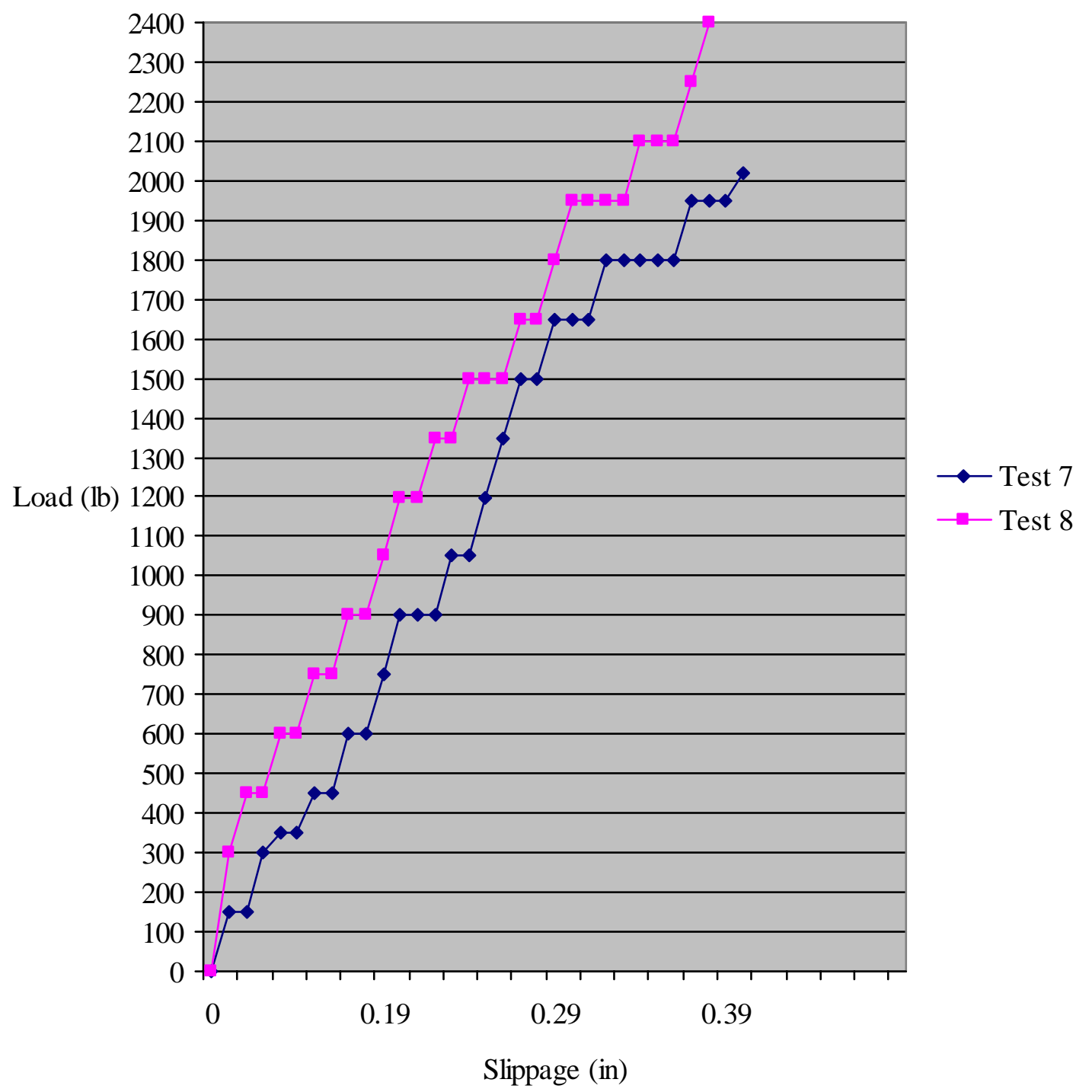

Figure 5.8 Graph showing two separate results from tests performed on double bolted column constructed from 2 foot bamboo poles. Source: Data collected by Author. 
Test number 7 showed fractures in all three pieces of bamboo before the spacer was completely sliced in half.

The column was able to take on over 1000 lbs before the fractures started to develop.

In test number 8 only the spacer was significantly damaged.

In a similar fashion to the previous test, the sample took on close to 1000 lbs before the first visible crack developed.
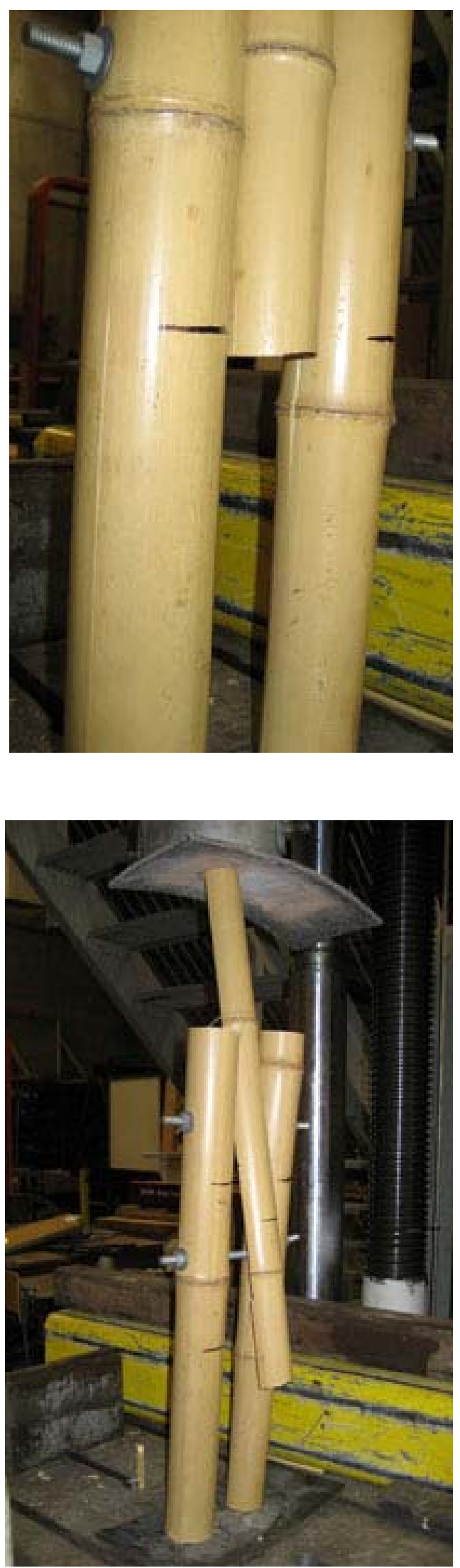


\subsubsection{Spliced column test}

The spliced column test was conducted on two similar samples built from 2 foot bamboo poles bolted six inches apart using 3/8” diameter threaded rods. Figure 5.9 illistrates test sample number 9 just before testing was conducted.

Test \# 9 and \#10) Spliced bamboo column

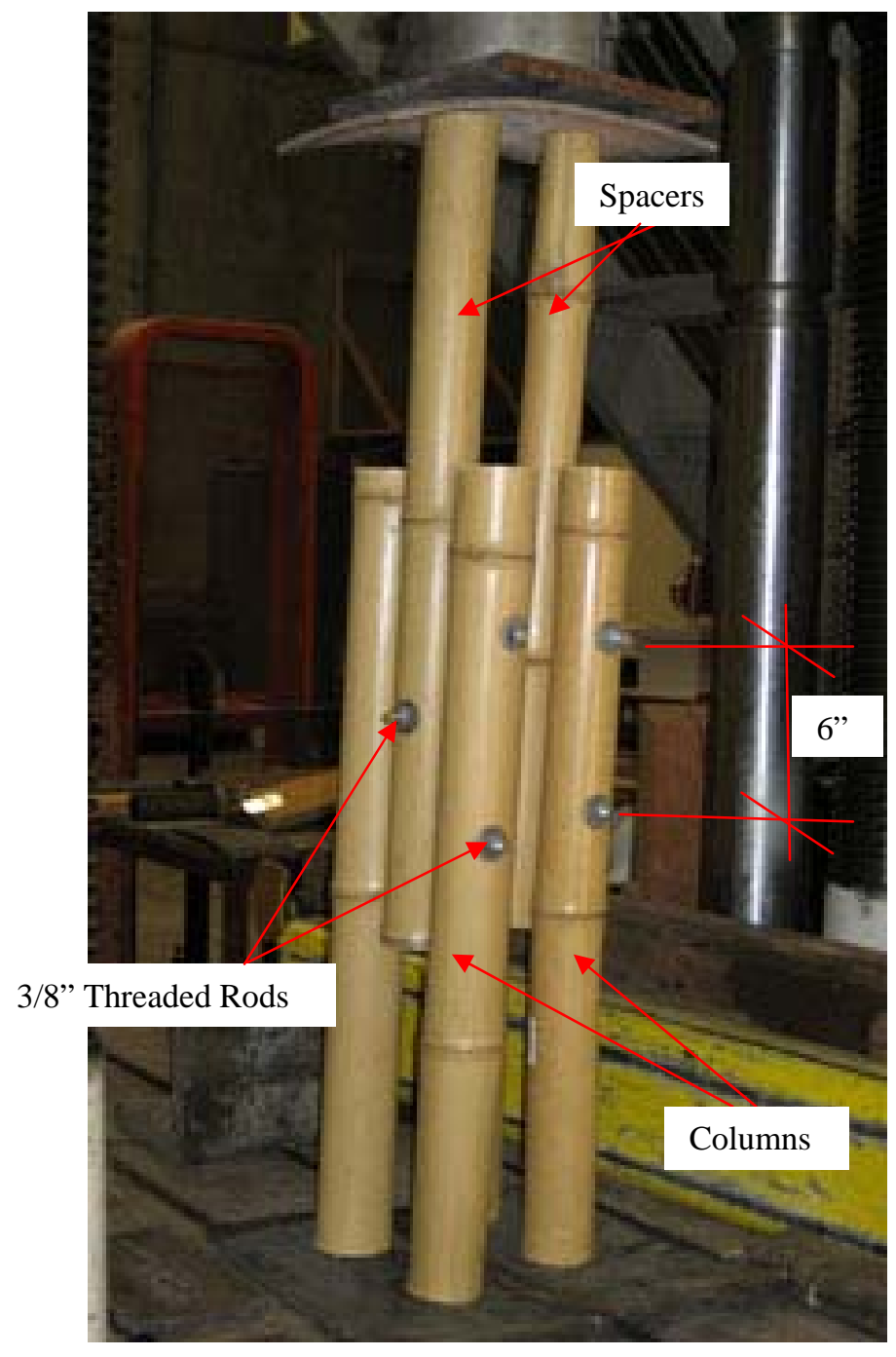

Figure 5.9 Spliced column test. Source: Photograph by Author. 
As the graph in figure 5.10 illustrates, the spliced column tests resulted in similar results. The assembly was able to take on close to $3600 \mathrm{lbs}$ before complete failure. In comparison to the results of tests number 7 and 8 , doubling the number of bamboo poles in the assembly doubled the amount of load the columns were able to carry, and slowed the failure of the assembly.

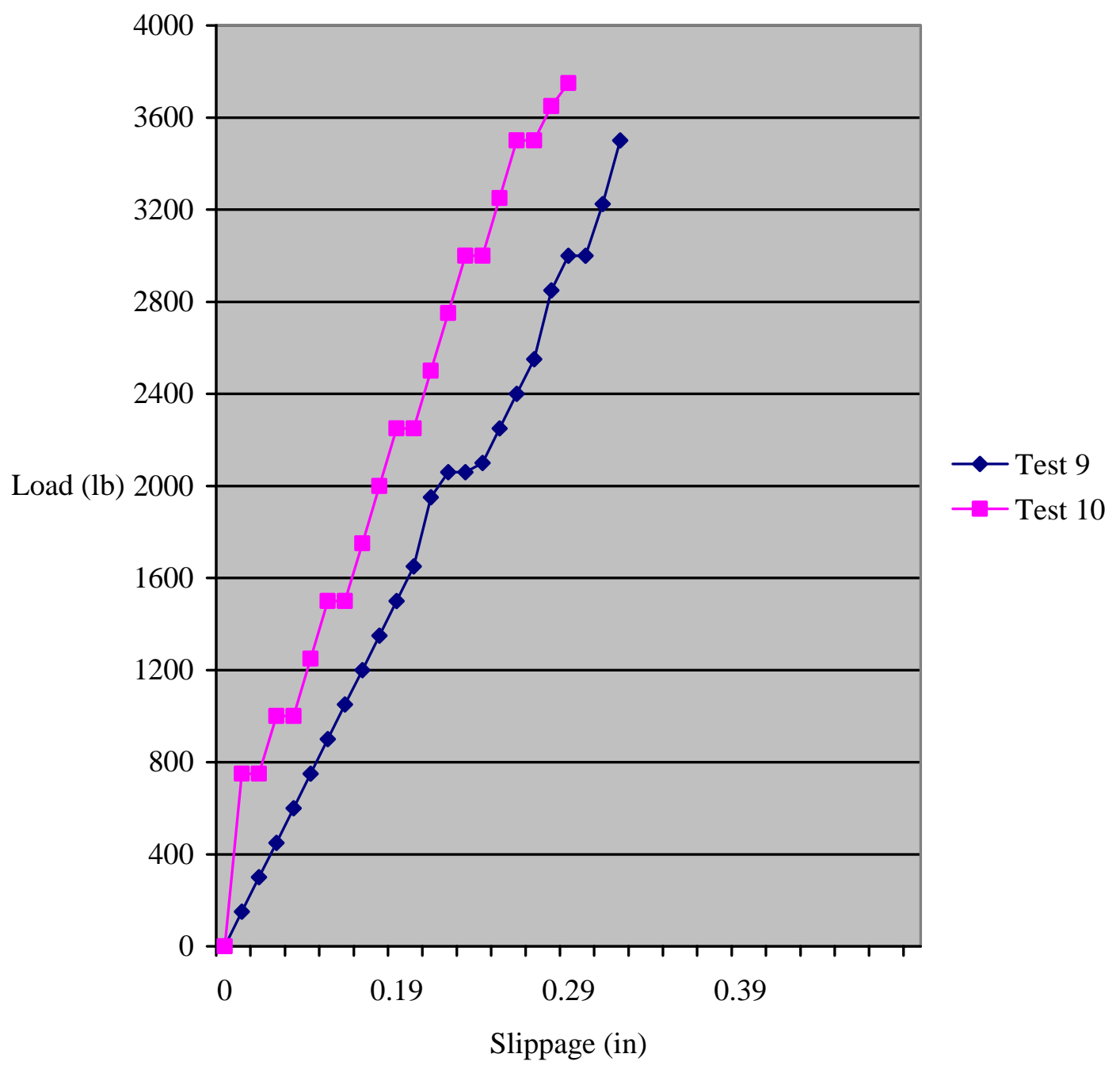

Figure 5.10 Graph showing two separate results from tests performed on spliced columns constructed from 2 foot bamboo poles. Source: Data collected by Author. 
Photo taken at the end of test number 9 shows one side of the spliced column still intact.

The assembly took on close to 3600 lbs before complete failure occurred.

Similar results were observed at the end of test number 10. One side of the spliced column took on relatively less damage, and slowed the failure of the assembly.

These results can be significantly improved by reinforcing the joints with concrete. This was proven in tests performed on trussed beam joints reinforced with concrete.
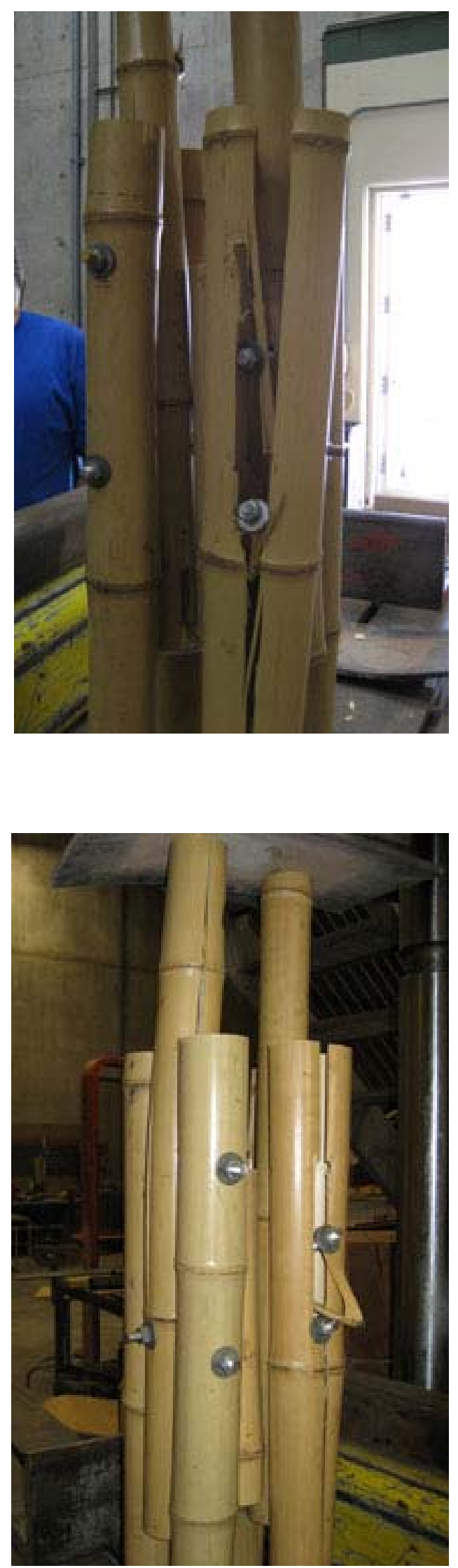


\subsubsection{Rigid connection test}

This test was particularly difficult to conduct. Due to the size of the test samples and complexity of the connection system, it was not possible to get accurate data for comparison. A better understanding of the connection was formed by observing its reaction on a prototype that was built subsequently. Figure 5.11 shows a test sample before and after it was modified for a better test setup, and an actual rigid connection on a full-scale prototype.

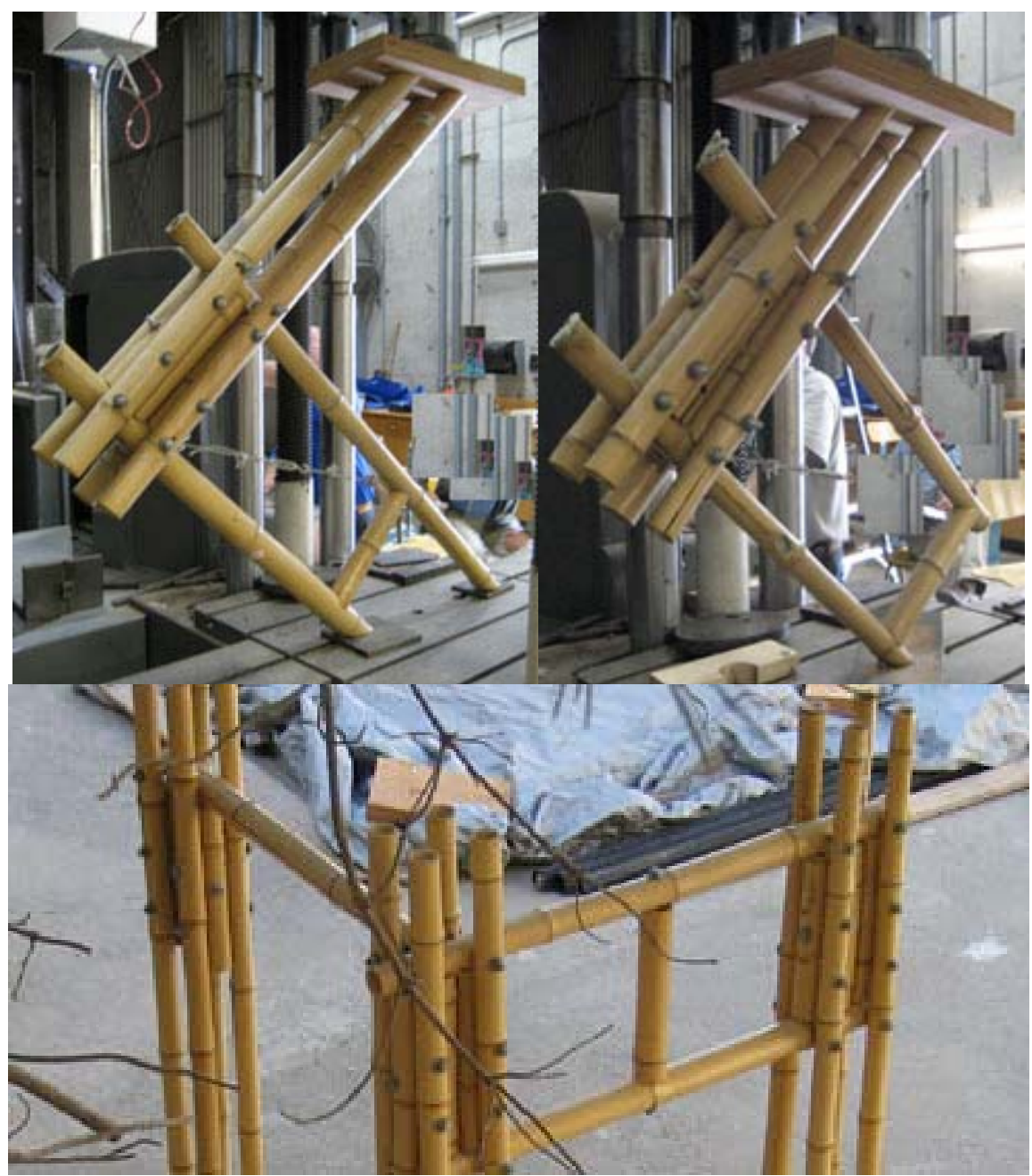

Figure 5.11 Top left: the initial test sample. Top right: modified test sample Bottom Rigid connection. Source: Photographs by Author. 


\subsection{Prototype}

The full-scale section prototype consists of a wall, floor, and partial roof system construction from bamboo poles, woven mat, corrugated steel sheets and threaded rods, similar to ones that could easily be obtained in Ethiopia.

The prototype shown in Figure 5.12 was constructed to test the feasibility of the proposed low cost housing design and gain firsthand knowledge in bamboo construction. Although no physical tests were performed on the prototype, it did provide ample information regarding the pros and cons of building with bamboo.

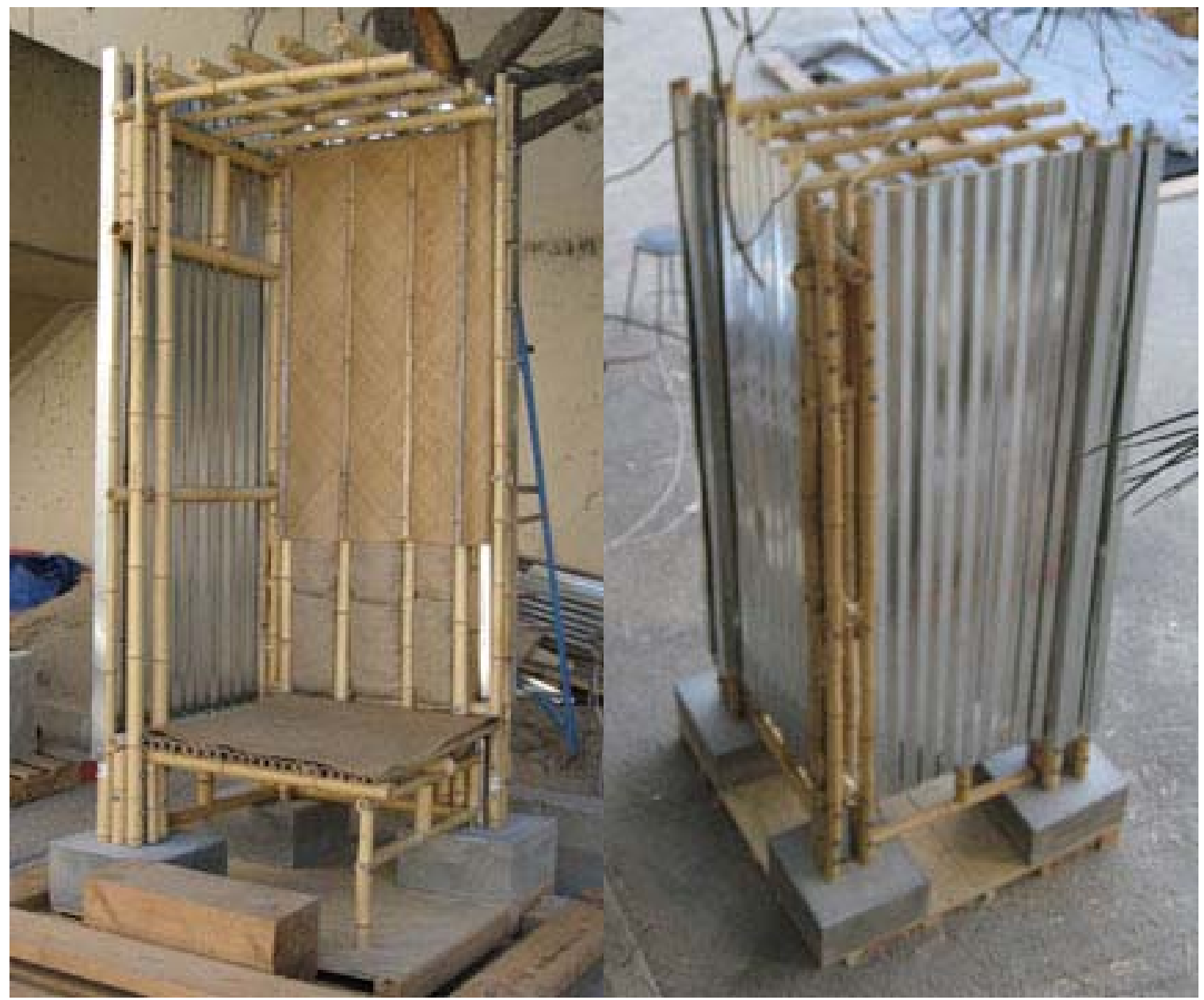

Figure 5.12 A full-scale section prototype constructed to test the feasibility of the proposed low cost housing solution. Source: Photographs by Author. 


\subsubsection{Anatomy of the prototype}

The upper portion of the prototype illustrated in Figure 5.13 shows parts of the structural system, a partial roof system and interior wall covering. The 4 foot by 4 foot floor system illustrated in Figure 5.14 consists of a support system constructed from 2 inch diameter poles and decking constructed from 1 inch diameter poles. Three precast concrete footings illustrated in Figure 5.15 provide support to the prototype.

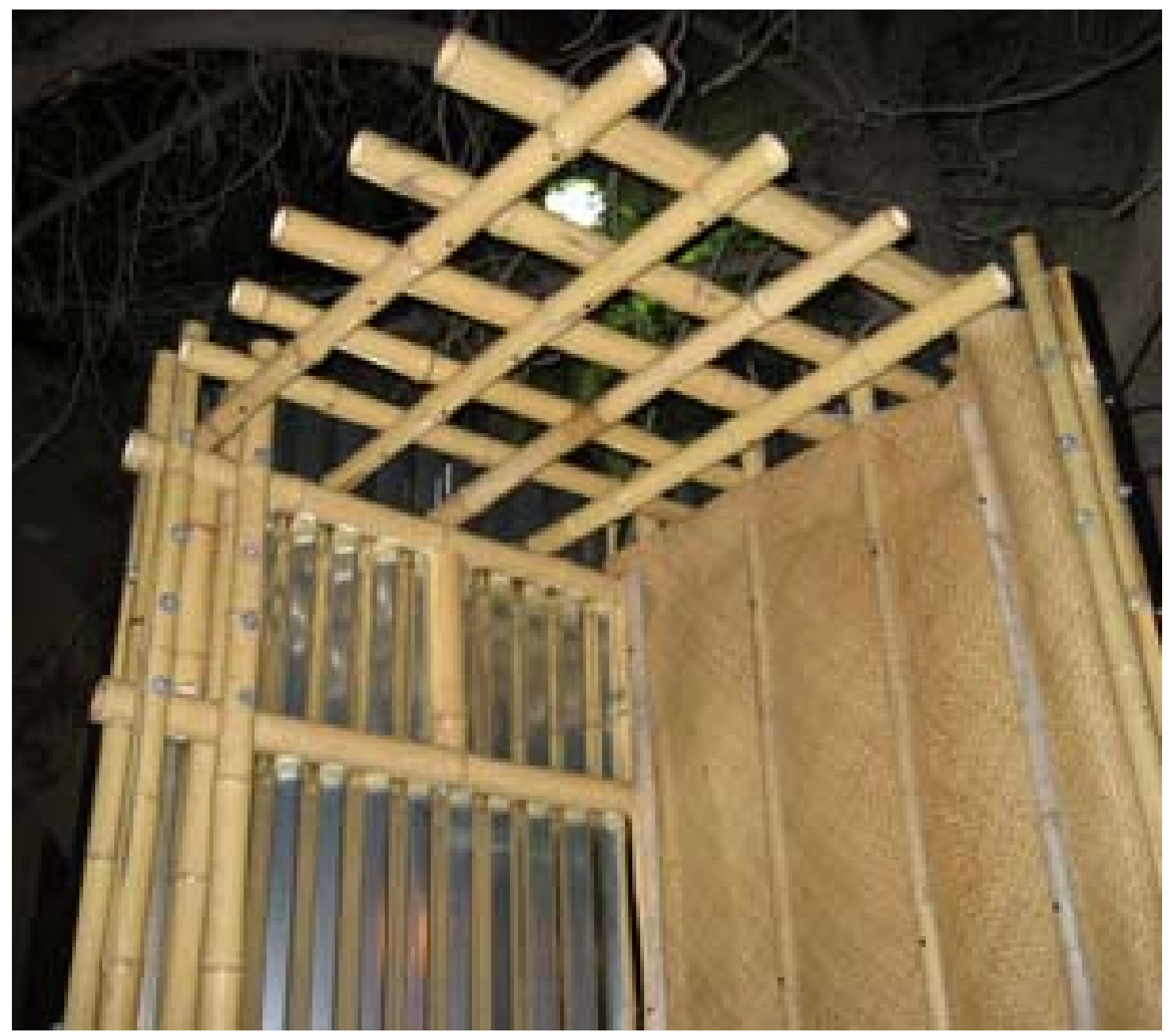

Figure 5.13 Upper portion of the prototype showing parts of the structural system, a partial roof system and the internal wall covering. Source: Photograph by Author. 


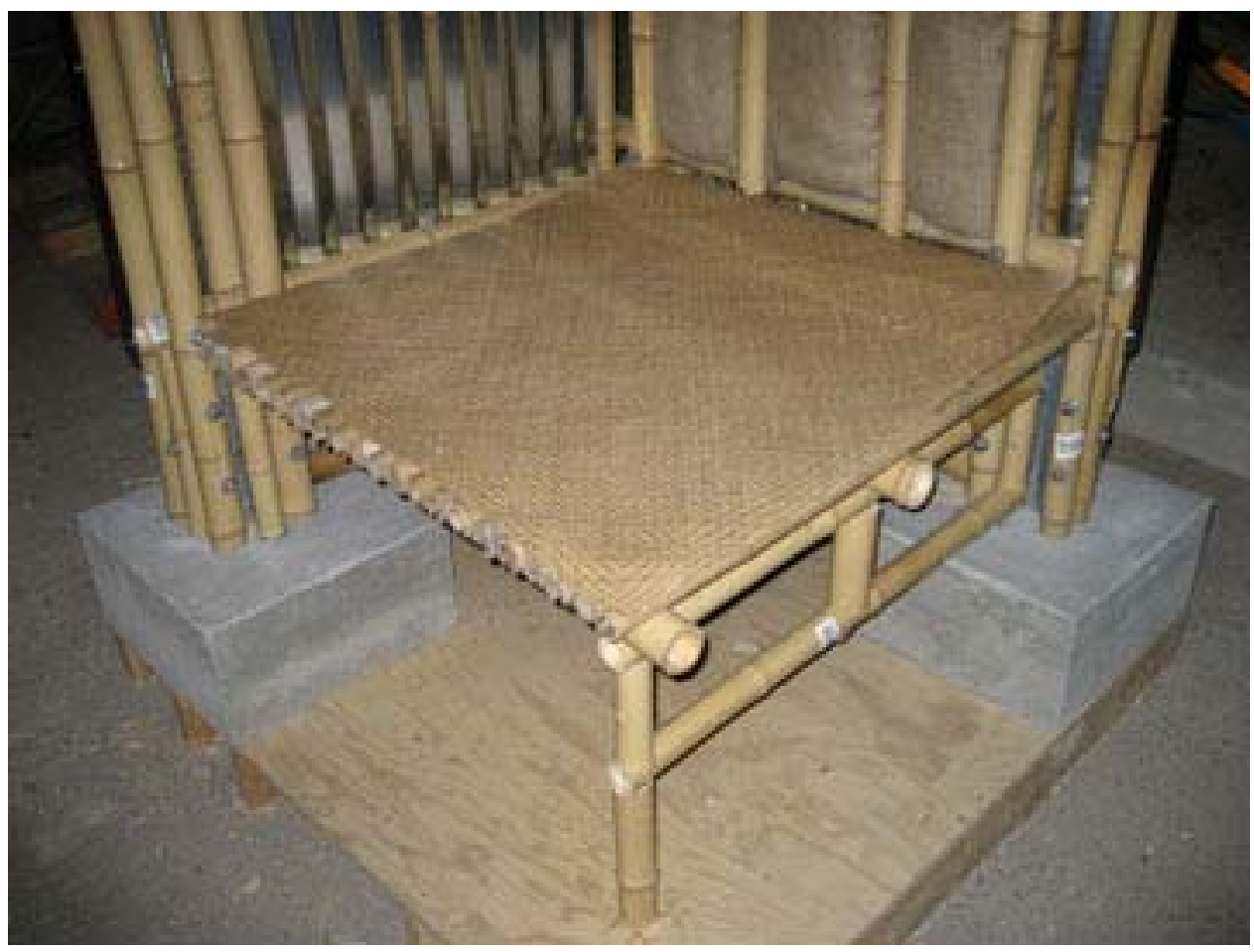

Figure 5.14 Lower portion of the prototype showing a floor system and decking constructed from 1 inch poles and woven mat covering. Source: Photograph by Author.

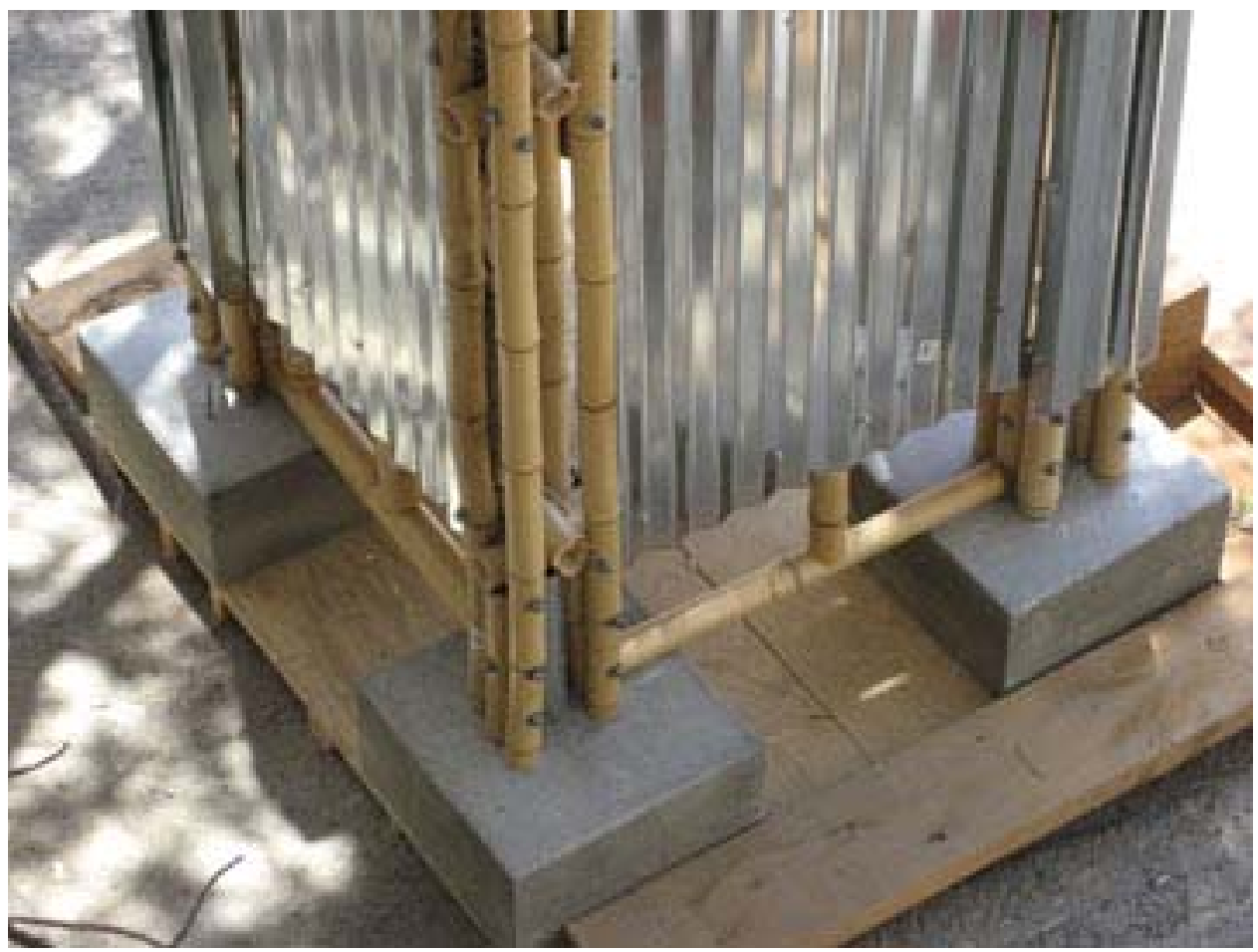

Figure 5.15 Lower external portion of the prototype showing three precast concrete footings and uncovered parts of the column system. Source: Photograph by Author. 


\subsubsection{Construction of the prototype}

The selection of quality poles

that are free from cracks, and

have consistent diameter/length

is key to the construction of

structural components with

proportional sizes.

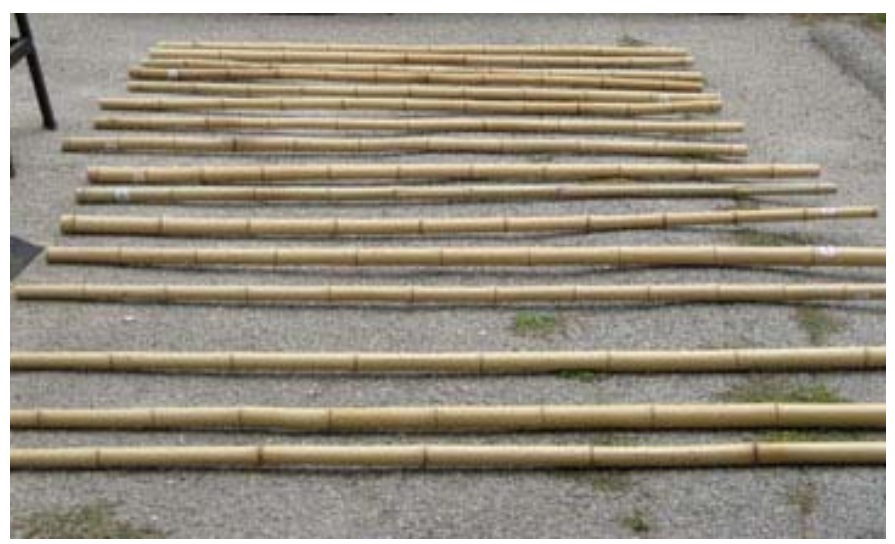

Columns were prefabricated off

site, and tested for proper fit

before they were transported to

the construction site.

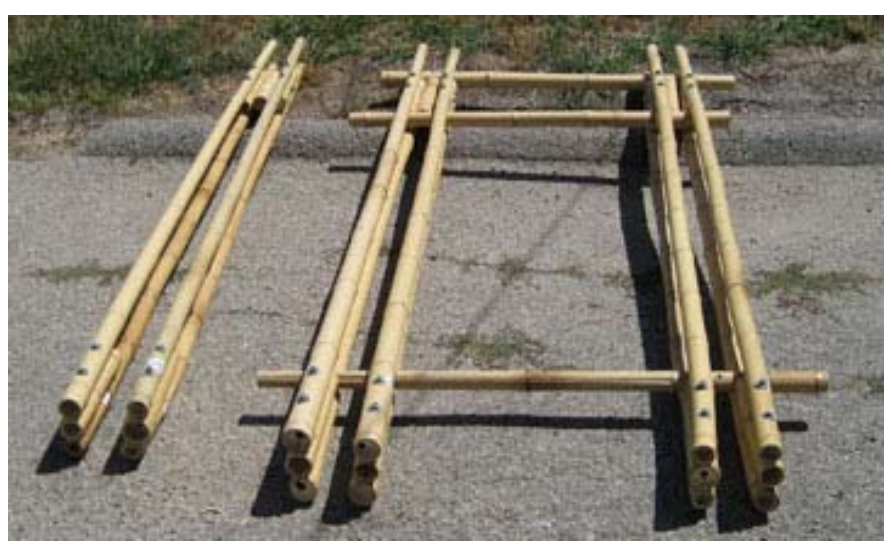

Components built for a standard

10 foot by 10 foot unit can easily

fit in a standard vehicle for

transportation.

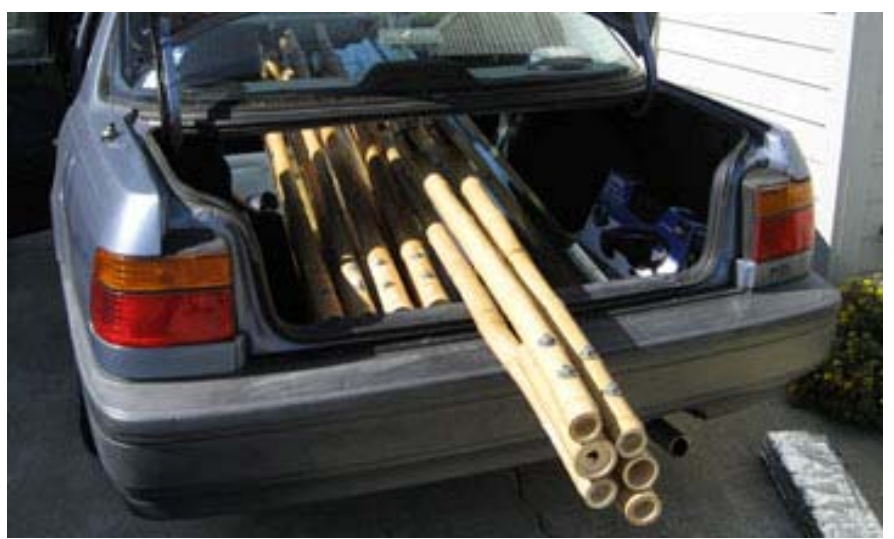


A temporary platform,

constructed from plyboard and

2 by $4 \mathrm{~s}$, was used to create a

level construction surface.

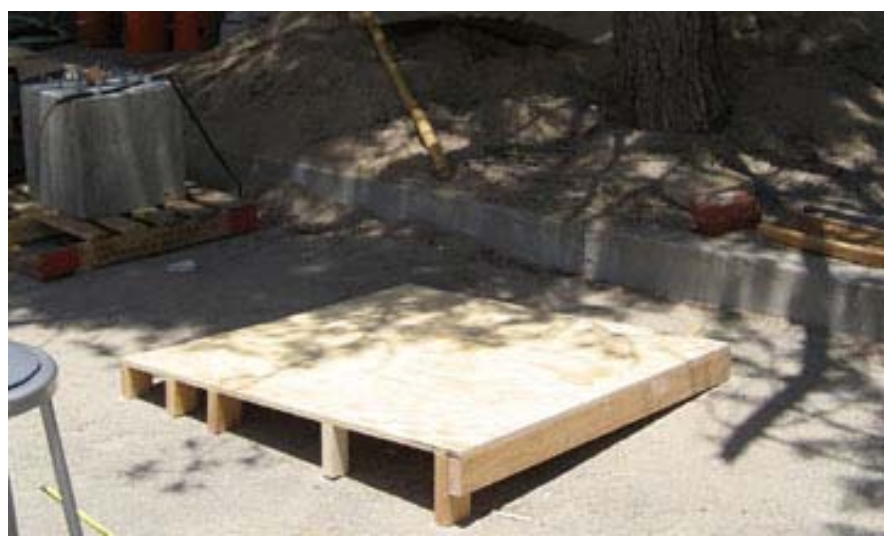

Three 16 by 16 by 8 concrete

footings were precast with 2

inch steel tube anchor where

prefabricated columns will be

erected.

Footings were moved to the

construction site, and placed in

the appropriate order prior to

the assembly process.
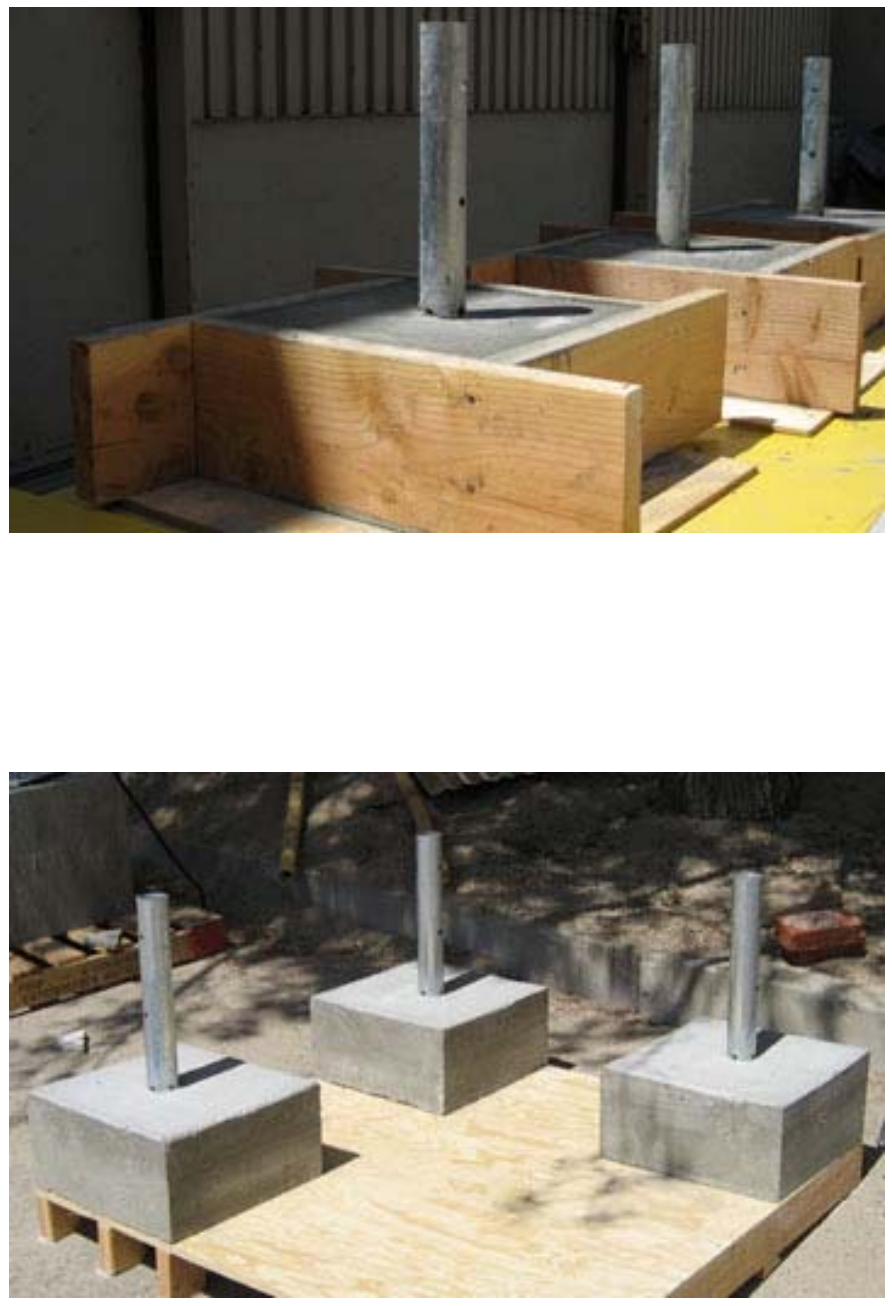
Prefabricated columns were erected in the proper order and bolted using 3/8 inch threaded rods.

A column can easily be erected by an individual in less than twenty minutes.

Holes connecting the steel tube anchor and bamboo spacers should be drilled on site to insure accuracy.

The additional precut structural members were bolted on to the erected columns to complete the prototype framing.

The left side of the prototype shows a proper post and beam frame.

The right side would eventually be covered with insulation and wall coverings, and therefore, it was partially framed
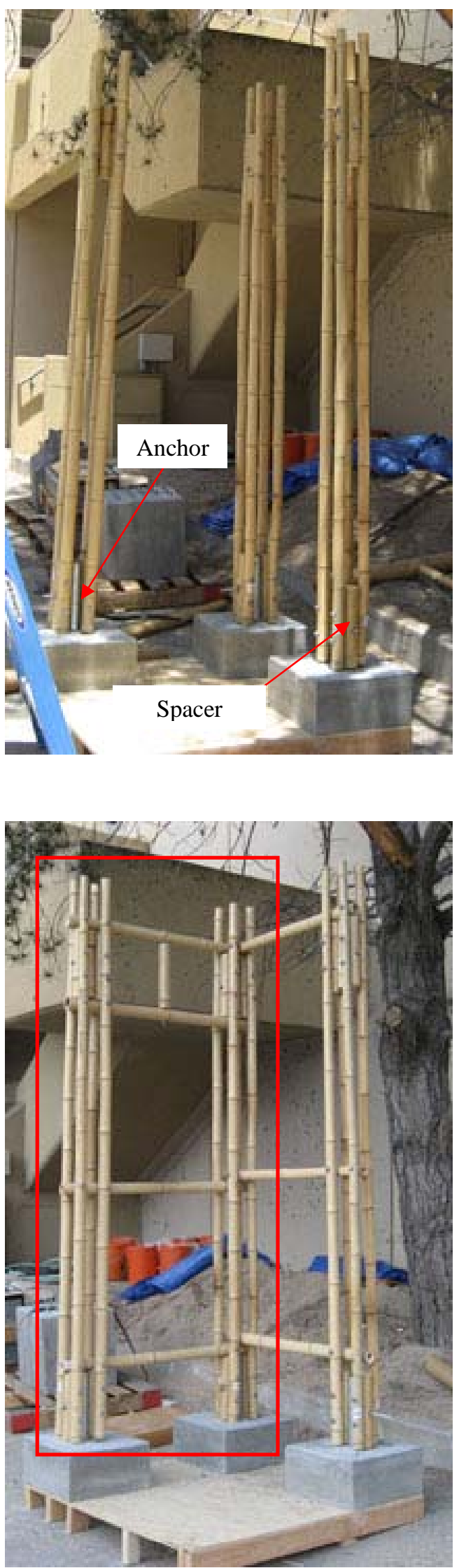
The exterior corrugated steel covering is

attached to the framing members using self

tapping screws shown in Figure 5.16.

Unlike regular screws or nails, self tapping screws can cut through bamboo without cracking its brittle surface.

In addition to providing protection from the elements, the corrugated steel sheet acts as a shear panel.
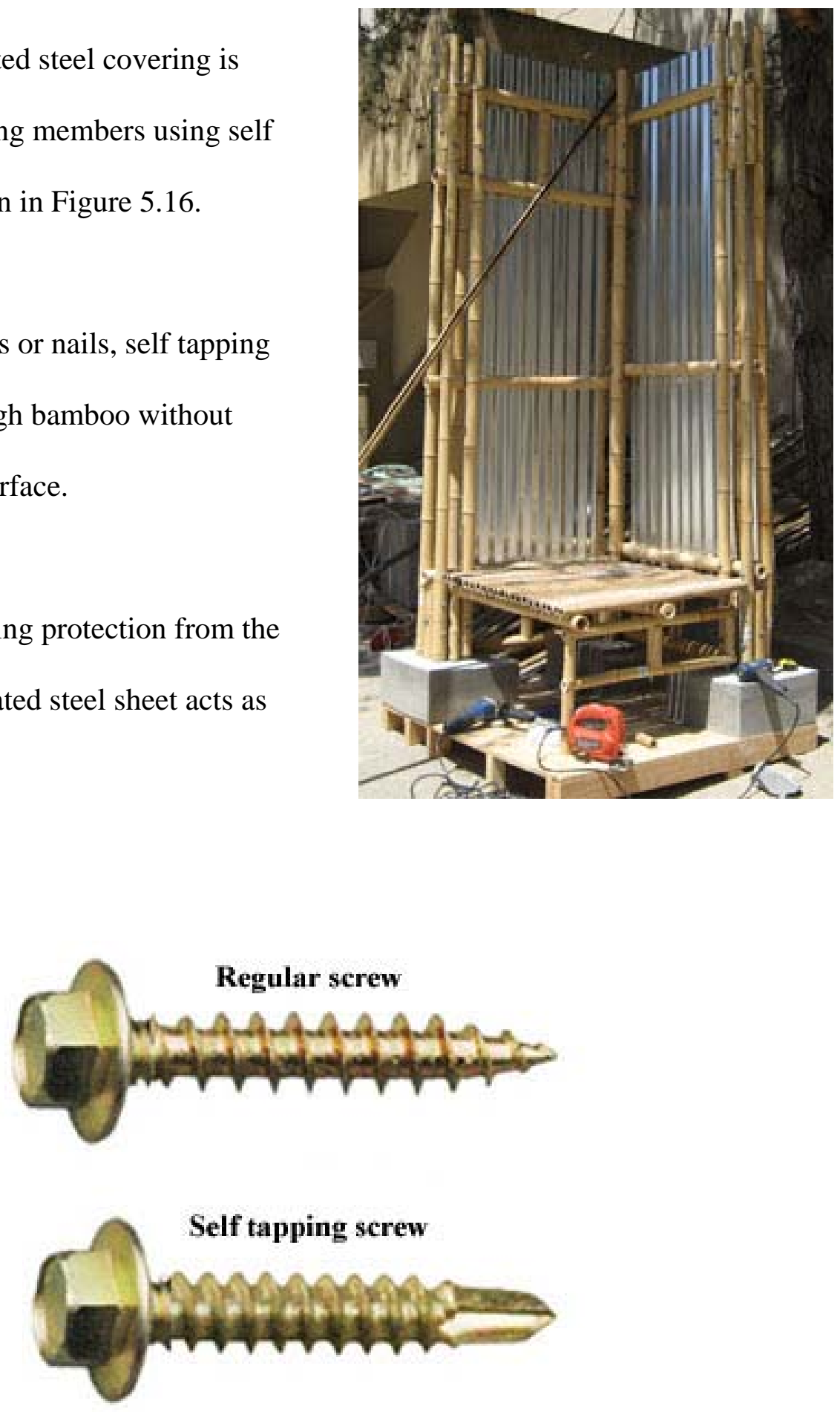

Figure 5.16 Regular wood and drywall screw in comparison to self tapping screw ideal for attaching corrugated sheet to bamboo poles. Source: http://img.alibaba.com/photo/10970887/Self_Tapping_Screws_Self_Drilling_Screw_Thread_Cutting_Scre w.jpg 
Straw bale filled burlap bags are used as optional wall insulation.

The gaps between the bamboo framing members allows for the installation of insulation material.
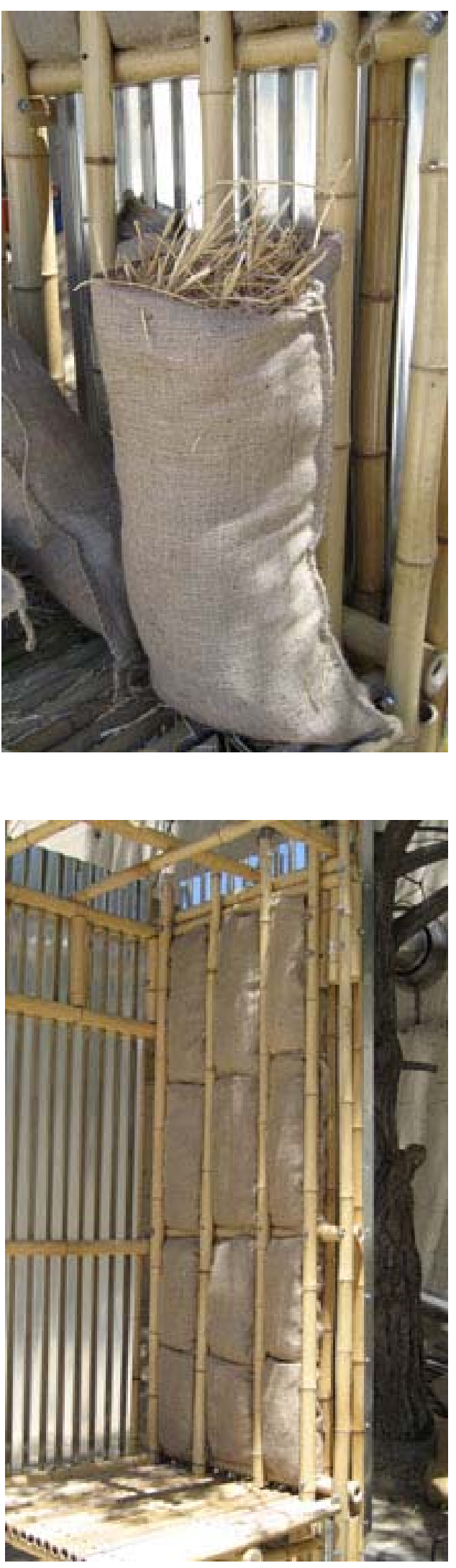
Handmade woven mat is used as wall

covering. This material is mainly

manufactured and imported from rural areas.

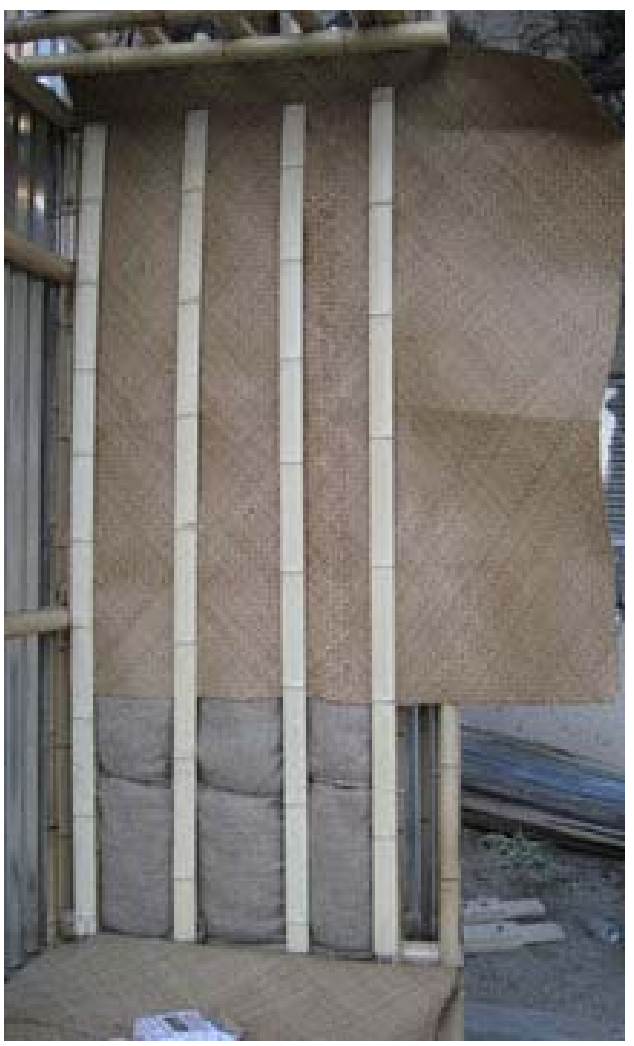

Traditional ties or smaller screws may be used to attach mat coverings directly to structural framing.

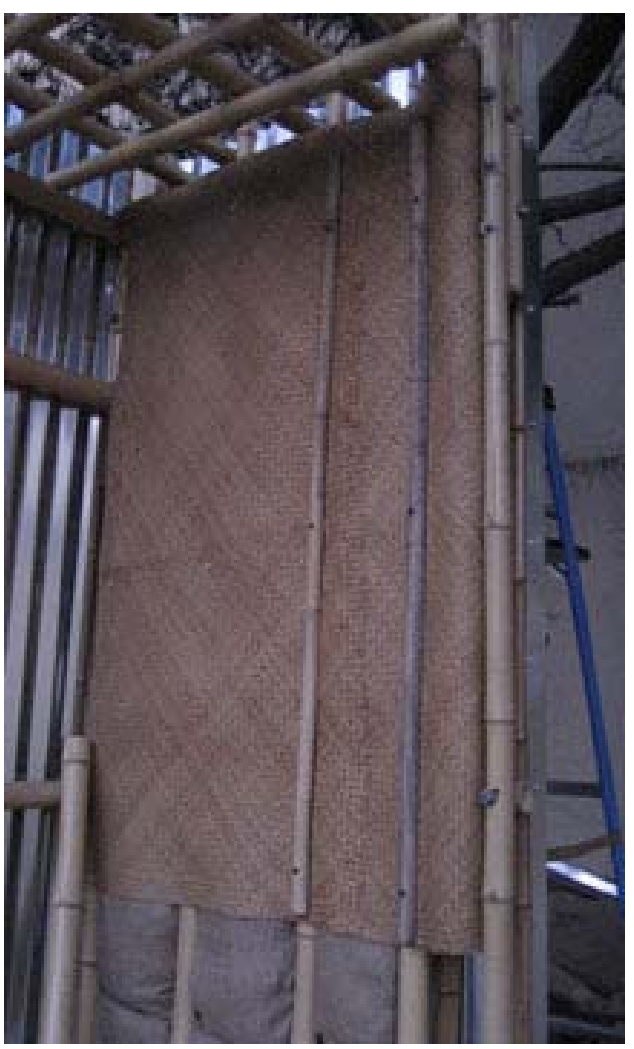


4-foot by 4-foot floor system

constructed from 2 inch diameter

poles, and 3/8 inch threaded roads.

Floor load directly supported by

concrete footings.

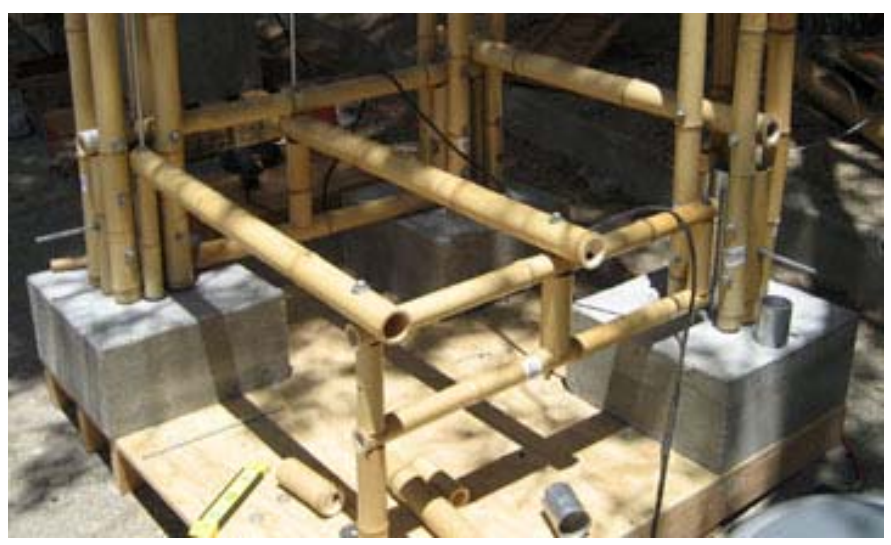

Floor decking utilizes 1 inch

diameter poles attached to the

support system using self tapping

screws (1 1 1/2 inch flat head).

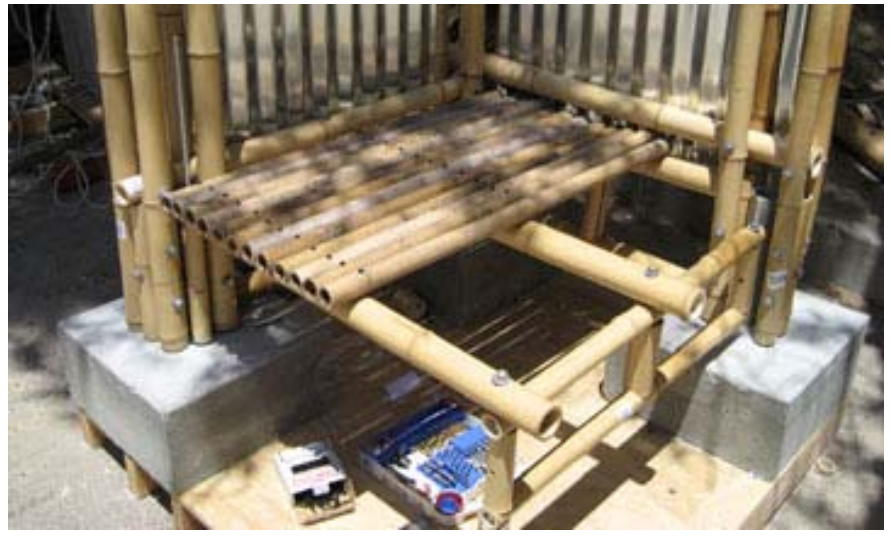

Woven mat covering applied over

bamboo decking to create an even

surface. Mat may be attached

permanently or used as movable

carpeting.

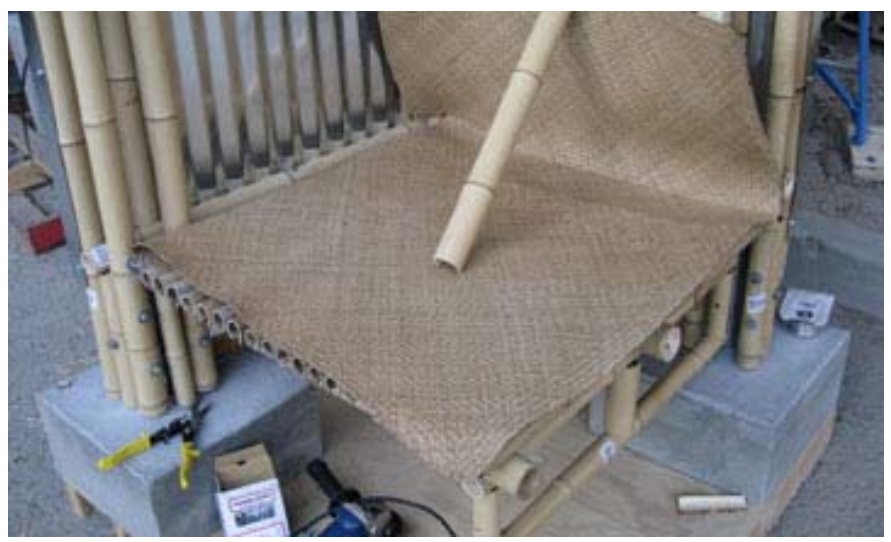




\section{CHAPTER 6}

Recommendations and Conclusion

\subsection{Recommendations}

As discussed in chapter 3, the initial processes of cultivating, harvesting and curing bamboo culms are critical to the production of quality bamboo poles. Proper preservation and handling of poles should continue during the construction process as well. The following section will focus on recommendations based on the designer's firsthand experience in handling bamboo poles, construction and testing of structural components and assembly of the prototype.

\section{Storage}

1) Prior to the delivery of bamboo poles and prefabricated components to the project site, proper storage should be setup. Protection from direct exposure to sunlight and rain is critical at all times.

2) Storage spaces should be dry, well ventilated and free from insects. Poles should be stacked on a horizontal surface to prevent bending, and off the ground to avoid contact with ground moisture.

\section{Cutting}

3) Basic wood working tool can be used to cut bamboo poles. Electric powered saws with fine teeth make smooth cuts and minimize cracking of poles. 
4) Bamboo poles have uneven round surface which makes them relatively hard to cut. It is advisable to use clumps or custom built jigs to keep them still while making cuts.

5) Work surfaces that support the full length of poles make the ideal cutting surface. Bending of poles during the cutting processes could result in small fractures that could eventually develop in to large cracks.

6) If possible, cuts should be made close to nodes; the strongest part of poles that are harder to crack.

7) Cuts should be made prior to drilling holes for bolting or pouring concrete into the hollow shafts.

8) Bamboo strips can be made by splitting bamboo poles in to several pieces longitudinally, and this can be accomplished accurately using a band saw.

\section{Drilling}

9) If possible, holes should be made close to nodes, and minimum 6 inches from either end of poles.

10) Drilling holes can compromise the integrity of bamboo poles; the appropriate type of drill bit and support jig should used. 
11) A general purpose twist bit shown in Figure 6.1 can make clean holes without damaging poles. Wood bits with spur points should be avoided. At higher speed, spurs can easily split bamboo poles.

A) Twist bit

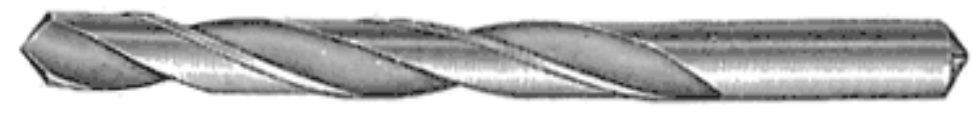

B) Spur point bit

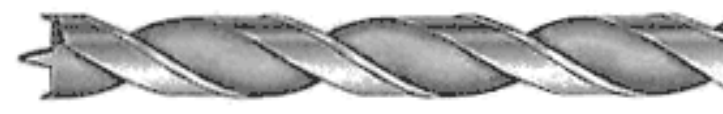

Figure $6.1 \quad$ A) general purpose twist bit ideal for drilling holes on bamboo poles. B) Spur point bit or commonly known as wood or dowel bit that causes bamboo to split easily. Source: www.diydata.com/tool/drillbits/drillbits.php (accessed March 2009)

12) To make accurate holes for connections and simplify the bolting proceses, pieces should be clumped together prior to drilling.

13) If possible, pieces should be bolted together before clumps are removed; matching holes in multiple pieces could be challenging.

14) When bolting a reinforcing steel strap onto bamboo poles, the strap should first be drilled and clumped to the bamboo poles for marking the exact location where the hole should be made. 


\section{Assembling}

15) Clumping pieces together is the key to a faster and simpler assembly process. Matching holes drilled on uneven surfaces could be time consuming.

16) The flexible nature of bamboo can throw measurments off; major components should be tested for proper fit prior to the final assembly proceess.

17) When possible, creating holes with larger tolerances can help expedite assembling multiple pieces.

18) To prevent rotation and maintain a perfect assembly, multiple pieces larger than 18 inches should be bolted in two locations or more at minimum 6 inch intervals.

\section{$\underline{\text { Reinforcing }}$}

19) In order to prevent poles from crushing, as illustrated in Figure 6.2, bolted joints, especially in beams and any load bearing horizontal components, should be reinforced with concrete.

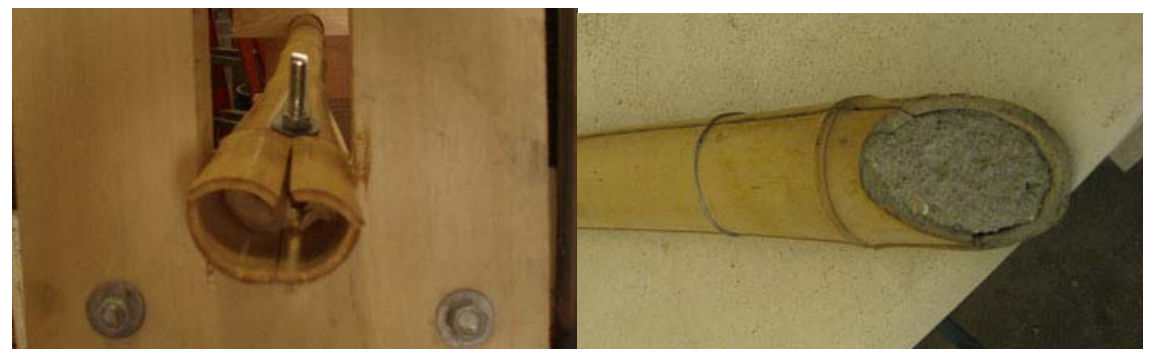

Figure 6.2 by Author.

Left: Crushed hollow pole Right: Concrete reinforced pole Source: Photograph 
20) 16 gauge still strap is an ideal tension element for reinforcing trussed beams. Steel washers should be used to cover ends as shown in Figure 6.3 to prevent the strap crushing the end of bamboo pole.

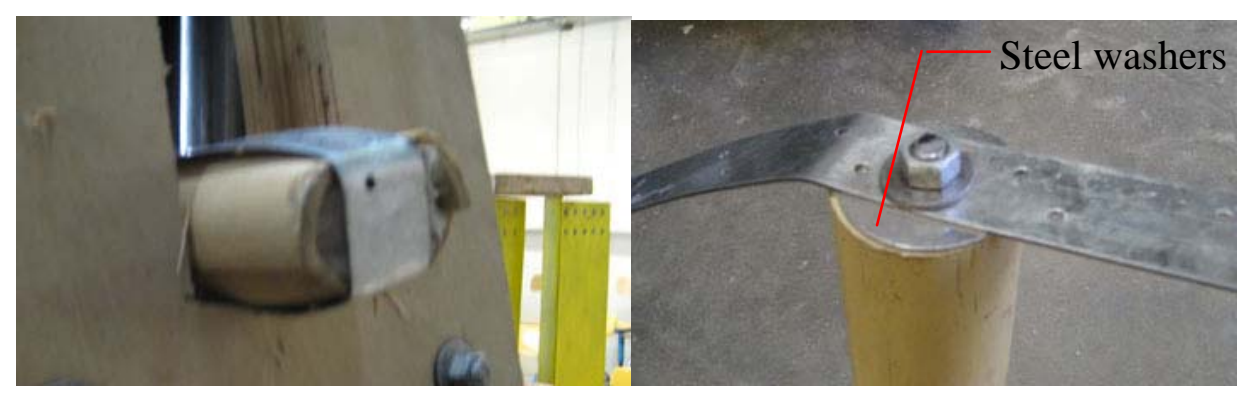

Figure 6.3 Left: Steel strap reinforcement crushing the end of bamboo pole. Right: Steel washer used to prevent steel strap crushing the end of bamboo pole. Source: Photograph by Author.

\section{Trussed Beam}

- $\quad$ Bamboo chord with concrete reinforced joints

- $\quad$ Tension element: 16 gauge steel strap

- $\quad$ Chords 8 feet or longer need two or more vertical supports

- $\quad 3 / 8$ inch bolts for 2 inch diameter bamboo chords, $1 / 2$ inch bolts for 4 inch diameter chords

- $\quad$ Bolt minimum 6 inches from ends and 6 inches between two bolts

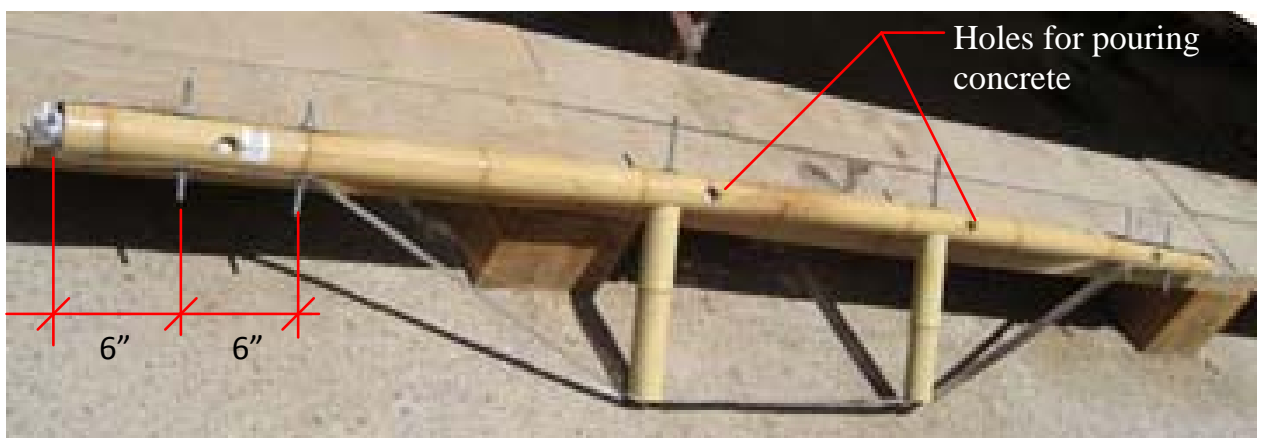

Figure 6.4 Trussed beam: Bamboo top chord, two vertical supports, 16 gauge steel strap bolted with 3/8” threaded rods. Source: Photograph by Author. 


\section{Columns}

Bamboo columns with concrete reinforced joints

- $\quad$ Minimum 2 spacers per column

- $\quad$ 3/8 inch bolts for 2 inch diameter bamboo poles

- $\quad 1 / 2$ inch bolts for 4 inch diameter bamboo poles

- $\quad$ Bolt minimum 6 inches from ends and 6 inches between two bolts

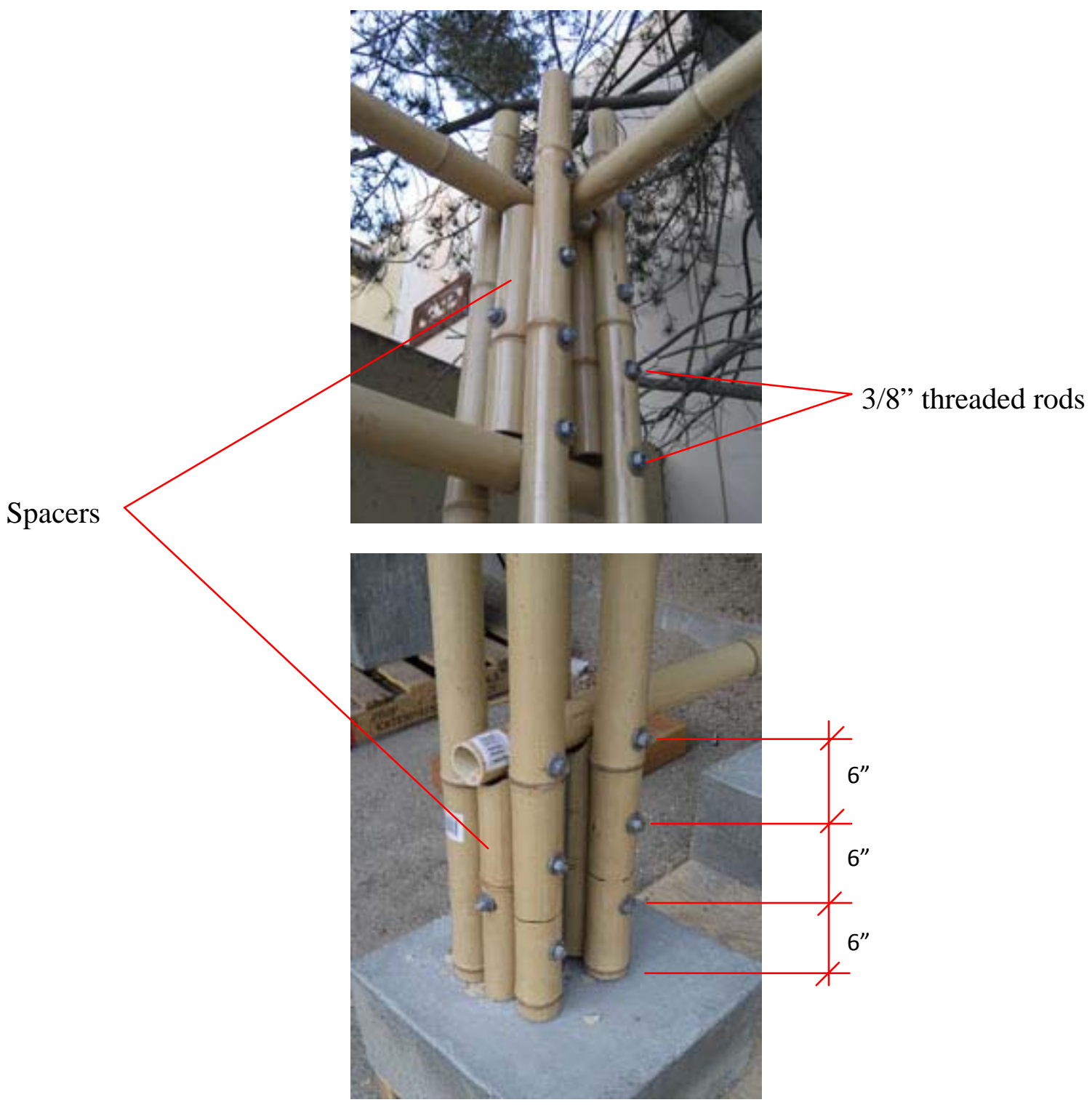

Figure 6.5 Top: Column and beam connection bolted at 6 inch intervals. Bottom: Column and footing connection and spacers. Source: Photograph by Author. 


\subsection{Conclusion}

The housing shortage in urban Ethiopia is a complex problem that requires a multifaceted solution. A major portion of the problem can be addressed by crafting a solution geared towards low-income families. The core of this solution should focus on reducing the cost of building material, simplifying construction methods and finding efficient ways to use urban land. Community participation during the planning and execution phases should also be the integral part of the solution.

This thesis has shown bamboo's potential as an alternative building material that could alleviate the high cost of housing in urban Ethiopia. The proposed bamboo framed structure can be easily assembled and seamlessly integrated into the urban landscape.

Further research and development of structural components, connection systems, and overall integrity of bamboo poles is crucial to the successful implementation of low cost housing projects throughout urban Ethiopia. 


\section{BIBLIOGRAPHY}

Ann Varlet and Edesio Fernandes, 'Illegal Cities: Law and Urban Change in Developing Countries; (New York: Zed Books Ltd 1998).

Carsten Stammeier, Ruth Eribeck and Ralph Trosse, Low Cost Housng: Technical Manual, (Addis Ababa: German Technical Co-operation 2003).

Dinesh Mohan and D. Narayanamurti, The use of Bamboo and Reeds in Building Construction (United Nations, New York 1972).

Federal Republic of Ethiopia Population Census Commission, Summery and Statistical Report of the 2007 Population and Housing Census, (Addis Ababa: CSA 2008).

Gebeyehu Abelti, Marco Brazzoduro and Behailu Gebremedhin, Housing Conditions and Demand for Housing in Urban Ethiopia (Addis Ababa: Central Statistical Authority 2005).

Kassahun Embaye, Ecological Aspects and Resource Management of Bamboo Forests in Ethiopia (Uppsala: SLU Service repro 2003).

Klaus Dunkelberg, Bamboo: Building with Vegetal Rods (Stuttgart: Karl Krämer, 2001).

Lynne Elizabeth and Cassandra Adams, Alternative Construction: Contemporary Natural Building Methods (New York: John Wiley \& sons, Inc. 2005).

Nadia Bystriakova, Valerie Kapos and Igor Lysenko, "Bamboo Biodiversity - Africa, Madagascar and the Americas.” http:/www.unepwcmc.org/resources/publications/UNEP_WCMC_bio_series/19.htm (accessed 15 December 2008).

Simon Velez, Jean Dethier and Klaus Steffen, Grow your own house: Simon Velez and Bamboo Architecture (Vitra Design Museum 2000).

Solomon Mulugeta and Ruth McLeod, Application of Community-Led Infrastructure, (Addis Ababa: Homeless International, 2004).

Steffen Abrams, World Changing: A user's guide for the $21^{\text {st }}$ Century (New York: 2007).

United Nations Department of Economic and Social Affairs (ESA), "World Population Prospects: The 2006 Revision Population Database,” http://esa.un.org/unpp/ (accessed 15 January 2008). 
United Nations Human Settlement Program, Situation Analysis of Informal Settlements in Addis Ababa, (Nairobi: UN-HABITAT, 2007).

Wikipedia, "General Information on Bamboo" http://en.wikipedia.org/wiki/Bamboo (accessed 27 January 2008). 